\title{
The shared socio-economic pathway (SSP) greenhouse gas concentrations and their extensions to 2500
}

\author{
Malte Meinshausen ${ }^{1,2,3}$, Zebedee R. J. Nicholls ${ }^{1,2}$, Jared Lewis $^{1}$, Matthew J. Gidden ${ }^{4,5}$, Elisabeth Vogel $^{1,2}$, \\ Mandy Freund $^{1,6}$, Urs Beyerle ${ }^{7}$, Claudia Gessner ${ }^{7}$, Alexander Nauels ${ }^{1,5}$, Nico Bauer ${ }^{3}$, Josep G. Canadell ${ }^{8}$, \\ John S. Daniel ${ }^{9}$, Andrew John ${ }^{1,10}$, Paul B. Krummel ${ }^{11}$, Gunnar Luderer ${ }^{3}$, Nicolai Meinshausen ${ }^{12}$, \\ Stephen A. Montzka ${ }^{13}$, Peter J. Rayner ${ }^{2,1}$, Stefan Reimann ${ }^{14}$, Steven J. Smith ${ }^{15}$, Marten van den Berg ${ }^{16}$, \\ Guus J. M. Velders ${ }^{17,18}$, Martin K. Vollmer ${ }^{14}$, and Ray H. J. Wang ${ }^{19}$ \\ ${ }^{1}$ Climate \& Energy College, The University of Melbourne, Parkville, Victoria, Australia \\ ${ }^{2}$ School of Earth Sciences, The University of Melbourne, Parkville, Victoria, Australia \\ ${ }^{3}$ Potsdam Institute for Climate Impact Research (PIK), Potsdam, Germany \\ ${ }^{4}$ IIASA Institute for Applied Systems Analysis, Laxenburg, Austria \\ ${ }^{5}$ Climate Analytics, Berlin, Germany \\ ${ }^{6}$ CSIRO Agriculture and Food, Melbourne, Victoria, Australia \\ ${ }^{7}$ Institute for Atmospheric and Climate Science, Swiss Federal Institute of Technology, ETH Zurich, Zurich, Switzerland \\ ${ }^{8}$ Global Carbon Project, CSIRO Oceans and Atmosphere, Canberra, ACT, Australia \\ ${ }^{9}$ NOAA, Earth System Research Laboratory, Chemical Sciences Laboratory, Boulder, Colorado, USA \\ ${ }^{10}$ Department of Infrastructure Engineering, The University of Melbourne, Parkville, Victoria, Australia \\ ${ }^{11}$ Climate Science Centre, CSIRO Oceans and Atmosphere, Aspendale, Victoria, Australia \\ ${ }^{12}$ Seminar for Statistics, Swiss Federal Institute of Technology, ETH Zurich, Zurich, Switzerland \\ ${ }^{13}$ NOAA Global Monitoring Laboratory, Boulder Colorado, USA \\ ${ }^{14}$ Empa, Laboratory for Air Pollution/Environmental Technology, Swiss Federal Laboratories for Materials Science and \\ Technology, Dübendorf, Switzerland \\ ${ }^{15}$ Joint Global Change Research Institute, Pacific Northwest National Laboratory, College Park, MD, USA \\ ${ }^{16}$ PBL Netherlands Environmental Assessment Agency, the Netherlands \\ ${ }^{17}$ National Institute for Public Health and the Environment (RIVM), Bilthoven, the Netherlands \\ ${ }^{18}$ Institute for Marine and Atmospheric Research Utrecht (IMAU), Utrecht University, Utrecht, the Netherlands \\ ${ }^{19}$ School of Earth and Atmospheric Sciences, Georgia Institute of Technology, Atlanta, GA 30332-0340, USA
}

Correspondence: Malte Meinshausen (malte.meinshausen@unimelb.edu.au)

Received: 7 August 2019 - Discussion started: 1 October 2019

Revised: 15 April 2020 - Accepted: 30 April 2020 - Published: 13 August 2020

\begin{abstract}
Anthropogenic increases in atmospheric greenhouse gas concentrations are the main driver of current and future climate change. The integrated assessment community has quantified anthropogenic emissions for the shared socioeconomic pathway (SSP) scenarios, each of which represents a different future socio-economic projection and political environment. Here, we provide the greenhouse gas concentrations for these SSP scenarios - using the reduced-complexity climate-carbon-cycle model MAGICC7.0. We extend historical, observationally based concentration data with SSP con-
\end{abstract}

centration projections from 2015 to 2500 for 43 greenhouse gases with monthly and latitudinal resolution. $\mathrm{CO}_{2}$ concentrations by 2100 range from 393 to $1135 \mathrm{ppm}$ for the lowest (SSP1-1.9) and highest (SSP5-8.5) emission scenarios, respectively. We also provide the concentration extensions beyond 2100 based on assumptions regarding the trajectories of fossil fuels and land use change emissions, net negative emissions, and the fraction of non- $\mathrm{CO}_{2}$ emissions. By 2150 , $\mathrm{CO}_{2}$ concentrations in the lowest emission scenario are approximately $350 \mathrm{ppm}$ and approximately plateau at that level 
until 2500, whereas the highest fossil-fuel-driven scenario projects $\mathrm{CO}_{2}$ concentrations of $1737 \mathrm{ppm}$ and reaches concentrations beyond $2000 \mathrm{ppm}$ by 2250 . We estimate that the share of $\mathrm{CO}_{2}$ in the total radiative forcing contribution of all considered 43 long-lived greenhouse gases increases from $66 \%$ for the present day to roughly $68 \%$ to $85 \%$ by the time of maximum forcing in the 21 st century. For this estimation, we updated simple radiative forcing parameterizations that reflect the Oslo Line-By-Line model results. In comparison to the representative concentration pathways (RCPs), the five main SSPs (SSP1-1.9, SSP1-2.6, SSP2-4.5, SSP3-7.0, and SSP5-8.5) are more evenly spaced and extend to lower 2100 radiative forcing and temperatures. Performing two pairs of six-member historical ensembles with CESM1.2.2, we estimate the effect on surface air temperatures of applying latitudinally and seasonally resolved GHG concentrations. We find that the ensemble differences in the March-April-May (MAM) season provide a regional warming in higher northern latitudes of up to $0.4 \mathrm{~K}$ over the historical period, latitudinally averaged of about $0.1 \mathrm{~K}$, which we estimate to be comparable to the upper bound ( $\sim 5 \%$ level) of natural variability. In comparison to the comparatively straight line of the last 2000 years, the greenhouse gas concentrations since the onset of the industrial period and this studies' projections over the next 100 to 500 years unequivocally depict a "hockey-stick" upwards shape. The SSP concentration time series derived in this study provide a harmonized set of input assumptions for long-term climate science analysis; they also provide an indication of the wide set of futures that societal developments and policy implementations can lead to ranging from multiple degrees of future warming on the one side to approximately $1.5^{\circ} \mathrm{C}$ warming on the other.

\section{Introduction}

The climate modelling community periodically undertakes large model intercomparison exercises with the latest and most sophisticated set of climate models, to gain a better understanding of the response of the climate system to a range of potential emission or concentration scenarios (Taylor et al., 2012; Meehl et al., 2007). The atmosphere-ocean general circulation models (AOGCMs) are physical climate models that may include biogeochemical model components, such as vegetation or some atmospheric chemistry, but they are not able to project $\mathrm{CO}_{2}$ concentrations from emissions due to an incomplete, imbalanced, or non-existent carbon cycle. The climate models that have this ability to project $\mathrm{CO}_{2}$ concentrations from emissions are often referred to as Earth system models (ESMs) (Lawrence et al., 2016; Jones et al., 2016). These ESMs are also often run in " $\mathrm{CO}_{2}$-concentration-driven mode" for computational ease and to allow for an easier separation between carbon cycle feedbacks and climate responses. As of today in phase 6 of the Coupled Model In- tercomparison Project (CMIP6) (Eyring et al., 2016), both AOGCMs and ESMs use concentrations from all non- $\mathrm{CO}_{2}$ greenhouse gases to perform multi-gas experiments (such as the future scenario projections) due to either missing non$\mathrm{CO}_{2}$ gas cycles or a prohibitive computational burden.

This study provides and describes the standardized set of greenhouse gas (GHG) concentration futures for $\mathrm{CO}_{2}, \mathrm{CH}_{4}$, $\mathrm{N}_{2} \mathrm{O}$, and 40 other minor greenhouse gases. For the historical period, this GHG concentration data for CMIP6 were provided by the companion paper Meinshausen et al. (2017). This study provides the GHG concentration data until 2100 on the basis of the emission scenarios derived from socioeconomically explicit integrated assessment models (IAMs) under the shared socio-economic pathway (SSP) framework (Gidden et al., 2019). We also provide an extension of the concentration data until 2500 on the basis of simplified assumptions.

These concentrations datasets are part of the protocols for several CMIP6 experiments, most notably ScenarioMIP (O'Neill et al., 2016) and AerChemMIP (Collins et al., 2017), that require concentration-driven runs (see search.esdoc.org for a full description). While greenhouse gases are arguably the most important influence of humankind on future climate in terms of radiative forcing, there is a wide range of other forcers, including anthropogenic aerosols (Hoesly et al., 2018), land use patterns, aerosol optical properties (Stevens et al., 2017), and natural forcers like solar (Matthes et al., 2017) and volcanic effects (Toohey et al., 2016). These forcers are described in the companion papers and compiled in the input $4 \mathrm{mip}$ interface to be used for the historical and future ESM experiments (Durack and Taylor, 2019), available on https://esgf-node.llnl.gov/projects/ input4mips/ (last access: 20 June 2020).

Our future greenhouse gas concentration datasets from 2015 onwards are provided for a total of nine SSP scenarios. These nine scenarios comprise five high-priority scenarios for the Sixth Assessment report by the IPCC report, which is the group of four "Tier 1" scenarios highlighted in ScenarioMIP (O'Neill et al., 2016) in addition to the SSP11.9 scenario that reflects most closely a $1.5^{\circ} \mathrm{C}$ target under the Paris Agreement. Specifically, these "high-priority" scenarios for IPCC AR6 are, firstly, the SSP $1-2.6 " 2{ }^{\circ} \mathrm{C}$ scenario" of the "sustainability" SSP1 socio-economic family, whose nameplate 2100 radiative forcing level is $2.6 \mathrm{~W} \mathrm{~m}^{-2}$. This SSP1-2.6 scenario approximately corresponds to the previous scenario generation Representative Concentration Pathway (RCP) 2.6. Secondly, the SSP2-4.5 of the "middle of the road" socio-economic family SSP2 with a nominal $4.5 \mathrm{~W} \mathrm{~m}^{-2}$ radiative forcing level by 2100 - approximately corresponding to the RCP-4.5 scenario. Thirdly, the SSP37.0 scenario is a medium-high reference scenario within the "regional rivalry" socio-economic family, while the final Tier 1 scenario, SSP5-8.5, marks the upper edge of the SSP scenario spectrum with a high reference scenario in a high fossilfuel development world throughout the 21 st century. The ad- 
ditional high-priority scenario that IPCC AR6 considers is SSP1-1.9 to better reflect the research regarding the Paris Agreement's $1.5^{\circ} \mathrm{C}$ target. It should be noted that the radiative forcing labels, such as "2.6" in the SSP1-2.6 scenario, are indicative "nameplates" only, approximating total radiative forcing levels by the end of the 21 st century. Those labels are merely indicative, given that actual radiative forcing uncertainties (and differences across ESMs that implement the same concentrations, aerosol abundances, ozone fields, and land use patterns) are substantial.

In addition to these five high-priority scenarios, we provide concentrations for four additional SSP scenarios, namely the three remaining "Tier 2" ScenarioMIP experiments, featuring a low reference scenario SSP4-6.0 within the socio-economic context of an "inequality"-dominated world, as well as its moderate mitigation scenario SSP43.4. Similarly, there is the geophysically interesting emission "overshoot" scenario, SSP5-3.4-OS, as it initially follows the high-emission SSP5-8.5 scenario until 2030 before exhibiting the steepest annual reduction rates of all SSP scenarios and the most net negative emissions by 2100 . Lastly, we also consider the SSP3-7.0-LowNTCF variant of the SSP3-7.0 scenario with reduced near-term climate forcer (NTCF) emissions. Given that the SSP3-7.0 scenario is the one with the highest methane and air pollution precursor emissions, the SSP3-7.0-LowNTCF variant investigates an alternative pathway for the AerChemMIP intercomparison project (Collins et al., 2017) that exhibits very low methane, aerosol, and tropospheric-ozone precursor emissions - approximately in line with the lowest other SSP scenarios for those species like SSP1-1.9 and SSP1-2.6. Note that the NTCF nomenclature is equivalent to the term short-lived climate forcer, SLCF, which is now more commonly used by the research community and IPCC context.

The presented historical global-mean and hemisphericmean surface mole fractions in this study transition smoothly from the end of the historical dataset (Meinshausen et al., 2017), 2014, into the start of the projections, 2015. Also, the latitudinal gradient and seasonality, and their temporal evolution, are consistent with the historical dataset - which in all cases is tied directly to past measurements. We used a reduced-complexity carbon cycle model, MAGICC (Meinshausen et al., 2011c, a), to produce global-mean future greenhouse gas concentration time series for each of the considered SSPs. The same model, albeit an earlier version, was also previously used to provide the RCP greenhouse gas concentrations projections (Meinshausen et al., 2011b). The MAGICC version used for this study (version 7.0) is calibrated to closely represent C4MIP carbon cycle responses and includes a permafrost module (Schneider von Deimling et al., 2012) and updated radiative forcing and non- $\mathrm{CO}_{2}$ gas cycle parameterizations (in particular for $\mathrm{CH}_{4}$ and $\mathrm{N}_{2} \mathrm{O}$ ) that represent recent literature findings (Prather et al., 2012; Holmes et al., 2013). The calibrated carbon cycle of MAGICC has previously been shown to reflect the CMIP5 ESM response range well (Friedlingstein et al., 2014). Given the nearly 2-year time difference between the completion of historical and future greenhouse gas concentrations, we also updated the historical observational datasets to reflect observations until early 2018 for $\mathrm{CO}_{2}, \mathrm{CH}_{4}$, and $\mathrm{N}_{2} \mathrm{O}$, as well as most other gases considered here.

This study first describes the methods with separate parts for the updated observational data until 2018 (Sect. 2.1), the emission input data from the IAM scenarios and the input preparation steps undertaken (Sect. 2.2), the extensions of the emissions and concentrations beyond 2100 (Sect. 2.3), the MAGICC model setup (Sect. 2.4), and the projections of latitudinal gradients (Sect. 2.5) and seasonality (Sect. 2.6). We also provide a new simplified formula to reflect the Oslo Line-By-Line model (OLBL) radiative forcing results (Etminan et al., 2016) in order to provide the radiative forcing aggregation of the output (Sect. 2.7) and discuss additional methodological steps (Sect. 2.8). We then show the results and compare these to other recent observational datasets (Sect. 3 "Results"). A discussion section follows (Sect. 4 "Discussion"), which includes a closer look at the two most dominant GHG forcers, $\mathrm{CO}_{2}$ and $\mathrm{CH}_{4}$, and their correlation (Sect. 4.1), a discussion on the most recent GHG concentration developments (Sect. 4.2), and the comparison with RCP concentrations (Sect. 4.4). We describe the limitations of the dataset (Sect. 5), which includes issues like the integration of observational and modelled future data, missing uncertainty estimates, potential biases in future seasonality and latitudinal gradients, and a lack of reference scenarios for Montrealcontrolled substances. Section 6 concludes the paper.

\section{Methods}

As for the historical concentrations, we provide 43 greenhouse gas future concentration projections, namely $\mathrm{CO}_{2}$, $\mathrm{CH}_{4}, \mathrm{~N}_{2} \mathrm{O}, 17$ ozone-depleting substances (namely CFC-11, CFC-12, CFC-113, CFC-114, CFC-115, HCFC-22, HCFC141b, HCFC-142b, $\mathrm{CH}_{3} \mathrm{CCl}_{3}, \mathrm{CCl}_{4}, \mathrm{CH}_{3} \mathrm{Cl}, \mathrm{CH}_{2} \mathrm{Cl}_{2}$, $\mathrm{CHCl}_{3}, \mathrm{CH}_{3} \mathrm{Br}$, Halon-1211, Halon-1301, and Halon-2402) and 23 other fluorinated compounds (namely 11 hydrofluorocarbons (HFCs) - HFC-134a, HFC-23, HFC-32, HFC125, HFC-143a, HFC-152a, HFC-227ea, HFC-236fa, HFC245fa, HFC-365mfc, HFC-43-10mee; $\mathrm{NF}_{3}, \mathrm{SF}_{6}$, and $\mathrm{SO}_{2} \mathrm{~F}_{2}$; and nine perfluorocarbons (PFCs) $-\mathrm{CF}_{4}, \mathrm{C}_{2} \mathrm{~F}_{6}, \mathrm{C}_{3} \mathrm{~F}_{8}, \mathrm{C}_{4} \mathrm{~F}_{10}$, $\mathrm{C}_{5} \mathrm{~F}_{12}, \mathrm{C}_{6} \mathrm{~F}_{14}, \mathrm{C}_{7} \mathrm{~F}_{16}, \mathrm{C}_{8} \mathrm{~F}_{18}$, and $\mathrm{c}-\mathrm{C}_{4} \mathrm{~F}_{8}$ ). Our projections refer to atmospheric dry-air mole fractions as do the historical data presented in Meinshausen et al. (2017), even though the projections are sometimes loosely referred to as "concentrations". For $\mathrm{CO}_{2}$, the usual unit is parts per million (ppm), for $\mathrm{CH}_{4}$ and $\mathrm{N}_{2} \mathrm{O}$, the usual unit is parts per billion (ppb), and other gases are usually denoted in parts per trillion (ppt). 


\subsection{Updated observational data}

The historical concentrations (until the end of 2014) were derived from various observational datasets of greenhouse gas concentrations or literature studies in the case of some of greenhouse gases with lower concentrations. The observational data were binned by latitudinal and longitudinal boxes, averaged for monthly values, and complemented by interpolations. The historical time series for every greenhouse gas were separated into three elements as part of the spatiotemporal binning: (i) latitudinal gradient, (ii) seasonality pattern, and (iii) global mean. This separation then permitted the use of longer observational time series, such as the highlatitudinal $\mathrm{CH}_{4}$ firn data - implicitly correcting for the highlatitude differences to the global mean that one would expect. Interpolations, regressed latitudinal gradients, and seasonality patterns were employed to derive the historical dataset, but no gas cycle models.

With additional observational data being available for 2015, 2016, and 2017, the previously used observational data sources from the AGAGE and NOAA networks (Dlugokencky, 2015a, b; Prinn et al., 2018), including multiple NOAA ESRL Global Monitoring Laboratory (https://www. esrl.noaa.gov/gmd/, last access: 14 July 2020) flask measurements, were updated and used to determine the initial years of the future concentration time series. The result of this is that - depending on the gases - the same concentrations are used across all nine SSPs in the initial years (Table 1). As outlined below, we employed MAGICC7.0 and its calibrated gas cycles to produce concentration time series from SSP emissions beyond the observationally based period.

\subsection{Emission data and their harmonization}

For the emission-driven MAGICC7 runs that produce the future global-mean greenhouse gas time series, we use the SSP emission data for $\mathrm{CO}_{2}, \mathrm{CH}_{4}$ and $\mathrm{N}_{2} \mathrm{O}$, HFCs, PFCs, and $\mathrm{SF}_{6}$ which are available from the SSP database at IIASA (https://tntcat.iiasa.ac.at/SspDb, last access: 20 June 2020). This emission data have already been subject to several categorization and harmonization steps to obtain regionally consistent (in the case of $\mathrm{CO}_{2}$ and $\mathrm{CH}_{4}$ ) and sectorally resolved data (for more details, see Gidden et al., 2019). We complemented those harmonization steps to consider the following species in the five RCP regions (OECD90, REF (economies in transition), LAM (Latin America), MAF (Middle East and northern Africa) and ASIA): $\mathrm{CO}_{2}, \mathrm{CH}_{4}$, and $\mathrm{N}_{2} \mathrm{O}$ in addition to black carbon (BC), carbon monoxide (CO), ammonium $\left(\mathrm{NH}_{3}\right)$, non- $\mathrm{CH}_{4}$ volatile organic compounds (NMVOCs), nitrates $\left(\mathrm{NO}_{x}\right)$, organic carbon (OC), and sulfate aerosol $\left(\mathrm{SO}_{x}\right)$. For those 10 species, we also distinguished between fossil and industrial sources and land-use-related sources.

Regional land use $\mathrm{CO}_{2}$ emissions are not provided in the SSP database (Gidden et al., 2019), so we downscaled to the $\mathrm{RCP}$ regions based on historical regional emission shares in the year 2015. Given land use $\mathrm{CO}_{2}$ emissions can be negative in some SSP scenarios, a simple scaling approach in the regional harmonization would yield unrealistic results (i.e. regions with low or negative current net land use emissions, like the OECD, would end up with positive emissions and the other world regions would be strongly negative in the future). Instead, we applied a normalization that assumes a negative $1.5 \mathrm{GtC}$ base level against which historical regional emission shares are continued into the future, scaled with global emissions.

Mathematically, the constant regional scaling factor is hence applied to the offset emission level, so that the future regional emissions $E_{\mathrm{r}}(y)$ in year $y$ are as follows:

$$
\begin{aligned}
& E_{\mathrm{r}}(y)=E_{\mathrm{g}}(2015) \times s_{2015}+\left(E_{\mathrm{g}}(y)-E_{\mathrm{g}}(2015)\right) \times r, \\
& \text { where } \\
& r=\frac{E_{\mathrm{r}}(2015)+1.5}{\sum_{r=1}^{n}\left(E_{\mathrm{r}}(2015)+1.5\right)},
\end{aligned}
$$

with $r$ being the regional share of emissions relative to that $1.5 \mathrm{GtC}$ offset level, $s$ being the regional share of emissions in 2015 relative to zero, i.e. $s_{2015}=E_{\mathrm{r}}(2015) / E_{\mathrm{g}}(2015)$, $E_{\mathrm{r}}(y)$ being the regional emissions in year $y$, and $E_{\mathrm{g}}(y)$ being the global emissions, i.e. the sum of the $n$ regional emissions. Specifically, the factors $s_{2015}$ and $r$ for were the following for the regions Asia, Latin America, the Middle East and Africa, OECD-90, and economies in transition: 0.483, $0.282,0.189,0.043$, and 0.003 for $s_{2015}$ and 0.2320 .209 , $0.199,0.182$, and 0.178 for $r$, respectively. This choice has little effect because the regional split up of $\mathrm{CO}_{2}$ emissions only marginally and indirectly affects the latitudinal concentrations in our chosen method. A very small difference arises for different regional land use $\mathrm{CO}_{2}$ emission assumptions because MAGICC7 scales albedo effects with land use $\mathrm{CO}_{2}$ emissions and these albedo effects impact temperatures and in turn the carbon cycle again.

Land-use-related $\mathrm{CH}_{4}$ and fossil and industrial $\mathrm{CO}_{2}$ and $\mathrm{CH}_{4}$ emissions were already harmonized with historical emissions and also regionally available (Gidden et al., 2019, 2018). $\mathrm{N}_{2} \mathrm{O}$ emissions were only available as a global total from the SSP database based on PRIMAP (Gütschow et al., 2016), which is why we assume to be constant regional and sectoral emission shares. This assumption does not have a bearing on final global concentrations.

For the emissions of fluorinated gases that are listed in the Kyoto Protocol and considered here (PFCs, HFCs, and $\mathrm{SF}_{6}$ ), namely $\mathrm{C}_{2} \mathrm{~F}_{6}, \mathrm{CF}_{4}$, HFC-125, HFC-134a, HFC-143a, HFC-227ea, HFC-23, HFC-245fa, HFC-43-10mee, and SF 6 , MAGICC7 takes the global and aggregated SSP emissions of the gas baskets as inputs, as provided by the IAM modellers using constant emission shares based on a future gasspecific scenario by Guus Velders (Velders et al., 2015) and described in Gidden et al. (2019). The basket of PFCs, HFCs, and $\mathrm{SF}_{6}$ is reported in the SSP database at IIASA (https: //tntcat.iiasa.ac.at/SspDb/, last access: 20 June 2020). Some few data points were corrected in consultation with the re- 
Table 1. Derivation and construction of future CMIP6 mixing ratio fields for the greenhouse gas concentration series from 2015 onwards. Note that in addition to the steps shown below, a post-processing step was implemented to scale any differences in the December 2014 values between the raw future data and the previously submitted historical greenhouse gas concentration data. Those data differences in monthly latitudinal values for December 2014 were linearly scaled to zero until December 2015 in order to provide for a smooth transition between historical and future datasets (Sect. 2.8). See Sect. 2.1 for a description of how the observational data were updated. n/a - not applicable

\begin{tabular}{|c|c|c|c|c|c|c|}
\hline Gas & Time period & Observational data source & $\begin{array}{l}\text { Global and annual-mean } \\
C_{\text {global }}\end{array}$ & Seasonality $\hat{S}_{l, m}$ & Seasonality change $\Delta S_{l, m}$ & Latitudinal gradient $\hat{L}$ \\
\hline \multirow[t]{2}{*}{$\mathrm{CO}_{2}$} & $2015-2016$ & $\begin{array}{l}\text { NOAA ESRL Carbon } \\
\text { Cycle Cooperative Global } \\
\text { Air Sampling Network, } \\
\text { 1968-2016. } \\
\text { Version: 2017-07-28 (up- } \\
\text { dated from historical run } \\
\text { version: 2015-08-03), } \\
\text { monthly station aver- } \\
\text { ages (Dlugokencky et } \\
\text { al., 2015b; NOAA ESRL } \\
\text { GMD, 2014b, c, d, a) }\end{array}$ & $\begin{array}{l}\text { Calculated based on obser- } \\
\text { vational data source as de- } \\
\text { scribed in Meinshausen et } \\
\text { al. (2017) }\end{array}$ & \multirow[t]{2}{*}{$\begin{array}{l}\text { Mean over 1984-2013 } \\
\text { period. }\end{array}$} & \multirow{2}{*}{$\begin{array}{l}\text { Leading EOF of resid- } \\
\text { uals from observation - } \\
\text { extended into future with } \\
\text { projected gross primary } \\
\text { productivity (GPP) from } \\
\text { MAGICC7.0 calibrated } \\
\text { carbon cycle to the UVIC } \\
\text { C4MIP model (Friedling- } \\
\text { stein et al., 2006). (This is a } \\
\text { change from the historical } \\
\text { GHG methodology, when } \\
\text { we used only observational } \\
\text { temperature and } \mathrm{CO}_{2} \\
\text { concentrations.) }\end{array}$} & $\begin{array}{l}\text { Two leading EOFs and their } \\
\text { scores derived from latitu- } \\
\text { dinal residuals from annual } \\
\text { mean values. }\end{array}$ \\
\hline & 2016 to 2500 & $\mathrm{n} / \mathrm{a}$ & $\begin{array}{l}\text { MAGICC7.0 } \mathrm{CO}_{2} \text { global- } \\
\text { mean projections driven } \\
\text { by harmonized SSP GHG } \\
\text { emissions (Gidden et } \\
\text { al., 2019) or extended } \\
\text { emissions beyond } 2100 \\
\text { (Sect. 2.3). }\end{array}$ & & & $\begin{array}{l}\text { The score for the first EOF } \\
\text { is regressed against global } \\
\text { annual fossil fuel and in- } \\
\text { dustry emissions from SSP } \\
\text { scenarios. Score for the sec- } \\
\text { ond EOF assumed to be } \\
\text { constant in future. }\end{array}$ \\
\hline \multirow[t]{2}{*}{$\mathrm{CH}_{4}$} & 2015-2016 & $\begin{array}{l}\text { AGAGE monthly station } \\
\text { means, incl. pollution } \\
\text { events (".mop") (Cunnold } \\
\text { et al., 2002) \& NOAA } \\
\text { ESRL monthly station } \\
\text { data (Dlugokencky et al., } \\
\text { 2015a); Version 2017-07- } \\
\text { 28; }\end{array}$ & $\begin{array}{l}\text { Calculated based on obser- } \\
\text { vational data source as de- } \\
\text { scribed in Meinshausen et } \\
\text { al. (2017). }\end{array}$ & \multirow[t]{2}{*}{$\begin{array}{l}\text { Mean over } 1985-2013 \text { pe- } \\
\text { riod. Applied as relative } \\
\text { seasonality, i.e. percent de- } \\
\text { viation from global mean. }\end{array}$} & $\begin{array}{l}\text { Absolute seasonality } \\
\text { changing given that it is } \\
\text { applied relative to global } \\
\text { mean. }\end{array}$ & \multirow{2}{*}{$\begin{array}{l}\text { Two leading EOFs and thei } \\
\text { scores derived from latitu } \\
\text { dinal residuals from annua } \\
\text { mean values. The score for } \\
\text { the first EOF is regressee } \\
\text { against global annual fos } \\
\text { sil fuel and industry emis } \\
\text { sions from SSP scenarios } \\
\text { Score for the second EOF } \\
\text { assumed to be constant in } \\
\text { future. }\end{array}$} \\
\hline & $2016-2500$ & $\mathrm{n} / \mathrm{a}$ & $\begin{array}{l}\text { MAGICC7.0 } \mathrm{CH}_{4} \text { global- } \\
\text { mean projections driven by } \\
\text { harmonized SSP emissions } \\
\text { extended emissions beyond } \\
2100 \text { (Sect. 2.3). }\end{array}$ & & & \\
\hline \multirow[t]{2}{*}{$\mathrm{N}_{2} \mathrm{O}$} & 2015 to 2016 & $\begin{array}{l}\text { AGAGE monthly station } \\
\text { means, incl. pollution } \\
\text { events (Prinn et al., } \\
\text { 1990) (Version Dec 2017) } \\
\text { and combined nitrous } \\
\text { oxide data (monthly sta- } \\
\text { tion averages) from the } \\
\text { NOAA/ESRL Global Mon- } \\
\text { itoring Division; Version } \\
\text { Thu, Jan 25, } 2018 \text { 01:50:47 } \\
\text { PM }\end{array}$ & $\begin{array}{l}\text { Calculated based on obser- } \\
\text { vational data source as de- } \\
\text { scribed in Meinshausen et } \\
\text { al. (2017). }\end{array}$ & \multirow[t]{2}{*}{$\begin{array}{l}\text { Mean over } 1985-2013 \text { pe- } \\
\text { riod. Applied as relative } \\
\text { seasonality, i.e. percent de- } \\
\text { viation from global mean. }\end{array}$} & \multirow[t]{2}{*}{$\begin{array}{l}\text { Absolute seasonality } \\
\text { changing given that it is } \\
\text { applied relative to global } \\
\text { mean. }\end{array}$} & \multirow[t]{2}{*}{$\begin{array}{l}\text { Two leading EOFs and their } \\
\text { scores derived from latitu- } \\
\text { dinal residuals from annua } \\
\text { mean values; The score } \\
\text { for the first EOF is re- } \\
\text { gressed against global to- } \\
\text { tal } \mathrm{N}_{2} \mathrm{O} \text { emissions to ex } \\
\text { trapolate into the future } \\
\text { Score for the second EOF } \\
\text { assumed to be constant in } \\
\text { future. }\end{array}$} \\
\hline & 2016 to 2500 & $\mathrm{n} / \mathrm{a}$ & $\begin{array}{l}\text { MAGICC7.0 } \mathrm{N}_{2} \mathrm{O} \text { global- } \\
\text { mean projections driven by } \\
\text { harmonized SSP emissions } \\
\text { (Gidden et al., 2019) ex- } \\
\text { tended emissions beyond } \\
2100 \text { (Sect. 2.3). }\end{array}$ & & & \\
\hline \multirow[t]{2}{*}{$\begin{array}{l}\text { Other } \\
\text { greenhouse } \\
\text { gases }\end{array}$} & 2015 to 2017 & $\begin{array}{l}\text { Data input sources as } \\
\text { described in Meinshausen } \\
\text { et al. (2017) with several } \\
\text { data inputs updated to } \\
\text { newer versions of the data, } \\
\text { namely AGAGE monthly } \\
\text { station means, incl. pol- } \\
\text { lution events (Prinn et } \\
\text { al., 2018) (Version Dec } \\
\text { 2017); } 4 \text { Feb } 2018 \text { update } \\
\text { of NOAA/ESRL/GMD } \\
\text { data (Montzka et al., 2015), } \\
\text { where appropriate. }\end{array}$ & $\begin{array}{l}\text { Calculated based on obser- } \\
\text { vational data source as de- } \\
\text { scribed in Meinshausen et } \\
\text { al. (2017). }\end{array}$ & \multirow[t]{2}{*}{$\begin{array}{l}\text { Depending on the gas, } \\
\text { either assumed to be } \\
\text { zero or mean over recent } \\
\text { historical period, nor- } \\
\text { mally 1990-2013, period. } \\
\text { See online fact sheets at } \\
\text { http://greenhousegases. } \\
\text { science.unimelb.edu.au for } \\
\text { a gas-to-gas depiction of } \\
\text { the seasonality. }\end{array}$} & \multirow[t]{2}{*}{$\begin{array}{l}\text { Either zero or absolute } \\
\text { seasonality changing given } \\
\text { that it is applied relative to } \\
\text { global mean - depending } \\
\text { on the gas. }\end{array}$} & \multirow[t]{2}{*}{$\begin{array}{l}\text { The leading EOF and its } \\
\text { score derived from residu- } \\
\text { als from observations, with } \\
\text { the score for the lead- } \\
\text { ing EOF regressed against } \\
\text { global total } \mathrm{CH}_{4} \text { emis- } \\
\text { sions to extrapolate into the } \\
\text { future. }\end{array}$} \\
\hline & $2016 / 2017$ to 2500 & $\mathrm{n} / \mathrm{a}$ & $\begin{array}{l}\text { MAGICC7.0 driven by har- } \\
\text { monized SSP emissions or } \\
\text { WMO (2014) scenario A1 } \\
\text { emission projections (with } \\
\text { extensions beyond } 2100 \text { ). }\end{array}$ & & & \\
\hline
\end{tabular}


spective IAM modelling teams, namely the SSP1-1.9 emission level in 2100 for $\mathrm{CF}_{4}$ and $\mathrm{C}_{2} \mathrm{~F}_{6}$, for which we assumed the rate of decline prolonged from the 2080 to 2090 to the 2090 to 2100 period. HFC-32 emissions were complemented from a Kigali Agreement-consistent scenario, which has also been derived from the scenarios by Velders et al. (2015). Those scenarios were published until 2050 and we use in addition an extension up to 2100 by proportional downscaling of the global warming potential (GWP)-weighted HFC basket - using SSP GDP and population data with an assumption of constant GDP and population after 2100.

The ozone-depleting substances controlled under the Montreal Protocol, namely CFC-11, CFC-12, CFC-113, CFC-114, CFC-115, HCFC-22, HCFC-141b, HCFC-142b, $\mathrm{CH}_{3} \mathrm{Br}, \mathrm{CH}_{3} \mathrm{Cl}, \mathrm{CH}_{3} \mathrm{CCl}_{3}, \mathrm{CCl}_{4}$, Halon-1202, Halon-1211, Halon-1301, and Halon-2402, are here assumed to follow the WMO 2014 scenario (WMO, 2014) from 1951 to 2099, as presented in detail in Velders and Daniel (2014). For times before 1951 and after 2099, the previous WMO A1 Baseline emission scenario from the year 2006 (WMO, 2006) is assumed, which is near-zero and close to the respective WMO 2014 values in 1951 and 2099.

Harmonized emissions of aerosol and ozone precursor species are also available for the SSP scenarios (Hoesly et al., 2018) but not discussed in this paper. These non-GHG emissions are used here as part of the complete scenario specification needed to produce future temperature and GHG concentration pathways.

\subsection{Extension of emissions and concentrations beyond 2100}

In 2011, the RCPs were extended beyond 2100 to provide the basis for longer-term scenario studies (Meinshausen et al., 2011b), then called "extended concentration pathways" (ECPs). Studying this longer-term behaviour of the climate system is of interest for quantities that exhibit a strong longterm commitment or non-linear behaviour (e.g. sea level rise, ice sheet dynamics). The RCP concentration extensions were - for some gases and scenarios - based on pragmatic extensions of emissions, like an RCP8.5 $\mathrm{CO}_{2}$ emission stabilization from 2100 to 2150 with a subsequent ramp-down until 2250. For other RCPs, concentrations were held constant and the inverse $\mathrm{CO}_{2}$ emissions exhibited a near-exponential decline.

Here, we present the extensions beyond 2100 of the ScenarioMIP and AerChemMIP SSPs (although we do not use a new acronym like ECPs at the time of the RCPs). The final choices differ, in some respects, from the initial sketch of these extensions that was offered in the ScenarioMIP overview paper (O'Neill et al., 2016). As described below, the collaborative exercise by the IAM modellers and MAGICC team updated the original SSP extension design. In summary, the extension principles are as follows:
1. From 2100 onwards, net negative fossil $\mathrm{CO}_{2}$ emissions are brought back to zero during the 22nd century, while positive fossil $\mathrm{CO}_{2}$ emissions are ramped down to zero by 2250 .

2. Land use $\mathrm{CO}_{2}$ emissions are brought back to zero by 2150 .

3. Non- $\mathrm{CO}_{2}$ fossil greenhouse gas emissions are ramped down to zero by 2250 .

4. Land-use-related non- $\mathrm{CO}_{2}$ emissions are held constant at 2100 levels.

In the initial ScenarioMIP design (O'Neill et al., 2016), fossil $\mathrm{CO}_{2}$ emissions for SSP5-3.4-OS and SSP1-2.6 are negative at 2100 levels until 2140 and gradually increase to zero until 2190 and 2185, respectively (Fig. 2a). We did not assume permanent net-negative $\mathrm{CO}_{2}$ emissions to maintain proximity to the original scenario design in the light of biophysical and economic limits of negative emissions, as well as potential side effects (Fuss et al., 2018; Smith et al., 2016). For all scenarios with net negative fossil fuel extensions, we implemented extensions assuming constant emissions until 2140 (as suggested) but reaching zero emissions in 2190 . The only exception is the SSP5-3.4-OS scenario, which was ramped back to zero by a slightly earlier date (2170) so that fossil and land use emissions (in combination with MAGICC7.0's default setting - see Sect. 2.4) met the design criteria of an approximate merge with SSP1-2.6 concentrations in the longerterm, i.e. after 2150.

In the initial ScenarioMIP extension sketch for SSP58.5 , total $\mathrm{CO}_{2}$ emissions were envisaged to be "less than

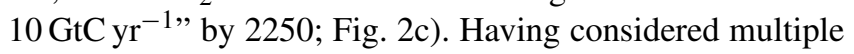
options, we opted for a straight ramp-down of fossil $\mathrm{CO}_{2}$ emissions to zero by 2250 due to its simplicity. Land use $\mathrm{CO}_{2}$ emissions for SSP1-2.6 in the initial ScenarioMIP design were held constant at 2100 levels indefinitely. SSP5-3.4OS levels were designed to reach the same net negative land use $\mathrm{CO}_{2}$ levels by 2120 (Fig. 2b). However, the extensions presented here assume that all land use $\mathrm{CO}_{2}$ emissions linearly phase out between 2100 and 2150, as continuing negative land use $\mathrm{CO}_{2}$ emissions are inconsistent with fixed 2100 land use and land cover patterns. In the original scenario design suggestion by O'Neill et al. (2016), all non- $\mathrm{CO}_{2}$ greenhouse gas emissions were kept constant at 2100 levels. However, the final extensions presented here assume differentiated extension rules by sector. Specifically, we assumed a linear phase-out of all fossil and industrial non- $\mathrm{CO}_{2}$ emissions by 2250 (including aerosols) (see, e.g., Fig. 2c). Similarly, synthetic industrial gases were assumed to be phased out by 2250 instead of assuming constant emissions (panel g, h). For land-use-related non- $\mathrm{CO}_{2}$ emissions, the assumption has been maintained that 2100 emission levels are held constant. That assumption seemed approximately consistent with constant land use and land cover patterns as food production 


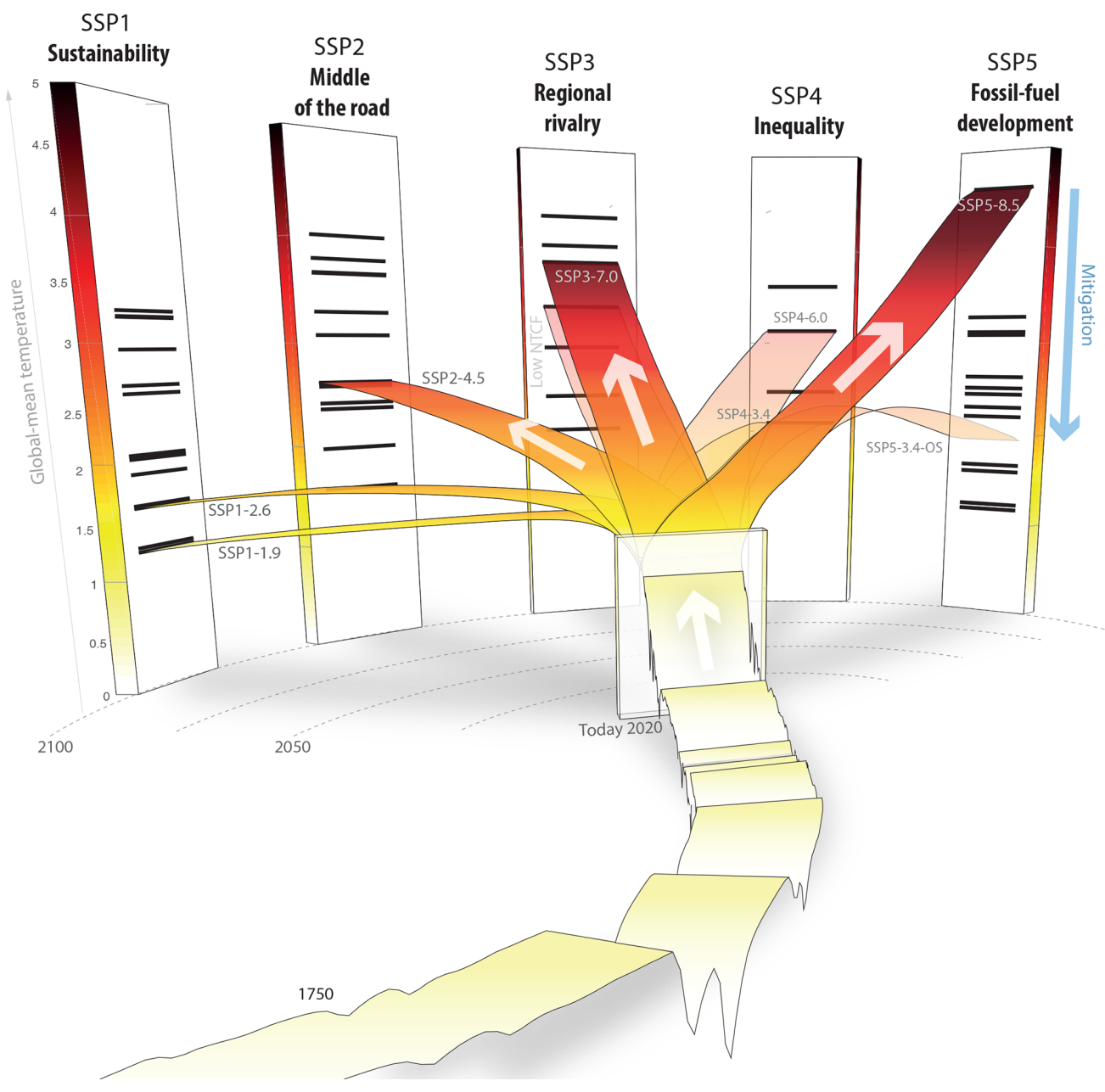

Figure 1. The SSP scenarios and their five socio-economic SSP families. Shown are illustrative temperature levels relative to pre-industrial levels with historical temperatures (front band), current (2020) temperatures (small block in middle), and the branching of the respective scenarios over the 21 st century along the five different socio-economic families. The small black horizontal bars on the 2100 pillars for each SSP indicate illustrative temperature levels (obtained by the MAGICC7.0 default setting used to produce the GHG concentrations) for the range of SSP scenarios that were available from the IAM community at the time of creating the benchmark SSP scenarios. The more opaque bands over the 21st century indicate the five SSP scenarios SSP1-1.9, SSP1-2.6, SSP2-4.5, SSP3-7.0, and SSP5-8.5 that are used as priority scenarios in IPCC. The more transparent bands indicate the remaining "Tier 2" SSP scenarios, namely SSP3-7.0-LowNTCF (used in AerChemMIP), SSP4-3.4, SSP4-6.0, and SSP5-3.4-OS. Also shown is a blue indicative bar on the right side, indicating the effect of mitigation action, which reduces temperature levels in 2100 and throughout the 21 st century - depending on the respective reference scenario and level of mitigation.

activities would continue to produce certain levels of $\mathrm{N}_{2} \mathrm{O}$ and $\mathrm{CH}_{4}$ emissions (panel d). In comparison to a uniform approach of holding all emissions constant at 2100 levels, the chosen differentiation to phase out fossil and industrialrelated emissions over time while holding land-use-related emissions constant seemed more consistent with plausible futures.

\subsection{Projecting global-mean concentrations with the MAGICC climate model}

For projecting the SSP greenhouse gas concentrations, we updated several gas cycles and also used MAGICC's per- mafrost module, which was not switched on when projecting the RCP concentrations. The sections below describe these updates.

\subsubsection{Methane cycle}

The methane $\left(\mathrm{CH}_{4}\right)$ cycle in MAGICC projects $\mathrm{CH}_{4}$ concentrations based on anthropogenic $\mathrm{CH}_{4}$ emissions as an input. Internally, MAGICC derives natural $\mathrm{CH}_{4}$ emissions by closing the $\mathrm{CH}_{4}$ budget over a user-defined historical period (here assumed to be 1994 to 2004; previously 1966 to 1976). The atmospheric $\mathrm{CH}_{4}$ lifetime as modelled in MAGICC changes over time both because of projected changes in tropospheric 

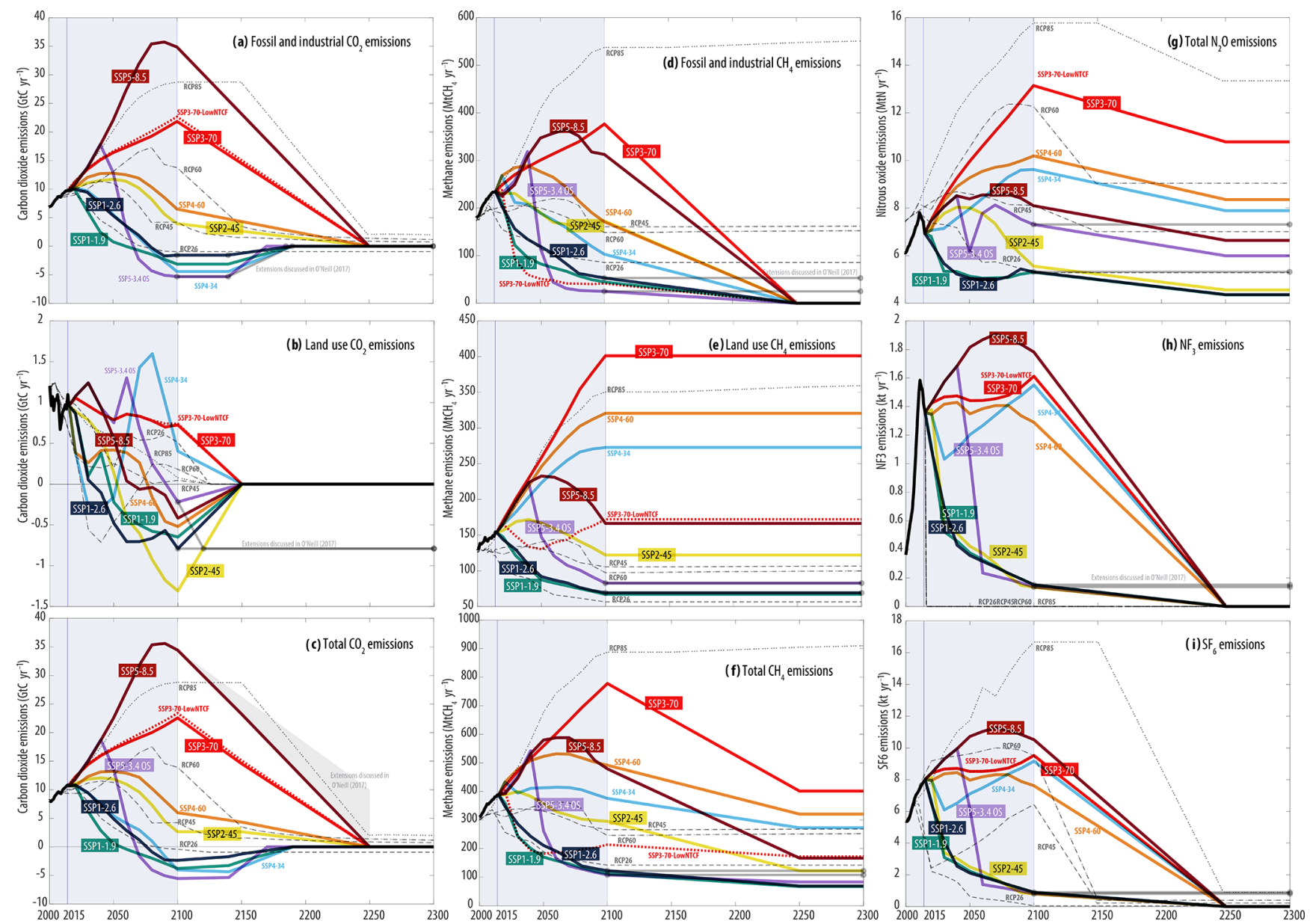

Figure 2. The anthropogenic emission scenarios to derive SSP concentration scenarios for $\mathrm{CO}_{2}(\mathbf{a}-\mathbf{c}), \mathrm{CH}_{4}(\mathbf{d}-\mathbf{e})$, nitrous oxide $(\mathbf{f}), \mathrm{NF}_{3}(\mathbf{g})$, and $\mathrm{SF}_{6}$ (i). Shown are the four SSP scenarios for which long-term CMIP6 model experiments are planned (bold lines with colour-box labels), namely for SSP5-8.5 (red), SSP5-34-OS (orange), SSP1-2.6 (blue), and SSP1-1.9 (turquoise). Also shown are RCP extensions (Meinshausen et al., 2011b), and those of other SSP scenarios following the same design principles (see text). While the design principles for $\mathrm{CO}_{2}$ emissions are specific, other gases from fossil and industrial sources are assumed to be phased out by 2225, and land-use-related emissions are assumed to stay constant at their 2100 values. The pre-2100 emission scenarios are derived from harmonized integrated assessment scenarios, while the post-2100 extensions follow simple extension assumptions.

$\mathrm{OH}$ concentrations and an increased stratospheric BrewerDobson circulation under increased climate change (Meinshausen et al., 2011a). On top of this, increased $\mathrm{CH}_{4}$ emissions are modelled to affect (alongside several other reactive gas emissions like $\mathrm{CO}, \mathrm{NMVOC}$, and $\mathrm{NO}_{x}$ ) tropospheric $\mathrm{OH}$ concentrations (as described for our modelling framework in Meinshausen et al., 2011a; based on Ehhalt et al., 2001). Thus, there is a feedback loop where increased $\mathrm{CH}_{4}$ emissions lead to decreased $\mathrm{OH}$-related $\mathrm{CH}_{4}$ sinks and in turn longer $\mathrm{CH}_{4}$ lifetimes and longer lifetimes of other GHGs, such as HCFCs and HFCs. The increased Brewer-Dobson circulation, on the other hand, leads to stronger $\mathrm{CH}_{4}$ removals, lowering the overall lifetime. As a net effect, $\mathrm{CH}_{4}$ lifetimes tend to be shorter in the lower emission scenarios and longer in the higher emission scenarios, such as RCP8.5.
In this study, we calibrate nine of MAGICC's $\mathrm{CH}_{4}$ cycle parameters (see its description and parameter denotations in Appendix A2.1 of Meinshausen et al., 2011c) to the modelled $\mathrm{CH}_{4}$ projections by Holmes et al. (2013). They included, like MAGICC, the temperature sensitivity of $\mathrm{CH}_{4}$ 's $\mathrm{OH}$-related lifetime, thereby updating results of Prather et al. (2012). These newly calibrated parameters are (a) the initial $\mathrm{CH}_{4}$ lifetime $\tau_{\mathrm{CH}_{4} \text {,tropos }}^{\prime}(9.95$ years, updated from 9.6 years), (b) the temperature-sensitivity of $\mathrm{CH}_{4}$ 's $\mathrm{OH}$-related lifetime $S_{\tau \mathrm{CH}_{4}}\left(0.07 \mathrm{~K}^{-1}\right.$, updated from $\left.0.058 \mathrm{~K}^{-1}\right)$, (c) a scaling factor on the sensitivity of $\mathrm{CH}_{4}$ 's lifetime to $\mathrm{OH}$-changes $S_{\text {scale }}^{\mathrm{OH}}(0.725$, formerly 1$)$, which is newly introduced and applies to all $S_{x}^{\mathrm{OH}}$ factors shown in equation A30 in Meinshausen et al. (2011c), (d) the unscaled sensitivity of $\mathrm{OH}$ to $\mathrm{CH}_{4}$ concentration changes $S_{\mathrm{CH}_{4}}^{\mathrm{OH}}(-0.5377$, updated from the unscaled -0.32), noting that this update largely offsets 
the effect of the newly introduced scaling factor $S_{\text {scale }}^{\mathrm{OH}}$, and (e) the other sensitivities of tropospheric $\mathrm{OH}$ to changes in $\mathrm{NO}_{x}, \mathrm{CO}$, and volatile organic compounds (VOCs), namely $S_{\mathrm{NO}}^{\mathrm{OH}}, S_{\mathrm{CO}}^{\mathrm{OH}}$, and $S_{\mathrm{VOC}}^{\mathrm{OH}}$ (updated to $9.3376 \times 10^{-3},-1.13 \times$ $10^{-4}$, and $-3.142 \times 10^{-4}$ from $4.2 \times 10^{-3},-1.05 \times 10^{-4}$, and $-3.15 \times 10^{-4}$, respectively). Also, we updated the partial soil-related lifetime of $\mathrm{CH}_{4}$ (150 years rather than 160 years), following Prather et al. (2012).

The net effect of the newly calibrated MAGICC is that Holmes et al. (2013) $\mathrm{CH}_{4}$ projections are closely matched across the range of RCPs (Supplement Fig. S1, left column). Both $\mathrm{OH}-$ related and total $\mathrm{CH}_{4}$ lifetimes exhibit similar changes over time as in Holmes et al. (Supplement Fig. S1, middle columns), with the slight upward offset explained by our historical budgeting approach deducting somewhat lower natural $\mathrm{CH}_{4}$ emissions (which MAGICC assumes to be constant over time) (Supplement Fig. S1, right column).

\subsubsection{Nitrous oxide projections}

Prather et al. (2012) suggested that the RCP projections for $\mathrm{N}_{2} \mathrm{O}$ concentrations performed with MAGICC6 were somewhat too low for the lower RCP2.6 scenario and slightly too high for the higher RCP8.5 scenario (although within their uncertainty ranges). Here, we use their model to derive natural emission assumptions and lifetimes to allow a multivariable calibration of MAGICC7 to the median of the RCP $\mathrm{N}_{2} \mathrm{O}$ concentration range suggested and these other variables by Prather et al. (2012) (Supplement Fig. S2).

To set up this calibration, we complement RCP emission pathways by historical $\mathrm{N}_{2} \mathrm{O}$ emissions from PRIMAP-hist (Gütschow et al., 2016). We also used observed $\mathrm{N}_{2} \mathrm{O}$ concentrations until 2014 (Meinshausen et al., 2017) to complement the future Prather et al. (2020) concentrations. The natural $\mathrm{N}_{2} \mathrm{O}$ emission levels are calibrated (as part of the overall calibration that optimized lifetimes, budgeting periods, and lifetime sensitivities) with a budgeting approach over the 10 years prior to 1991 , resulting in a slightly lower assumed natural $\mathrm{N}_{2} \mathrm{O}$ emission level of $8.013 \mathrm{MtN}-\mathrm{N}_{2} \mathrm{O}$ compared to Prather et al $\left(9.1 \mathrm{MtN}-\mathrm{N}_{2} \mathrm{O}\right)$ and AR5 (11.0 MtN-N $\left.2 \mathrm{O}\right)$. Nonetheless, the total natural and anthropogenic emissions are similar for present-day conditions because Prather et al. (2020) assume lower anthropogenic emissions (6.5 MtN$\mathrm{N}_{2} \mathrm{O}$ ) compared to the RCP pathways, which assume on average 7.9 $\mathrm{MtN}-\mathrm{N}_{2} \mathrm{O}$. Apart from the budgeting period, MAGICC7's $\mathrm{N}_{2} \mathrm{O}$ gas cycle has three further $\mathrm{N}_{2} \mathrm{O}$ parameters, which we calibrate to the Prather et al. (2020) results. The first is the initial $\mathrm{N}_{2} \mathrm{O}$ lifetime $\tau_{\mathrm{N}_{2} \mathrm{O}}^{0}$ (updated from 123 to 139 years). The second is the sensitivity coefficient $S_{\tau_{\mathrm{N}_{2} \mathrm{O}}}$

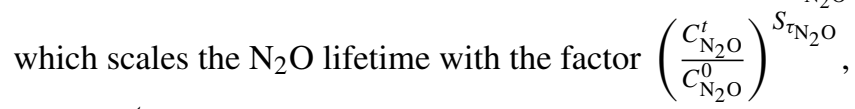
where $C_{\mathrm{N}_{2} \mathrm{O}}^{t}$ is the current atmospheric burden at time $t$ and $C_{\mathrm{N}_{2} \mathrm{O}}^{0}$ the pre-industrial burden $\left(S_{\tau_{\mathrm{N}_{2} \mathrm{O}}}\right.$ updated from -0.05 to $-0.04)$. The third is the sensitivity of the stratospheric life- time, with which $\mathrm{N}_{2} \mathrm{O}$ 's partial stratospheric lifetime is adjusted in response to a change in the Brewer-Dobson circulation $(0.04 \%$ change in partial lifetime per percent change in meridional flux).

\subsubsection{Additional gas cycles}

We extended the number of fluorinated gases to cover the full range of 43 greenhouse gases in MAGICC (i.e. including HFCs) from 12 to 23 and the number of ozone-depleting substances from 16 to 18 . Specifically, the newly modelled fluorinated species are perfluorocarbons $\mathrm{C}_{3} \mathrm{~F}_{8}, \mathrm{C}_{4} \mathrm{~F}_{10}, \mathrm{C}_{5} \mathrm{~F}_{12}$, $\mathrm{C}_{7} \mathrm{~F}_{16}, \mathrm{C}_{8} \mathrm{~F}_{18}, \mathrm{c}-\mathrm{C}_{4} \mathrm{~F}_{8}$, hydrofluorocarbons HFC-152a, HFC236fa, HFC-365mfc, as well as $\mathrm{NF}_{3}$, and $\mathrm{SO}_{2} \mathrm{~F}_{2}$. The newly modelled ozone-depleting substances are methylene chloride $\mathrm{CH}_{2} \mathrm{Cl}_{2}$, with a very short lifetime of 0.4 years, and methyl chloride $\mathrm{CH}_{3} \mathrm{Cl}$, with a lifetime of around 1 year (for lifetimes, see Table 8.A.1 of IPCC AR5 WG1 chap. 8, Myhre et al., 2013). We scale the partial stratospheric lifetime (HFC-152a, 39 years; HFC-236fa, 1800 years; HFC-365mfc, 125 years; $\mathrm{NF}_{3}, 740$ years; and $\mathrm{SO}_{2} \mathrm{~F}_{2}$ with 630 years - taken from Tables 1-3 in WMO, 2014) with a change in the Brewer-Dobson circulation strength. The BrewerDobson circulation is assumed to increase by $15 \%$ per degree of warming beyond 1980, derived from Butchart and Scaife's finding of an approximately $3 \%$ increase per decade (Butchart and Scaife, 2001) and assuming a $0.2^{\circ} \mathrm{C}$ warming per decade (Meinshausen et al., 2011a). Calibrating our gas cycle models to the results by Holmes et al. (2013), it seemed however that our Brewer-Dobson circulation speed-up shortened the longer-term lifetimes in higher-warming scenarios substantially more than predicted by the results of Holmes et al. (2013). Assuming no change in the height-age distribution of the air parcels that travel through the stratosphere, the speed-up of this meridional circulation could lower stratospheric lifetimes $1: 1$. However, assuming shorter residence times could offset some of the effect. We proceeded with a pragmatic approach and calibrated an effectiveness/scaling factor of 0.3 to match methane concentration projections by Holmes et al. (2013). That means that for every $1 \%$ increase in the Brewer-Dobson circulation, the partial stratospheric lifetimes are reduced by $0.3 \%$. However, we acknowledge that this effectiveness factor possibly summarizes multiple underlying differences between unscaled MAGICC results and the Holmes et al. (2013) projections that are unrelated to the Brewer-Dobson circulation.

For the partial lifetimes related to the (changing) tropospheric $\mathrm{OH}$ sink, we assume a scaling of the lifetimes with relative changes over time of the $\mathrm{OH}$ - and temperaturedependent methane lifetime.

\subsubsection{Permafrost feedbacks}

Earth system feedbacks from permafrost melting and its associated $\mathrm{CO}_{2}$ and $\mathrm{CH}_{4}$ releases were underrepresented 
in CMIP5 climate models, leading - inter alia - to an ad hoc adjustment of remaining carbon budgets by $27 \mathrm{GtC}$ $\left(100 \mathrm{GtCO}_{2}\right)$ in the IPCC Special Report on $1.5^{\circ} \mathrm{C}$ warming. Also, they were not part of the concentration projections for the RCP scenarios. Here, we include a representation of permafrost feedbacks based on the MAGICC permafrost (Schneider von Deimling et al., 2012), leading to additional cumulative $\mathrm{CO}_{2}$ emissions of 25 to $88 \mathrm{GtC}$ by 2100 , 42 to $378 \mathrm{GtC}$ by 2200 , and 51 to $542 \mathrm{GtC}$ by 2300 for the lowest (SSP1-1.9) and highest (SSP5-8.5) scenario, respectively (Table 2). Thus, our permafrost module is in line with the IPCC Special Report on $1.5^{\circ} \mathrm{C}$ warming assumptions for the lowest scenarios $(25 \mathrm{GtC}$ versus $27 \mathrm{GtC})$. While we do not entertain the probabilistic version in this study, our default settings are comparable to the median values reported in Schneider von Deimling (2012). In the highest scenarios (SSP5-8.5), these permafrost-related Earth system feedbacks cause $\mathrm{CO}_{2}$ concentrations that are up to $200 \mathrm{ppm}$ higher by 2200 (Fig. 3a). A later study included a more complex offline model with deep carbon deposits, a vertical soil resolution, and abrupt thaw processes like thermokarst lake formations. Generally, the results are comparable, although our settings might underestimate 21 st-century contributions and overestimate long-term cumulative emissions in comparison to Schneider von Deimling (2015).

In addition to elevated $\mathrm{CO}_{2}$ concentrations, the permafrost module also estimates future $\mathrm{CH}_{4}$ emissions related to permafrost thawing, i.e. annual emissions of up to $75 \mathrm{MtCH}_{4} \mathrm{yr}^{-1}$ in the highest SSP5-8.5 scenario by 2200 . Cumulatively, 0.34 to $1.07 \mathrm{GtC}$ of carbon are projected to be released as 451 to $1431 \mathrm{MtCH}_{4}$ over the course of the 21 st century across the nine considered SSP scenarios (Table 2), with even more coming in the 22nd century. The extra emissions lead to $10-240 \mathrm{ppb}$ higher $\mathrm{CH}_{4}$ concentrations in 2200 (Fig. 3b). Most of the carbon decomposition is assumed to happen as aerobic decomposition in the mineral soils, stretching from the more southerly zonal permafrost bands to the higher latitudes from now to 2200 (Fig. 3e to h).

\subsection{Projecting latitudinal gradients}

Compared to the previous input datasets for CMIP intercomparisons, which consisted of global-mean values only, latitudinal gradients (and seasonality) are new elements. For the historical period, these latitudinal gradients and seasonally changing surface air concentrations can be estimated from the large set of in situ and flask sampling sites with a monthly sampling resolution. Further back in time, when there was insufficient latitudinal coverage, the latitudinal gradient was decomposed into two empirical orthogonal functions (EOFs, the principal components). The multiplier or score (also known as the principal component time series) for the first EOF was regressed against global anthropogenic emissions. Except for $\mathrm{CO}_{2}$, the score for the second EOF was kept constant. For $\mathrm{CO}_{2}$, we assumed a simplified approach by both assuming a zero intercept for the regression of global emissions versus the first EOF and a phase-out back in time of the second EOF score. These lead to the simplified and uncertain assumption that the pre-industrial $\mathrm{CO}_{2}$ gradient was zero (Fig. 9b in Meinshausen et al., 2017). For a more detailed description of the interpolation and assimilation algorithms for the historical data, see Meinshausen et al. (2017).

For the future, there are obviously no observations from which the changes in the latitudinal gradients can be derived. We hence apply the regression procedure from the historical dataset into the future, i.e. we project the score of the first EOF of the latitudinal gradient of each greenhouse gas with its global emissions. That makes the simplifying assumption that, in the future, the sources (and sinks) of these gases remain approximately constant in terms of their latitudinal location (not in terms of their magnitude). For $\mathrm{CO}_{2}$ in the very low emission scenarios, like SSP1-1.9 with net negative $\mathrm{CO}_{2}$ emissions, that leads to a plausible reversal of the latitudinal gradient if the Northern Hemisphere is the main location for the natural and anthropogenically induced net $\mathrm{CO}_{2}$ sink.

There are large natural $\mathrm{CH}_{4}$ emission sources, predominantly in the Northern Hemisphere. Also, anthropogenic emissions are higher in the Northern Hemisphere. This largely explains the observed atmospheric concentration gradient: At the end of the historical period (2010 to 2014), $\mathrm{CH}_{4}$ concentrations are $80 \mathrm{ppb}$ above the global average in the northern midlatitudes while southern hemispheric concentrations gently slope towards a minimum of $60 \mathrm{ppb}$ below the global average at the pole (Fig. 11b in Meinshausen et al., 2017). As for $\mathrm{CO}_{2}$, we use anthropogenic $\mathrm{CH}_{4}$ emissions to extrapolate the first EOF score into the future. Given that $\mathrm{CH}_{4}$ emissions do not converge to zero in any scenario, let alone become negative, the strong north-south gradient is maintained in all scenarios.

\subsection{Projecting seasonality}

Seasonality of concentrations is by far most strongly pronounced for $\mathrm{CO}_{2}$, given the large seasonal sink (photosynthesis) and source (heterotrophic respiration) pattern of the northern hemispheric terrestrial biomass. Projecting future seasonality changes depends on a correct understanding of the past seasonality changes and how those seasonality changes are related to changes in ecosystem productivity (Forkel et al., 2016; Graven et al., 2013; Welp et al., 2016), increased cropland productivity (Gray et al., 2014), and other factors. Here, we use the net primary productivity (NPP) as a proxy for future seasonality changes and regress the historically derived seasonality change EOF score with modelled future net ecosystem exchange by MAGICC7. NPP in MAGICC7 is projected to increase strongly in the highest SSP58.5 scenario, while following a maximum-then-decline pattern in the lower SSP1-1.9 scenario. At the end of the historical period, the total seasonality is derived to have a minimum concentration deviation of $-10.1 \mathrm{ppm}$ in northern midlati- 

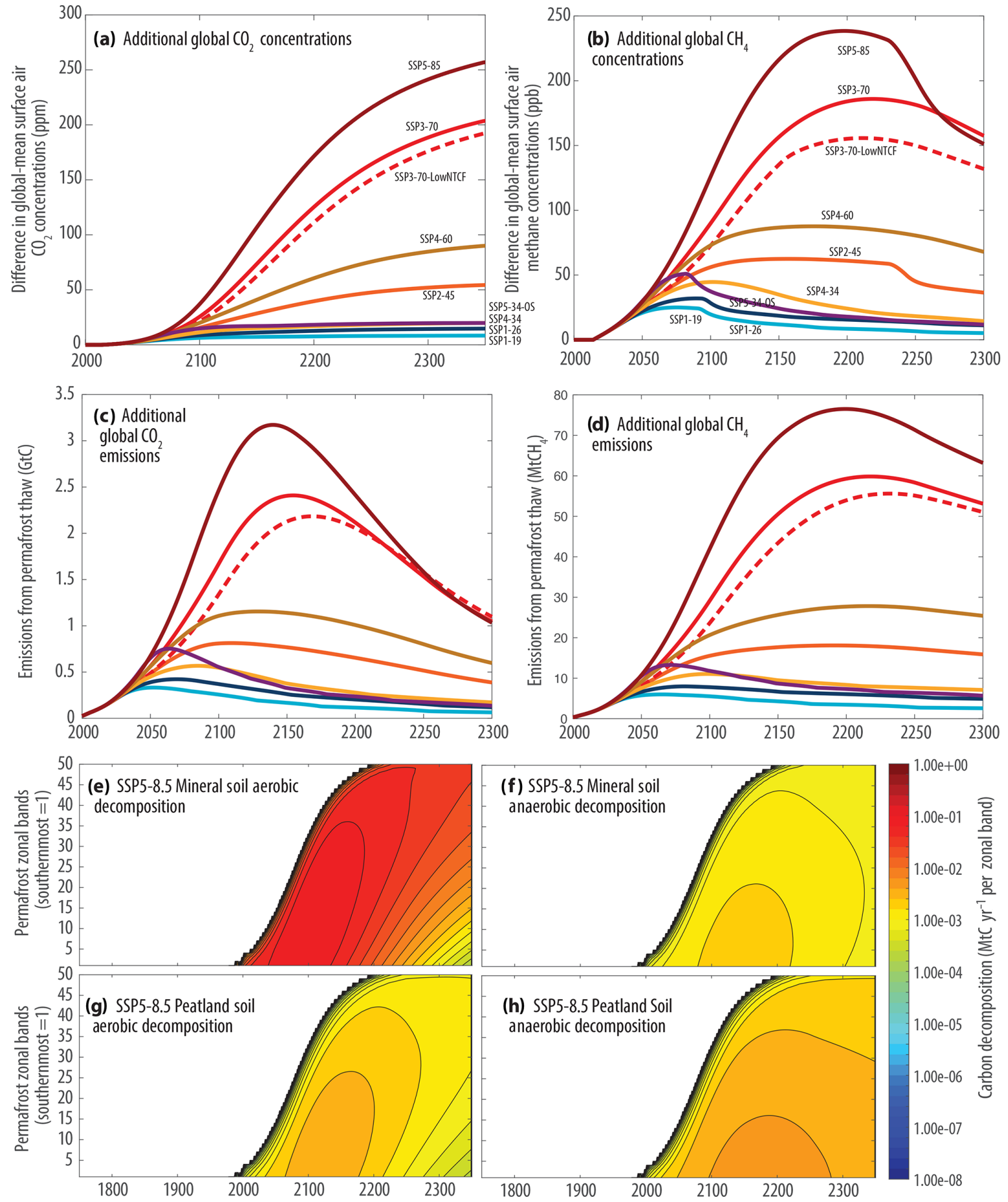

Figure 3. The assumed permafrost-related emissions by using MAGICC's permafrost module in its default settings for the SSP GHG concentration projections, close to the median of the probabilistic MAGICC permafrost version (Schneider von Deimling et al., 2012). In the highest scenario, SSP5-8.5, $\mathrm{CO}_{2}$ and $\mathrm{CH}_{4}$ concentrations by 2300 would have been about $250 \mathrm{ppm}$ and 150 ppb, respectively, lower without including the permafrost module (a, b). The additional $\mathrm{CO}_{2}$ from mineral soil and peatland carbon decomposition reach a maximum in the highest scenario SSP5-8.5 around 2140 of about $3 \mathrm{GtC}$ emissions per year (c), mainly due to the aerobic mineral soil decomposition (e). The mineral and peatland soil decomposition under aerobic conditions (e and $\mathbf{g}$, respectively) and also the oxidized part of the methane that originates from the anaerobic decomposition $(\mathbf{f}, \mathbf{h})$ contribute to the net $\mathrm{CO}_{2}$ emissions from permafrost thawing. The permafrost zonal bands are a simplified approach to represent the range of thawing thresholds and permafrost carbon contents and are described in Schneider von Deimling et al. (2012). See Table 2 for cumulative emissions. 
Table 2. Cumulative $\mathrm{CO}_{2}$ and $\mathrm{CH}_{4}$ emissions from MAGICC's permafrost module under the considered SSPs. The permafrost module has 50 zonal bands, a mineral and peatland soil module, and 50 latitudinal zonal bands. See Schneider von Deimling et al. (2012) for a detailed description. See Fig. 3 for time series of induced $\mathrm{CO}_{2}$ and $\mathrm{CH}_{4}$ atmospheric concentration changes.

\begin{tabular}{lrrrrrrrrrr}
\hline & $\begin{array}{r}\text { Time } \\
\text { horizon }\end{array}$ & SSP1-1.9 & SSP1-2.6 & SSP2-4.5 & $\begin{array}{r}\text { SSP3-7.0 } \\
\text {-LowNTCF }\end{array}$ & SSP3-7.0 & SSP4-3.4 & SSP4-6.0 & SSP5-3.4 & SSP5-8.5 \\
-OS & & & & & \\
\hline Cumulative $\mathrm{CO}_{2}$ & 2100 & 25 & 31 & 46 & 54 & 65 & 38 & 56 & 48 & 88 \\
emissions (GtC) & 2200 & 42 & 58 & 121 & 252 & 288 & 78 & 167 & 83 & 378 \\
& 2300 & 51 & 74 & 173 & 410 & 444 & 99 & 248 & 101 & 542 \\
\hline Cumulative $\mathrm{CH}_{4}$ & 2100 & 451 & 549 & 789 & 919 & 1089 & 670 & 953 & 835 & 1431 \\
emissions $\left(\mathrm{MtCH}_{4}\right)$ & 2200 & 884 & 1231 & 2527 & 5083 & 5911 & 1639 & 3467 & 1744 & 7999 \\
& 2300 & 1177 & 1774 & 4246 & 10505 & 11673 & 2404 & 6170 & 2389 & 15096 \\
\hline
\end{tabular}

tude August. Given these projected NPP changes in the high SSP5-8.5 scenario, the projected total seasonality increases to approximately twice that by 2100 , a projection that comes with a high degree of uncertainty.

For all other gases for which we identified a significant seasonal cycle in the historical observational data, we assume that the relative seasonality (i.e. the magnitude of monthly anomalies relative to the annual mean) stays constant, i.e. that the absolute seasonality concentration changes scale with global-mean concentrations.

\subsection{Simplified formula to reflect radiative forcing from $\mathrm{CO}_{2}, \mathrm{CH}_{4}$, and $\mathrm{N}_{2} \mathrm{O}$}

In order to present $\mathrm{CO}_{2}, \mathrm{CH}_{4}$, and $\mathrm{N}_{2} \mathrm{O}$ in our compilation of 43 greenhouse gases and their relative importance for future effective radiative forcings (ERFs), we use simplified radiative forcing formulas (for radiative forcing after stratospheric temperature adjustments) that represent the Oslo Line-By-Line model results - which now take into account the short-wave absorption of $\mathrm{CH}_{4}$, among other aspects (Etminan et al., 2016). While Etminan et al. (2016) provided simplified formulas for their Oslo Line-By-Line model results, we here adjust those simplified formulas, resulting in a virtual elimination of the model fit errors by Etminan of up to $3.6 \%$ for $\mathrm{CO}_{2}$ (see Table 1 in Etminan et al., 2016, and our Fig. $4 \mathrm{~d}$ and Table 3 below). Aside from slight model misfits, the original Etminan simplified formula for $\mathrm{CO}_{2}$ has a validity range of only up to $2000 \mathrm{ppm} \mathrm{CO}_{2}$ concentrations. Their simplified formula is an adaptation of the classical approach to approximate radiative forcing by $\alpha \times \ln \left(\frac{C}{C_{0}}\right)$, where $\alpha$ is a scaling coefficient, $C$ the $\mathrm{CO}_{2}$ concentration at time $t$ and $C_{0}$ the concentration at the reference state, normally the pre-industrial reference value. Etminan et al. introduce the overlap of the absorption spectra between $\mathrm{CO}_{2}$ and $\mathrm{N}_{2} \mathrm{O}$ and also modulate the logarithmic approximation by quadratic and linear terms. When using their suggested coefficients $\left(a_{1}, b_{1}\right.$, and $c_{1}$ in their Table 1$)$, the factor $\alpha$ in front of the $\ln \left(\frac{C}{C_{0}}\right)$ part reaches a maximum at $C_{0}-\frac{b_{1}}{2 a_{1}}$, i.e. at around $1777 \mathrm{ppm}$, when assuming $C_{0}$ as the pre-industrial concentration (277.15 ppm). For $\mathrm{CO}_{2}$ concentrations beyond
$1777 \mathrm{ppm}$, the alpha value decreases, leading to an unrealistic flattening off above $2000 \mathrm{ppm}$ (and eventual decline well above $3000 \mathrm{ppm}$ ). The highest projected SSP concentration (SSP5-8.5) reaches beyond the nominated validity range of $2000 \mathrm{ppm}$. Hence, we adapt the $\mathrm{CO}_{2}$ radiative forcing formula to assume a constant $\alpha$, once $\alpha$ reaches its maximal value (which is around 1808 ppm with our optimized parameter settings - see Table 3 ).

In summary, building on the work of Etminan, our optimized modifications of the simplified radiative forcing expressions for $\mathrm{CO}_{2}, \mathrm{CH}_{4}$, and $\mathrm{N}_{2} \mathrm{O}$ as presented in Table 3 have the two advantages of (a) representing the 48 Oslo LineBy-Line model results within rounding errors and also (b) extending its likely validity range in line with previous forcing approximations (and pending examinations by Line-By-Line models) to higher $\mathrm{CO}_{2}$ concentrations. However, there is one disadvantage of our simplified formula. While our formula starts from fixed $C_{0}, N_{0}$, and $M_{0}$ values at pre-industrial levels, the formulas presented in Etminan cater for the option to set $C_{0}, N_{0}$ and $M_{0}$ at any value within the validity range. Hence, our formula would have to be applied twice to calculate the difference in terms of radiative forcing between a $C_{1}, N_{1}, M_{1}$ and a $C_{2}, N_{2}, M_{2}$ concentration state if both are different from pre-industrial levels $C_{0}, N_{0}$, and $M_{0}$.

We also take into account new findings regarding rapid adjustments (Smith et al., 2018). In the multi-model analysis by Smith et al. (2018), $\mathrm{CO}_{2}$ is suggested to have a slightly $(\sim 5 \%)$ higher effective radiative forcing than its instantaneous radiative forcing after stratospheric temperature adjustments alone, an adjustment also used here. While the tropospheric rapid adjustments in the case of $\mathrm{CO}_{2}$ is substantial, it is largely offset by the corresponding water vapour adjustment and the cloud-related rapid adjustments (Fig. 3 in Smith et al., 2018). Following Smith et al. (2018), we assume that rapid adjustments largely cancel out for $\mathrm{CH}_{4}$.

\subsection{Data-flow, mean-preserving higher resolutions, and merging with historical files}

In this study's projections, the data is provided in $15^{\circ}$ latitudinal bands with monthly resolution. These are constructed 

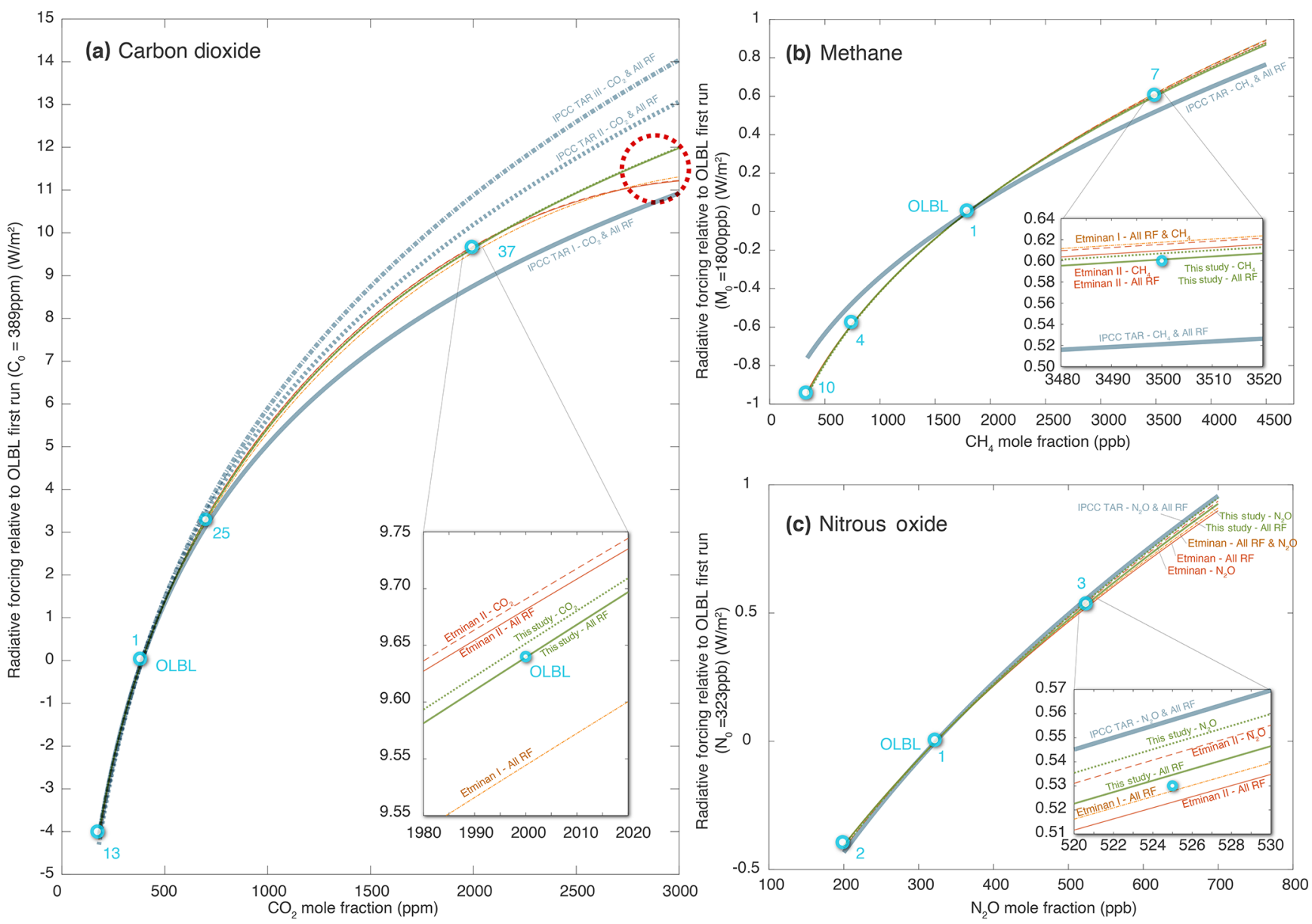

(d) Errors (differences between 48 Oslo LBL model cases compared to parameterizations)

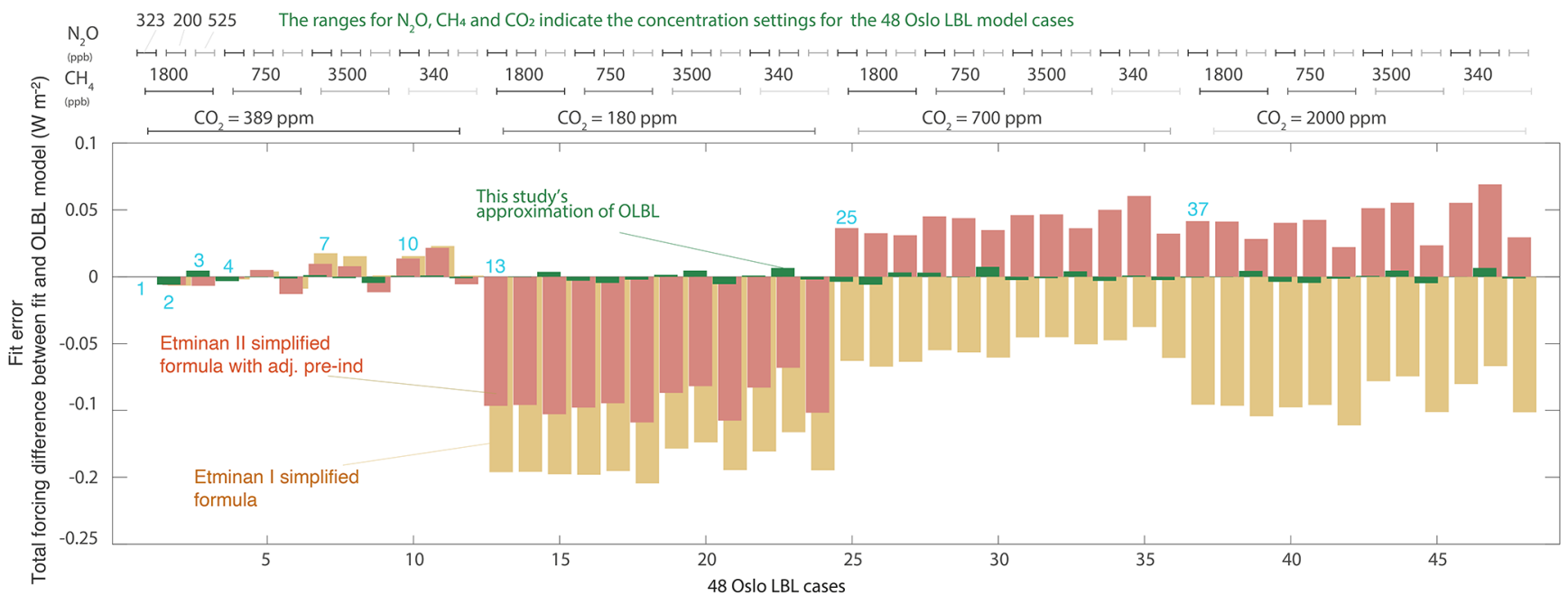

Figure 4. Simplified parameterization to emulate 48 Oslo Line-By-Line model results (bright blue open numbered circles). Shown are the IPCC TAR simplified formula for $\mathrm{CO}_{2}$ (three options), $\mathrm{CH}_{4}$, and $\mathrm{N}_{2} \mathrm{O}$ forcing with their default parameter settings (grey-blue lines) in the background. The simplified formula results by Etminan et al. (2016) are shown as orange lines. Adjusting pre-industrial concentration values to default 1750 values improves the fit of the Etminan simplified formula (red lines in panels a to $\mathbf{c}$ and red error terms in panel d). This study's simplified formula results are shown in green, matching the Oslo Line-By-Line model results within rounding - and continuing a forcing approximation beyond $2000 \mathrm{ppm} \mathrm{CO}$ in line with previously derived formulas (red dashed circle in panel a). See text. 
Table 3. Simplified expressions for radiative forcing relative to pre-industrial (1750) levels by changes in surface air mole fractions of $\mathrm{CO}_{2}$, $\mathrm{CH}_{4}, \mathrm{~N}_{2} \mathrm{O}$ - reflecting the Oslo Line-by-Line model results. This table can be compared to Table 1 in Etminan et al. (2016), but note that their formulas can be directly applied to any sets of $(C, \mathrm{Co}),(M, \mathrm{Mo})$, and $(N, \mathrm{No})$ within the range of fitting, unlike the case here where Co, Mo, and No are pre-specified at pre-industrial levels.

\begin{tabular}{|c|c|c|c|}
\hline Gas & $\begin{array}{l}\text { Simplified } \\
\text { Expression }\end{array}$ & $\begin{array}{l}\text { Coefficients } \\
\text { error } \%\left(\mathrm{~W} \mathrm{~m}^{-2}\right)\end{array}$ & Maximal absolute fit \\
\hline $\mathrm{CO}_{2}$ & $\begin{array}{l}C_{\alpha_{\max }}=C_{0}-\frac{b_{1}}{2 a_{1}} \approx 1808 \mathrm{ppm} \\
\alpha^{\prime}=d_{1}-\frac{b_{1}^{2}}{4 a_{1}}, \text { for } C>C_{\alpha_{\max }} \\
\alpha^{\prime}=d_{1}+a_{1}\left(C-C_{0}\right)^{2}+b_{1}\left(C-C_{0}\right), \text { for } C_{0}<C<C_{\alpha_{\max }} \\
\alpha^{\prime}=d_{1}, \text { for } C<C_{0} \\
\alpha_{\mathrm{N}_{2} \mathrm{O}}=c_{1} \cdot \sqrt{N} \\
\mathrm{RF}_{\mathrm{CO}_{2}}=\left(\alpha^{\prime}+\alpha_{\mathrm{N}_{2} \mathrm{O}}\right) \cdot \ln \left(\frac{C}{C_{0}}\right)\end{array}$ & $\begin{array}{l}a_{1}=-2.4785 \times 10^{-7} \mathrm{~W} \mathrm{~m}^{-2} \mathrm{ppm}^{-2} \\
b_{1}=0.00075906 \mathrm{~W} \mathrm{~m}^{-2} \mathrm{ppm}^{-1} \\
c_{1}=-0.0021492 \mathrm{~W} \mathrm{~m}^{-2} \mathrm{ppb}^{-0.5} \\
d_{1}=5.2488 \mathrm{~W} \mathrm{~m}^{-2} \\
C_{0}=277.15 \mathrm{ppm}\end{array}$ & $0.11 \%\left(0.0037 \mathrm{~W} \mathrm{~m}^{-2}\right)$ \\
\hline $\mathrm{N}_{2} \mathrm{O}$ & $\mathrm{RF}_{\mathrm{N}_{2} \mathrm{O}}=\left(a_{2} \sqrt{C}+b_{2} \sqrt{N}+c_{2} \sqrt{M}+d_{2}\right) \cdot\left(\sqrt{N}-\sqrt{N_{0}}\right)$ & $\begin{array}{l}a_{2}=-0.00034197 \mathrm{~W} \mathrm{~m}^{-2} \mathrm{ppm}^{-1} \\
b_{2}=0.00025455 \mathrm{~W} \mathrm{~m}^{-2} \mathrm{ppb}^{-1} \\
c_{2}=-0.00024357 \mathrm{~W} \mathrm{~m}^{-2} \mathrm{ppb}^{-1} \\
d_{2}=0.12173 \mathrm{~W} \mathrm{~m}^{-2} \mathrm{ppb}^{-0.5} \\
N_{0}=273.87 \mathrm{ppb}\end{array}$ & $1.5 \%\left(0.0059 \mathrm{~W} \mathrm{~m}^{-2}\right)$ \\
\hline $\mathrm{CH}_{4}$ & $\mathrm{RF}_{\mathrm{CH}_{4}}=\left(a_{3} \sqrt{M}+b_{3} \sqrt{N}+d_{3}\right) \cdot\left(\sqrt{M}-\sqrt{M_{0}}\right)$ & $\begin{array}{l}a_{3}=-8.9603 \times 10^{-5} \mathrm{~W} \mathrm{~m}^{-2} \mathrm{ppb}^{-1} \\
b_{3}=-0.00012462 \mathrm{~W} \mathrm{~m}^{-2} \mathrm{ppb}^{-1} \\
d_{3}=0.045194 \mathrm{~W} \mathrm{~m}^{-2} \mathrm{ppb}^{-0.5} \\
M_{0}=731.41 \mathrm{ppb}\end{array}$ & $0.55 \%\left(0.0032 \mathrm{~W} \mathrm{~m}^{-2}\right)$ \\
\hline
\end{tabular}

from the global-mean time series generated by MAGICC7, with the modulation towards latitudinal annual means by the time-changing latitudinal gradients (Sect. 2.5). These latitudinal annual means are then turned into monthly data values using the latitudinally and monthly resolved seasonality fields.

There are two additional post-processing steps involved. For one, the mean-preserving interpolation routines from Sect. 2.1.9 of Meinshausen et al. (2017) are used to generate a monthly surface air mole fraction field at a finer $0.5^{\circ}$ latitudinal resolution. The other step is merging the projections with the historical concentrations. To ensure a smooth transition from the previously derived historical concentration fields to the ones derived in this study, we use the latitudinally resolved differences in the month of December 2014 between the historical fields derived in Meinshausen et al. (2017) and the raw data produced here. We then add those December 2014 differences to the 2015 future datasets, phasing them out linearly over 12 months.

\section{Results}

This study's projected greenhouse gas concentrations provide the "official" greenhouse gas concentrations for the SSP scenarios. They help enable the CMIP6 exercises and span a wide range of possible futures. Below, the results are presented for the various gases. The complete data repository of all projected mole fractions in various data formats, with interactive plots and fact sheets is avail- able at http://greenhousegases.science.unimelb.edu.au (last access: 20 June 2020). The subset of the data recommended for the nine SSPs that are part of the ScenarioMIP and AerChemMIP experiments in netcdf format is also available on https://esgf-node.llnl.gov/search/input4mips/ (last access: 20 June 2020).

\subsection{Carbon dioxide}

The projected $\mathrm{CO}_{2}$ concentrations range from 393 to $1135 \mathrm{ppm}$ in 2100 , with the low scenario SSP1-1.9 decreasing to $350 \mathrm{ppm}$ by 2150 (Fig. $5 \mathrm{~g}$ ). Given the assumption of zero $\mathrm{CO}_{2}$ emissions in the lower scenarios beyond that, the lower end of the projected $\mathrm{CO}_{2}$ concentrations is not projected to decrease much further. On the upper end, under the SSP5-8.5 scenario global-average concentrations are projected to increase up to $2200 \mathrm{ppm}$ by 2250 (Tables 4 and 5, and see also online "GHG fact sheets" at http://greenhousegases.science.unimelb.edu.au). The latitudinal gradient implies a difference of annual-average northern midlatitudes to South Pole concentrations of about $6 \mathrm{ppm}$ in current times (Fig. 5b). As future seasonality is correlated with projected NPP, the $\mathrm{CO}_{2}$ seasonality change pattern (Fig. 5a.1) is scaled with the a normalized projected NPP (Fig. 5a.2). Future latitudinal gradients are derived by projecting the first two principal components or EOFs, where the first (dark-blue line in Fig. 5c) is regressed against global emissions - with the implied future scaling factor show in Fig. 5d (dark-blue line). The second EOF (turquoise line in Fig. 5c) is assumed to be constant in the future (turquoise line 
in Fig. 5d). The applied projection methods result in a continuous projection of $\mathrm{CO}_{2}$ concentration from the observationally derived historical values, including their latitudinal gradients and seasonality (Fig. 5h). By approximately 2060, a zero latitudinal gradient is projected in the lowest SSP1-1.9 scenario (Fig. 5b) because $\mathrm{CO}_{2}$ emissions revert from positive to net negative. Under the highest SSP5-8.5 scenario, the northern midlatitude to South Pole difference expands to more than 23 ppm by 2100 (not shown in plot, but viewable in online data repository at http://greenhousegases.science. unimelb.edu.au).

\subsection{Methane}

Global-mean $\mathrm{CH}_{4}$ surface air mole fractions across the SSP scenarios are projected to range from 999.7 to $3372 \mathrm{ppb}$ by 2100 , with maximal northern hemispheric averages being $\sim 60 \mathrm{ppb}$ higher than the global average (Table 4). The largest difference between average northern and southern hemispheric concentrations (up to $120 \mathrm{ppb}$ by 2100 , Table 5) is in the highest $\mathrm{CH}_{4}$ emissions scenario (SSP3-7.0) and whilst the smallest difference $(\sim 70 \mathrm{ppb})$ is seen in the scenarios with the lowest global $\mathrm{CH}_{4}$ emissions (SSP1-1.9, SSP1-2.6, and SSP5-3.4OS). While SSP5-8.5 is projected to be the scenario with the highest radiative forcing because of high $\mathrm{CO}_{2}$ emissions, SSP5-8.5 is not the highest $\mathrm{CH}_{4}$ emissions scenario, with both SSP3-7.0 and SSP4-6.0 suggesting higher total $\mathrm{CH}_{4}$ emission by 2100 (and in our extensions beyond 2100) (Fig. 2f).

\subsection{Nitrous oxide}

$\mathrm{N}_{2} \mathrm{O}$ concentrations are not projected to decrease at any point before 2200, regardless of the SSP scenario we consider. Even under the lowest emissions scenarios, SSP1-1.9 and SSP1-2.6, current global-average concentrations are projected to increase from $328.5 \mathrm{ppb}$ in 2015 to $361 \mathrm{ppb}$ by 2100 (Table 5). Under the highest $\mathrm{N}_{2} \mathrm{O}$ scenarios (SSP3-7.0 and SSP3-7.0-lowNTCF), concentrations are projected to increase to 422 ppb by 2100 and over 500 ppb by 2500 . Both seasonality and the latitudinal gradient is rather subdued for $\mathrm{N}_{2} \mathrm{O}$, as it is both a long-lived greenhouse gas and does not exhibit strong seasonal variability in either sources or sinks.

\subsection{Ozone-depleting substances and other chlorinated substances}

As all ozone-depleting substances' emissions are assumed to follow a single emission scenario as a result of the Montreal Protocol (Velders and Daniel, 2014), the SSP concentration scenarios exhibit no substantial variation across their projected concentrations. For example, by 2100, CFC-11 and CFC-12 concentrations are assumed to vary from 51.4 to $56.2 \mathrm{ppt}$, and from 114.3 to $133.5 \mathrm{ppt}$, respectively (Table 4). These differences across the concentration scenarios are hence not a result of different emission assumptions but solely due to factors that influence the substances' lifetimes. The stratospheric partial lifetime of these substances is affected by a change in the meridional Brewer-Dobson circulation, assumed to strengthen with increasing climate forcing. The tropospheric OH-related partial lifetime is scaled by changing $\mathrm{OH}$ concentrations. Those $\mathrm{OH}$ concentrations are in turn mainly affected by $\mathrm{CH}_{4}$ abundances and emissions of other reactive gases $\left(\mathrm{CO}, \mathrm{NMVOC}, \mathrm{NO}_{x}\right)$. Overall, the concentrations and radiative forcing contributions of all ozonedepleting substances are assumed to strongly reduce until 2100 and beyond, following the phase-out schedules under the Montreal Protocol (Fig. 10). See Sect. 4.2 for a discussion of the unexpectedly slow declines of CFC-11 (Montzka et al., 2018) and other species, though.

\subsection{Other fluorinated greenhouse gases}

Emissions of fluorinated gases with a virtually zero ozonedepleting potential - HFCs, PFCs, $\mathrm{SF}_{6}$, and $\mathrm{NF}_{3}$ - vary across the SSP scenarios. Most SSP scenarios assume strong decreases for several of these substances (e.g. $\mathrm{NF}_{3}$ and $\mathrm{SF}_{6}$ ), while SSP5-8.5 assumes strong increases for most of the 21st century (Fig. 2h, i). Until recently, these fluorinated gases were not controlled under the Montreal Protocol. With the 2016 Kigali Amendment, however, a select number of HFCs have been included in the Montreal Protocol and GWPweighted emissions of these particular HFCs will have to be phased-down globally in coming decades. When aggregating all these non-ozone-depleting fluorinated gases into HFC134a equivalent concentrations, the SSP scenarios project a wide range of 2100 values, ranging from $278 \mathrm{ppt}$ to more than 10-fold that value, i.e. $2985 \mathrm{ppt}$ (last row in Table 4). While the HFC projections are derived from the IAM modelling team assumptions regarding the SSPs, several of the resulting HFC projections would exceed the phase-out emission levels agreed to in the Kigali Agreement.

\subsection{Radiative forcing since $\mathbf{1 7 5 0}$}

In this section, we aggregate all 43 greenhouse gases' radiative forcing effect using the updated radiative forcing formula for $\mathrm{CO}_{2}, \mathrm{CH}_{4}$, and $\mathrm{N}_{2} \mathrm{O}$ and standard radiative efficiencies from IPCC AR5 (Sect. 2.7). Across the nine SSP scenarios, it is apparent that $\mathrm{CO}_{2}$ makes the largest contribution to future warming (blue parts in Fig. 7), constituting between $68 \%$ and $85 \%$ of GHG radiative forcing by 2100 , and $68 \%$ to $92 \%$ of radiative forcing by the time of maximum GHG-induced radiative forcing (Table 6). In the scenario with the greatest radiative forcing, SSP5-8.5, radiative forcing in 2100 is projected to be approximately 8 and $9.7 \mathrm{~W} \mathrm{~m}^{-2}$ for $\mathrm{CO}_{2}$ or all GHGs, respectively (right-axis bars in Fig. 7i). This greenhouse-gas-induced radiative forcing is projected to increase to nearly $13 \mathrm{~W} \mathrm{~m}^{-2}$ by 2250 under SSP5-8.5. On the lower side, the SSP1-1.9 scenario exhibits a $\mathrm{CO}_{2}$ radiative forcing of around $1 \mathrm{~W} \mathrm{~m}^{-2}$ in 2150 and be- 

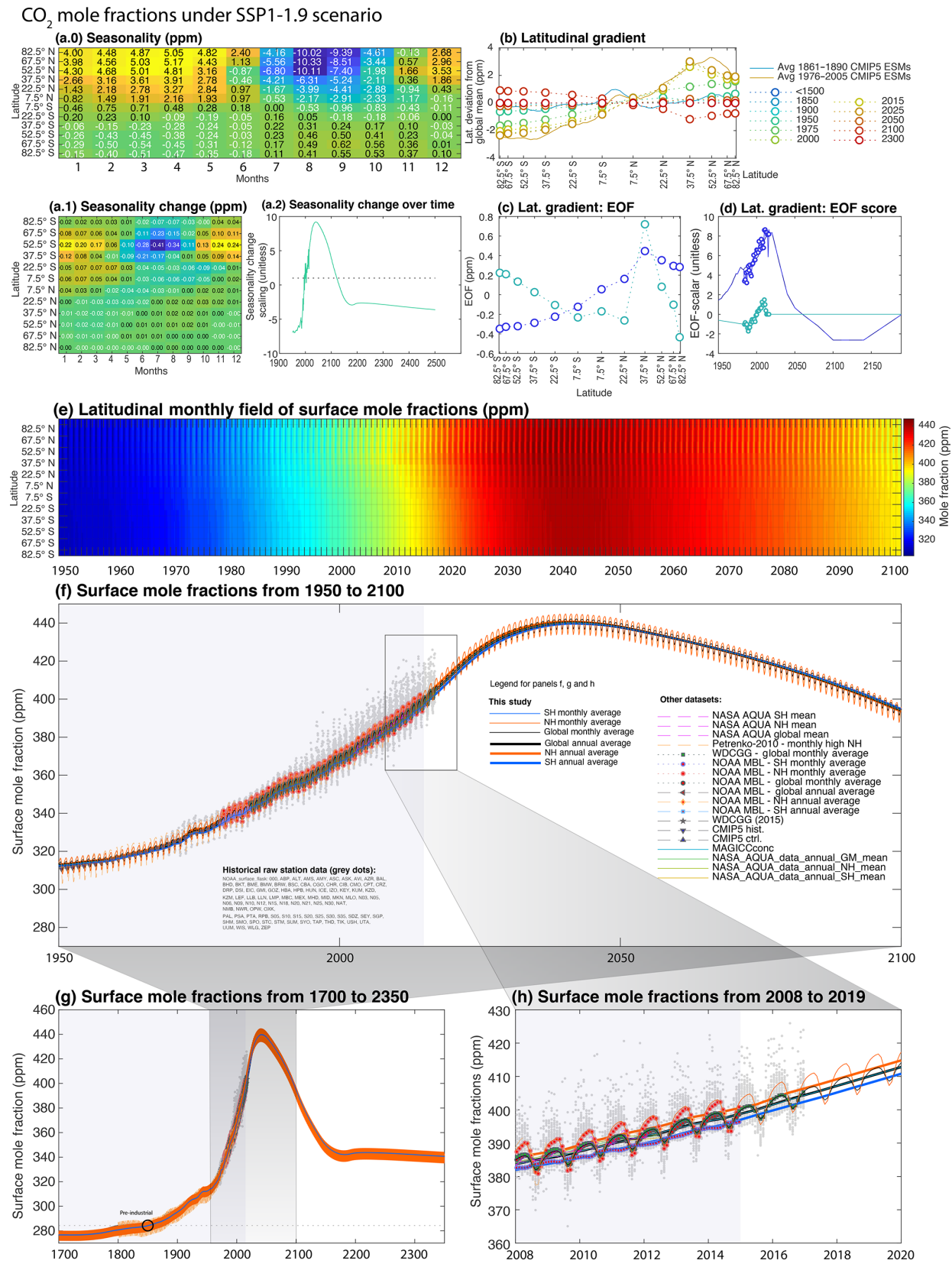

Figure 5. $\mathrm{CO}_{2}$ concentrations under the SSP1-1.9 scenario. The base seasonality pattern derived from historical observations with monthly and $15^{\circ}$ latitudinal resolution (a) is modulated over time using the first EOF of the residuals (a.1), scaled with projected NPP into the future (a.2). The latitudinal gradient is assumed to be flat in pre-industrial times, with latitudinal gradients over the observational record being derived from historical observations - and here compared with CMIP5 ESM models - see Meinshausen et al. (2017) (b). The projection of the latitudinal gradient uses global total $\mathrm{CO}_{2}$ emissions regressed against the score (dark-blue line in panel d) of the first latitudinal EOF (dark-blue line in panel c). The principal component's score of the second EOF's is assumed to be zero in the future (turquoise line in panel c, d). Resulting surface air mole fractions fields show a return to current $\mathrm{CO}_{2}(\sim 2019)$ concentrations by the end of the 21 st century $(\mathbf{e}, \mathbf{f})$. Historical NOAA surface flask station datasets (grey dots in panels $\mathbf{f}, \mathbf{g}, \mathbf{h}$ with station indicators provided in legend of panel $\mathbf{f}$ ) are used for these future projections beyond the end of 2014 reach of the historical dataset (grey shaded background in panels $\mathbf{f}, \mathbf{g}$, $\mathbf{h}$ ). Various comparison datasets shown, namely the WDCGG time series (Tsutsumi et al., 2009), the NOAA Marine Boundary Layer (MBL) product (https://www.esrl.noaa.gov/gmd/ccgg/mbl/, last access: 20 June 2020) and the NASA AQUA satellite data (ftp://acdisc.gsfc.nasa.gov/ftp/ data/s4pa/Aqua_AIRS_Level3/AIRX3C2M.005/, last access: 20 June 2020), the Petrenko time series (made available in the Supplement to Buizert et al., 2012). Also shown are the MAGICC global-mean projections (bright blue line "MAGICCconc"). These overview figures are available for all 43 gases and all nine scenarios on http://greenhousegases.science.unimelb.edu.au as a total of 387 so-called fact sheets. See also Table 12 in Meinshausen et al. (2017) for a description of all data labels. 
Table 4. Overview of future scenario range of individual GHG concentrations. The table indicates the minimum and maximum surface air mole fractions across the nine SSP scenarios considered in this study. For spreadsheets with annual data tables per scenario, see http: //greenhousegases.science.unimelb.edu.au. The third column indicates the region, with global ("GL"), northern hemispheric ("NL") and southern hemispheric ("SH") data shown for $\mathrm{CO}_{2}, \mathrm{CH}_{4}$ and $\mathrm{N}_{2} \mathrm{O}$. The last three rows provide the equivalence concentrations. The $\mathrm{CFC}-11$ eq concentrations summarize - in terms of radiative forcing equivalent - all greenhouse gases aside from $\mathrm{CO}_{2}, \mathrm{CH}_{4}, \mathrm{~N}_{2} \mathrm{O}$, and $\mathrm{CFC}-12$. The CFC-12-eq concentrations summarize all the ozone-depleting substances (ODSs) controlled under the Montreal Protocol, while HFC-134aeq summarizes the remaining fluorinated gases. Altogether $\mathrm{CO}_{2}, \mathrm{CH}_{4}, \mathrm{~N}_{2} \mathrm{O}, \mathrm{CFC}$-12-eq, and HFC-134a-eq together represent the radiative forcing of the entirety of the 43 greenhouse gases considered here (cf. Table 5 in Meinshausen et al., 2017).

\begin{tabular}{|c|c|c|c|c|c|c|c|c|c|c|c|c|}
\hline Gas & Unit & Reg & 2015 & 2025 & 2050 & 2075 & 2100 & 2150 & 2200 & 2250 & 2300 & 2500 \\
\hline \multirow[t]{3}{*}{$\mathrm{CO}_{2}$} & $\mathrm{ppm}$ & GL & 399.9 & $426.5-432.4$ & $437.6-562.8$ & $419.7-801.7$ & $393.5-1135.2$ & $349-1737.3$ & $343.4-2108.3$ & $343.3-2206.4$ & $342-2161.7$ & $336.9-2010$ \\
\hline & Ppint & $\mathrm{NH}$ & 401.7 & $428.2-434.9$ & $437.8-567.2$ & $419.5-808.5$ & $392.9-1142.3$ & $348.5-1742$ & $343.4-2110.7$ & $343.3-2206.4$ & $342-2161.7$ & $336.9-2010$ \\
\hline & & $\mathrm{SH}$ & 398.2 & $424.9-429.9$ & $437.5-558.3$ & 419.9-794.9 & $394.1-1128.2$ & $349.5-1732.6$ & $343.4-2106$ & $343.3-2206.3$ & $342-2161.7$ & $336.9-2010$ \\
\hline \multirow[t]{3}{*}{$\mathrm{CH}_{4}$} & ppb & GL & 1841.9 & $1865.1-2049.1$ & $1358.8-2503.7$ & $1184.3-2934.1$ & $999.7-3372.2$ & $961.8-3096.2$ & 927.6-2571.6 & $875.2-2107.1$ & $864.4-1988.1$ & 864-1938.4 \\
\hline & & $\mathrm{NH}$ & & $10.3-2098.2$ & $1400-2554.8$ & $4.3-2989.5$ & $1038.8-3430.7$ & $1000.6-3151.1$ & $966.1-2622.8$ & $913.1-2154.7$ & $02.4-2035.7$ & 901.9-1986 \\
\hline & & SH & 1794.1 & 1820-1999.9 & $1317.5-2452.5$ & $1144.3-2878.7$ & $960.6-3313.7$ & $922.9-3041.3$ & $889.1-2520.3$ & $837.2-2059.5$ & $826.4-1940.5$ & $826-1890.8$ \\
\hline \multirow[t]{3}{*}{$\mathrm{N}_{2} \mathrm{O}$} & $\mathrm{ppb}$ & GL & 328.2 & $334.9-336.4$ & $343.5-361.9$ & $348.5-391$ & $353.9-422.4$ & $361.2-472.5$ & $363.4-498.5$ & $362.2-508.7$ & $360-512$ & $356.4-517.5$ \\
\hline & & $\mathrm{NH}$ & & $335.1-336.7$ & $343.8-362.2$ & $348.8-391.3$ & $354.2-422.7$ & $361.5-472.8$ & $363.7-498.8$ & $362.5-509$ & $360.3-512.3$ & $356.7-517.8$ \\
\hline & & $\mathrm{SH}$ & 327.9 & $334.6-336.1$ & $343.2-361.6$ & $348.2-390.7$ & $353.6-422.1$ & $360.9-472.2$ & $363.2-498.3$ & $361.9-508.4$ & $359.7-511.8$ & $356.1-517.2$ \\
\hline $\mathrm{SF}_{6}$ & ppt & GL & 8.6 & $11.3-11.9$ & $14.3-21.7$ & $16.1-32.7$ & $17.2-43.5$ & $18.5-60.7$ & $19.1-70.5$ & $19.1-73.1$ & $18.8-72$ & $17.7-67.6$ \\
\hline $\mathrm{NF}_{3}$ & ppt & GL & 1.4 & $2.3-2.5$ & $3.3-5.8$ & $3.8-9.3$ & $4-12.7$ & $4.2-17.4$ & $4.1-19.2$ & $3.9-18.5$ & $3.6-16.6$ & $2.5-10.9$ \\
\hline $\mathrm{SO}_{2} \mathrm{~F}_{2}$ & ppt & GL & 2.1 & $2.8-3$ & $2.4-4$ & $1.6-4.4$ & $1.1-4.1$ & $0.5-2.9$ & $0.2-1.8$ & $0.1-0.8$ & $0-0.2$ & $0-0$ \\
\hline $\mathrm{CF}_{4}$ & ppt & GL & 81.8 & $88.3-89.7$ & $96.1-106.3$ & $99.2-123.2$ & $101.3-136$ & $103.8-154.6$ & $105.3-165.7$ & $105.7-169.4$ & $105.6-169.2$ & $105.2-168.6$ \\
\hline $\mathrm{C}_{2} \mathrm{~F}_{6}$ & ppt & GL & 4.5 & $5.1-5.2$ & $5.7-6.9$ & $5.8-8.6$ & $5.8-10$ & $5.8-12.2$ & $5.8-13.4$ & $5.7-13.8$ & $5.7-13.7$ & $5.6-13.5$ \\
\hline $\mathrm{C}_{3} \mathrm{~F}_{8}$ & ppt & GL & 0.6 & $0.7-0.8$ & $0.9-1.1$ & $0.9-1.5$ & $0.9-1.8$ & $0.9-2.2$ & $0.9-2.5$ & $0.9-2.6$ & $0.9-2.5$ & $0.8-2.5$ \\
\hline c- $-\mathrm{C}_{4} \mathrm{~F}_{8}$ & $\mathrm{ppt}$ & GL & 1.4 & $1.7-1.8$ & $2.1-2.6$ & $2.2-3.5$ & $2.3-4.1$ & $2.4-5$ & $2.5-5.5$ & $2.5-5.6$ & $2.4-5.5$ & $2.3-5.2$ \\
\hline $\mathrm{C}_{4} \mathrm{~F}_{10}$ & ppt & GL & 0.2 & $0.2-0.2$ & $0.2-0.3$ & $0.2-0.3$ & $0.2-0.4$ & $0.2-0.5$ & $0.2-0.5$ & $0.2-0.5$ & $0.2-0.5$ & $0.2-0.5$ \\
\hline $\mathrm{C}_{5} \mathrm{~F}_{12}$ & ppt & GL & 0.1 & $0.1-0.1$ & $0.1-0.2$ & $0.1-0.2$ & $0.1-0.2$ & $0.1-0.2$ & $0.1-0.2$ & $0.1-0.2$ & $0.1-0.2$ & $0.1-0.2$ \\
\hline $\mathrm{C}_{6} \mathrm{~F}_{14}$ & ppt & GL & 0.3 & $0.3-0.4$ & $0.4-0.5$ & $0.4-0.7$ & $0.4-0.8$ & $0.4-1$ & $0.4-1.1$ & $0.4-1.1$ & $0.4-1.1$ & $0.4-1$ \\
\hline $\mathrm{C}_{7} \mathrm{~F}_{16}$ & $\mathrm{ppt}$ & GL & 0.1 & $0.2-0.2$ & $0.2-0.3$ & $0.2-0.3$ & $0.2-0.4$ & $0.2-0.5$ & $0.2-0.6$ & $0.2-0.6$ & $0.2-0.6$ & $0.2-0.6$ \\
\hline $\mathrm{C}_{8} \mathrm{~F}_{18}$ & ppt & GL & 0.1 & $0.1-0.1$ & $0.1-0.1$ & $0.1-0.2$ & $0.1-0.2$ & $0.1-0.2$ & $0.1-0.3$ & $0.1-0.3$ & $0.1-0.3$ & $0.1-0.2$ \\
\hline HFC-23 & ppt & GL & 27.9 & $31.5-32$ & $28.7-29.9$ & $25.8-27$ & $22.8-24.1$ & $17.2-19.4$ & $12.8-16$ & $9.5-13.1$ & $7.1-10.7$ & $2.1-4.8$ \\
\hline HFC-32 & ppt & GL & 9.8 & $6.5-7.5$ & $0.1-0.7$ & $0-0.2$ & $0-0$ & $0-0$ & $0-0$ & $0-0$ & $0-0$ & $0-0$ \\
\hline HFC-43-10mee & ppt & GL & 0.3 & $0.3-0.3$ & $0.1-0.4$ & $0-0.4$ & $0-0.4$ & $0-0.2$ & $0-0.1$ & $0-0$ & $0-0$ & $0-0$ \\
\hline HFC-125 & $\mathrm{ppt}$ & GL & 17.8 & $52.1-78.6$ & $49.8-371.6$ & $31.5-744.8$ & $22.7-988.8$ & $14.2-809.2$ & $8.5-458.2$ & 3.4-137 & $0.8-13.7$ & $0-0$ \\
\hline HFC-134a & ppt & GL & 84.8 & $109.6-143.7$ & $36.1-239.4$ & $11.4-358$ & $6.6-423.3$ & $4.4-286.9$ & $2.5-145.5$ & $0.6-24.6$ & $0-0.2$ & $0-0$ \\
\hline HFC-143a & ppt & GL & 16.7 & $36.7-50.9$ & $39-234.3$ & $29.6-509.6$ & $23.7-745.9$ & $16.1-748.4$ & $10.4-500.9$ & $5.4-213.3$ & $2.2-53.1$ & $0.1-0.4$ \\
\hline HFC-152a & ppt & GL & 7.5 & $4.6-8.2$ & $0.2-6.5$ & $0.1-7.6$ & $0.1-6.5$ & $0.1-3.8$ & $0-1.8$ & $0-0.1$ & $0-0$ & $0-0$ \\
\hline HFC-236fa & ppt & GL & 0.1 & $0.2-0.3$ & $0.3-1.3$ & $0.3-3.1$ & $0.3-5.3$ & $0.3-7.9$ & $0.3-8.2$ & $0.2-6.7$ & $0.2-4.9$ & $0.1-1.4$ \\
\hline HFC-227ea & ppt & GL & 1.1 & $1.8-2.4$ & $1.4-6.4$ & $0.8-9.8$ & $0.5-10.9$ & $0.2-8.2$ & $0.1-4.7$ & $0-1.5$ & $0-0.2$ & $0-0$ \\
\hline HFC-245fa & ppt & GL & 2.2 & $3.6-5.8$ & $1.1-18.4$ & $0.5-34.5$ & $0.5-39.1$ & $0.4-24.5$ & $0.2-12.1$ & $0-1.3$ & $0-0$ & $0-0$ \\
\hline HFC-365mfc & ppt & GL & 0.9 & $1.2-1.6$ & $0.2-2.5$ & $0.1-3.8$ & $0.1-4.3$ & $0-2.7$ & $0-1.3$ & $0-0.2$ & $0-0$ & $0-0$ \\
\hline $\mathrm{CCl}_{4}$ & ppt & GL & 82.1 & $67.4-67.4$ & $32.4-32.7$ & $13.3-13.8$ & $5-5.5$ & $0.6-0.8$ & $0.1-0.1$ & $0-0$ & $0-0$ & $0-0$ \\
\hline $\mathrm{CHCl}_{3}$ & ppt & GL & 10.4 & $8.8-9.7$ & $5.8-9.5$ & $5.5-9$ & $5.5-8.3$ & $5.4-7.4$ & $5.4-6.4$ & $5.4-5.5$ & $\begin{array}{l}5.4-5.4 \\
\end{array}$ & $5.4-5.4$ \\
\hline $\mathrm{CH}_{2} \mathrm{Cl}_{2}$ & ppt & GL & 37.8 & $24.7-46.7$ & $8-59.2$ & $7.7-86.2$ & $7.8-90$ & $7.6-63$ & $7.3-35.5$ & $7.1-8$ & $7.1-7.1$ & $7.1-7.1$ \\
\hline $\mathrm{CH}_{3} \mathrm{CCl}_{3}$ & $\mathrm{ppt}$ & GL & 3.2 & $0.4-0.4$ & $0-0$ & $0-0$ & $0-0$ & $0-0$ & $0-0$ & $0-0$ & $0-0$ & $0-0$ \\
\hline $\mathrm{CH}_{3} \mathrm{Cl}$ & ppt & GL & 549.8 & $546.5-577.6$ & $466.1-582.4$ & $425.6-566$ & $421.6-556.5$ & $418.5-536.2$ & $394-509.7$ & $363.7-479.1$ & $358.2-475.9$ & $358.1-476.8$ \\
\hline $\mathrm{CH}_{3} \mathrm{Br}$ & $\mathrm{ppt}$ & GL & 6.7 & $6.5-6.9$ & $5.3-6.9$ & $5-6.8$ & $4.9-6.6$ & $4.7-6.3$ & $4.6-5.9$ & $4.4-5.5$ & $4.4-5.5$ & $4.4-5.5$ \\
\hline CFC-11 & ppt & GL & 231.5 & 204.4-204.4 & $137.8-138.9$ & $86.3-89.4$ & $51.4-56.2$ & $17.3-22.4$ & $5.5-8.7$ & $1.7-3.4$ & $0.5-1.3$ & $0-0$ \\
\hline CFC-12 & ppt & GL & 518 & $471.6-471.7$ & $364.3-366$ & $277.6-283.6$ & $208.7-220.2$ & $114.3-133.5$ & $61.2-81.4$ & $32.5-49.6$ & $17.3-30.3$ & $1.4-4.2$ \\
\hline CFC-113 & ppt & GL & $72.1-72.1$ & $64.7-64.7$ & $48.7-48.9$ & $36.1-37$ & $26.4-28$ & $13.7-16.2$ & $6.9-9.4$ & $3.5-5.5$ & $1.7-3.2$ & $0.1-0.4$ \\
\hline CFC-114 & ppt & GL & $16.3-16.3$ & $15.8-15.8$ & $13.9-13.9$ & $12-12.1$ & $10.3-10.6$ & $7.5-8.1$ & $5.4-6.2$ & $3.8-4.7$ & $2.7-3.6$ & $0.7-1.3$ \\
\hline CFC-115 & ppt & GL & $8.5-8.5$ & $8.8-8.8$ & $9.1-9.1$ & $9-9$ & $8.6-8.7$ & $7.7-7.9$ & $6.9-7.2$ & $6.2-6.6$ & $5.5-6$ & $3.5-4.1$ \\
\hline HCFC-22 & ppt & GL & $233.7-233.7$ & $237.2-241.1$ & $49.9-59.5$ & $4.5-8.8$ & $0.3-1.4$ & $0-0$ & $0-0$ & $0-0$ & $0-0$ & $0-0$ \\
\hline HCFC-141b & ppt & GL & $24.2-24.2$ & $27.2-27.7$ & $14.1-16.2$ & $3.5-5.2$ & $0.8-1.4$ & $0.3-0.5$ & $0.2-0.3$ & $0-0$ & $0-0$ & $0-0$ \\
\hline HCFC-142b & ppt & GL & $22.1-22.1$ & $21.2-21.5$ & $8.7-9.8$ & $1.9-3$ & $0.4-0.9$ & $0-0.1$ & $0-0$ & $0-0$ & $0-0$ & $0-0$ \\
\hline Halon-1211 & ppt & GL & $3.7-3.7$ & $2.6-2.6$ & $0.7-0.8$ & $0.2-0.2$ & $0-0$ & $0-0$ & $0-0$ & $0-0$ & $0-0$ & $0-0$ \\
\hline Halon-1301 & ppt & GL & $3.3-3.3$ & $3.3-3.3$ & $2.8-2.8$ & $2.1-2.1$ & $1.5-1.6$ & $0.6-0.8$ & $0.3-0.4$ & $0.1-0.2$ & $0-0.1$ & $0-0$ \\
\hline Halon-2402 & ppt & GL & $0.4-0.4$ & $0.4-0.4$ & $0.2-0.2$ & $0.1-0.1$ & $0-0$ & $0-0$ & $0-0$ & $0-0$ & $0-0$ & $0-0$ \\
\hline CFC-11-eq & ppt & GL & $818.9-818.9$ & $848.9-908.6$ & $528.3-1102.9$ & $371-1599.7$ & $305.6-1975$ & $235-1698.5$ & $189.8-1126.9$ & $155-563.5$ & $135.3-323.9$ & $115.2-251.1$ \\
\hline CFC-12-eq & ppt & GL & $1047.8-1047.9$ & $967.1-969$ & $627.8-637.9$ & $433-444.4$ & $320.6-329.5$ & $175.3-197.1$ & $99.2-124.3$ & $58.4-82.2$ & $38.7-57.5$ & $17.7-24.5$ \\
\hline HFC-134a-eq & ppt & GL & $271.1-271.1$ & $388.3-485.4$ & $327.5-1259.5$ & 286.2-2274 & $277.9-2984.9$ & $254.7-2638$ & $223.2-1755.3$ & $186.7-864$ & $165.4-483.5$ & $147-375.5$ \\
\hline
\end{tabular}


Table 5. Overview of $\mathrm{CO}_{2} \mathrm{CH}_{4}$ and $\mathrm{N}_{2} \mathrm{O}$ concentrations in the eight SSP scenarios considered in this study with global-average ("GL") northern hemispheric ("NH") and southern hemispheric ("SH") surface air mole fractions. For annual and latitudinally resolved mole fractions and other greenhouse gases see the Supplement or http://greenhousegases.science.unimelb.edu.au.

\begin{tabular}{|c|c|c|c|c|c|c|c|c|c|c|c|c|c|}
\hline SSP1-1.9 & & & 2015 & 2025 & 2050 & 2075 & 2100 & 2150 & 2200 & 2250 & 2300 & 2400 & 2500 \\
\hline \multirow[t]{3}{*}{$\mathrm{CO}_{2}$} & \multirow[t]{3}{*}{ ppm } & GL & 399.9 & 426.5 & 437.6 & 419.7 & 393.5 & 349.0 & 343.4 & 343.3 & 342.0 & 339.2 & 336.9 \\
\hline & & $\mathrm{NH}$ & 401.7 & 428.2 & 437.8 & 419.5 & 392.9 & 348.5 & 343.4 & 343.3 & 342.0 & 339.2 & 336.9 \\
\hline & & $\mathrm{SH}$ & 398.2 & 424.9 & 437.5 & 419.9 & 394.1 & 349.5 & 343.4 & 343.3 & 342.0 & 339.2 & 336.9 \\
\hline \multirow[t]{3}{*}{$\mathrm{CH}_{4}$} & \multirow[t]{3}{*}{$\mathrm{ppb}$} & GL & 1842.0 & 1875.2 & 1427.9 & 1184.3 & 1036.4 & 969.8 & 928.9 & 881.3 & 1112.0 & 870.9 & 871.4 \\
\hline & & $\mathrm{NH}$ & 1889.7 & 1919.9 & 1468.8 & 1224.3 & 1075.6 & 1008.6 & 967.2 & 919.2 & 909.6 & 908.8 & 909.3 \\
\hline & & SH & 1794.2 & 1830.6 & 1387.0 & 1144.3 & 997.2 & 931.1 & 890.5 & 843.4 & 833.8 & 833.0 & 833.5 \\
\hline \multirow[t]{3}{*}{$\mathrm{N}_{2} \mathrm{O}$} & \multirow[t]{3}{*}{$\mathrm{ppb}$} & GL & 328.2 & 335.1 & 343.6 & 349.0 & 354.0 & 361.4 & 363.9 & 362.7 & 360.6 & 358.2 & 357.1 \\
\hline & & $\mathrm{NH}$ & 328.5 & 335.4 & 343.8 & 349.3 & 354.3 & 361.7 & 364.2 & 363.0 & 360.9 & 358.5 & 357.4 \\
\hline & & SH & 327.9 & 334.8 & 343.3 & 348.7 & 353.7 & 361.2 & 363.6 & 362.4 & 360.3 & 357.9 & 356.8 \\
\hline SSP1-2.6 & & & 2015 & 2025 & 2050 & 2075 & 2100 & 2150 & 2200 & 2250 & 2300 & 2400 & 2500 \\
\hline \multirow[t]{3}{*}{$\mathrm{CO}_{2}$} & \multirow[t]{3}{*}{ ppm } & GL & 399.9 & 427.7 & 469.3 & 471.0 & 445.6 & 411.1 & 403.2 & 399.7 & 396.0 & 389.5 & 384.3 \\
\hline & & $\mathrm{NH}$ & 401.7 & 429.6 & 470.4 & 471.2 & 445.3 & 410.9 & 403.2 & 399.7 & 396.0 & 389.5 & 384.3 \\
\hline & & SH & 398.2 & 425.7 & 468.2 & 470.8 & 445.9 & 411.4 & 403.2 & 399.7 & 396.0 & 389.4 & 384.3 \\
\hline \multirow[t]{3}{*}{$\mathrm{CH}_{4}$} & \multirow[t]{3}{*}{ ppb } & GL & 1842.0 & 1865.1 & 1519.4 & 1248.4 & 1056.4 & 977.4 & 927.6 & 875.2 & 1112.0 & 863.5 & 864.0 \\
\hline & & $\mathrm{NH}$ & 1889.7 & 1910.3 & 1561.5 & 1288.8 & 1095.9 & 1016.4 & 966.1 & 913.1 & 902.4 & 901.5 & 901.9 \\
\hline & & SH & 1794.2 & 1820.0 & 1477.3 & 1208.0 & 1016.9 & 938.4 & 889.1 & 837.2 & 826.4 & 825.6 & 826.0 \\
\hline \multirow[t]{3}{*}{$\mathrm{N}_{2} \mathrm{O}$} & \multirow[t]{3}{*}{$\mathrm{ppb}$} & GL & 328.2 & 334.9 & 343.5 & 348.5 & 353.9 & 361.2 & 363.4 & 362.2 & 360.0 & 357.5 & 356.4 \\
\hline & & $\mathrm{NH}$ & 328.5 & 335.1 & 343.8 & 348.8 & 354.2 & 361.5 & 363.7 & 362.5 & 360.3 & 357.8 & 356.7 \\
\hline & & SH & 327.9 & 334.6 & 343.2 & 348.2 & 353.6 & 360.9 & 363.2 & 361.9 & 359.7 & 357.2 & 356.1 \\
\hline SSP2-4.5 & & & 2015 & 2025 & 2050 & 2075 & 2100 & 2150 & 2200 & 2250 & 2300 & 2400 & 2500 \\
\hline \multirow[t]{3}{*}{$\mathrm{CO}_{2}$} & \multirow[t]{3}{*}{ ppm } & GL & 399.9 & 429.0 & 506.9 & 575.5 & 602.8 & 626.3 & 643.1 & 637.0 & 621.3 & 597.8 & 579.2 \\
\hline & & $\mathrm{NH}$ & 401.7 & 431.2 & 509.2 & 577.3 & 603.6 & 626.8 & 643.4 & 637.0 & 621.3 & 597.8 & 579.2 \\
\hline & & SH & 398.2 & 426.9 & 504.5 & 573.6 & 602.0 & 625.7 & 642.8 & 637.0 & 621.3 & 597.8 & 579.2 \\
\hline \multirow[t]{3}{*}{$\mathrm{CH}_{4}$} & \multirow[t]{3}{*}{$\mathrm{ppb}$} & GL & 1841.9 & 1960.7 & 2020.2 & 1815.7 & 1683.2 & 1479.6 & 1255.4 & 1038.1 & 1112.0 & 999.2 & 997.3 \\
\hline & & $\mathrm{NH}$ & 1889.7 & 2008.0 & 2066.6 & 1860.7 & 1727.7 & 1522.4 & 1296.6 & 1077.6 & 1040.9 & 1038.7 & 1036.8 \\
\hline & & $\mathrm{SH}$ & 1794.2 & 1913.3 & 1973.9 & 1770.8 & 1638.6 & 1436.7 & 1214.2 & 998.6 & 961.8 & 959.7 & 957.8 \\
\hline \multirow[t]{3}{*}{$\mathrm{N}_{2} \mathrm{O}$} & ppb & GL & 328.2 & 336.0 & 356.2 & 371.5 & 377.3 & 378.3 & 375.9 & 371.4 & 367.0 & 362.0 & 359.8 \\
\hline & & $\mathrm{NH}$ & 328.5 & 336.3 & 356.5 & 371.8 & 377.6 & 378.6 & 376.2 & 371.7 & 367.2 & 362.3 & 360.1 \\
\hline & & $\mathrm{SH}$ & 327.9 & 335.7 & 355.9 & 371.2 & 377.0 & 378.0 & 375.6 & 371.1 & 366.7 & 361.7 & 359.5 \\
\hline SSP3-7.0 & & & 2015 & 2025 & 2050 & 2075 & 2100 & 2150 & 2200 & 2250 & 2300 & 2400 & 2500 \\
\hline $\mathrm{CO}_{2}$ & ppm & GL & 399.9 & 432.3 & 540.6 & 683.0 & 867.2 & 1235.3 & 1456.8 & 1513.7 & 1482.8 & 1423.6 & 1371.1 \\
\hline & & $\mathrm{NH}$ & 401.7 & 434.8 & 543.9 & 686.8 & 871.6 & 1238.3 & 1458.3 & 1513.7 & 1482.8 & 1423.6 & 1371.1 \\
\hline & & $\mathrm{SH}$ & 398.2 & 429.9 & 537.3 & 679.2 & 862.8 & 1232.4 & 1455.3 & 1513.6 & 1482.7 & 1423.6 & 1371.1 \\
\hline $\mathrm{CH}_{4}$ & $\mathrm{ppb}$ & GL & 1841.9 & 2006.5 & 2472.0 & 2934.1 & 3372.2 & 3096.2 & 2571.6 & 2107.1 & 1112.0 & 1959.1 & 1938.4 \\
\hline & & $\mathrm{NH}$ & 1889.7 & 2055.4 & 2524.2 & 2989.5 & 3430.7 & 3151.1 & 2622.8 & 2154.7 & 2035.7 & 2006.7 & 1986.0 \\
\hline & & SH & 1794.2 & 1957.7 & 2419.8 & 2878.7 & 3313.7 & 3041.3 & 2520.3 & 2059.5 & 1940.5 & 1911.5 & 1890.8 \\
\hline $\mathrm{N}_{2} \mathrm{O}$ & $\mathrm{ppb}$ & GL & 328.2 & 336.4 & 361.8 & 390.7 & 421.8 & 471.4 & 497.2 & 507.2 & 510.5 & 514.3 & 516.0 \\
\hline & & $\mathrm{NH}$ & 328.5 & 336.7 & 362.1 & 391.0 & 422.1 & 471.7 & 497.4 & 507.5 & 510.8 & 514.6 & 516.3 \\
\hline & & $\mathrm{SH}$ & 327.9 & 336.1 & 361.5 & 390.4 & 421.5 & 471.1 & 496.9 & 506.9 & 510.2 & 514.0 & 515.7 \\
\hline SSP3-7.0-lowNTCF & & & 2015 & 2025 & 2050 & 2075 & 2100 & 2150 & 2200 & 2250 & 2300 & 2400 & 2500 \\
\hline $\mathrm{CO}_{2}$ & ppm & GL & 399.9 & 432.4 & 538.8 & 677.5 & 858.7 & 1221.5 & 1447.2 & 1509.7 & 1482.8 & 1426.1 & 1374.1 \\
\hline & & $\mathrm{NH}$ & 401.7 & 434.9 & 542.2 & 681.4 & 863.2 & 1224.6 & 1448.7 & 1509.7 & 1482.8 & 1426.1 & 1374.1 \\
\hline & & SH & 398.2 & 429.9 & 535.5 & 673.5 & 854.1 & 1218.5 & 1445.7 & 1509.7 & 1482.7 & 1426.1 & 1374.1 \\
\hline $\mathrm{CH}_{4}$ & $\mathrm{ppb}$ & GL & 1841.9 & 1940.3 & 1358.8 & 1202.5 & 1219.9 & 1203.5 & 1164.6 & 1129.1 & 1112.0 & 1088.0 & 1068.8 \\
\hline & & $\mathrm{NH}$ & 1889.7 & 1985.6 & 1400.0 & 1244.0 & 1262.1 & 1245.3 & 1205.9 & 1170.1 & 1152.9 & 1129.0 & 1109.8 \\
\hline & & SH & 1794.2 & 1895.0 & 1317.5 & 1161.0 & 1177.8 & 1161.8 & 1123.2 & 1088.2 & 1071.0 & 1047.1 & 1027.9 \\
\hline $\mathrm{N}_{2} \mathrm{O}$ & $\mathrm{ppb}$ & GL & 328.2 & 336.4 & 361.9 & 391.0 & 422.4 & 472.5 & 498.5 & 508.7 & 512.0 & 515.8 & 517.5 \\
\hline & & $\mathrm{NH}$ & 328.5 & 336.7 & 362.2 & 391.3 & 422.7 & 472.8 & 498.8 & 509.0 & 512.3 & 516.1 & 517.8 \\
\hline & & SH & 327.9 & 336.1 & 361.6 & 390.7 & 422.1 & 472.2 & 498.3 & 508.4 & 511.8 & 515.5 & 517.2 \\
\hline
\end{tabular}


Table 5. Continued.

\begin{tabular}{|c|c|c|c|c|c|c|c|c|c|c|c|c|c|}
\hline SSP4-3.4 & & & 2015 & 2025 & 2050 & 2075 & 2100 & 2150 & 2200 & 2250 & 2300 & 2400 & 2500 \\
\hline \multirow[t]{3}{*}{$\mathrm{CO}_{2}$} & \multirow[t]{3}{*}{ ppm } & GL & 399.9 & 427.3 & 472.9 & 490.2 & 473.4 & 408.8 & 396.2 & 395.2 & 392.4 & 387.5 & 383.4 \\
\hline & & $\mathrm{NH}$ & 401.7 & 429.3 & 474.0 & 490.3 & 472.5 & 408.0 & 396.2 & 395.2 & 392.4 & 387.5 & 383.4 \\
\hline & & SH & 398.2 & 425.3 & 471.8 & 490.1 & 474.3 & 409.5 & 396.2 & 395.2 & 392.4 & 387.5 & 383.4 \\
\hline \multirow[t]{3}{*}{$\mathrm{CH}_{4}$} & \multirow[t]{3}{*}{$\mathrm{ppb}$} & GL & 1841.9 & 2030.9 & 2223.4 & 2370.0 & 2336.3 & 2177.6 & 2023.8 & 1842.7 & 1112.0 & 1786.8 & 1786.2 \\
\hline & & $\mathrm{NH}$ & 1889.7 & 2078.9 & 2271.3 & 2417.9 & 2383.2 & 2223.4 & 2068.6 & 1886.6 & 1832.2 & 1830.7 & 1830.1 \\
\hline & & $\mathrm{SH}$ & 1794.1 & 1983.0 & 2175.4 & 2322.2 & 2289.5 & 2131.7 & 1978.9 & 1798.8 & 1744.5 & 1743.0 & 1742.3 \\
\hline \multirow[t]{3}{*}{$\mathrm{N}_{2} \mathrm{O}$} & \multirow[t]{3}{*}{ ppb } & GL & 328.2 & 335.7 & 353.9 & 373.7 & 394.7 & 425.2 & 441.1 & 446.8 & 448.2 & 449.9 & 450.7 \\
\hline & & $\mathrm{NH}$ & 328.5 & 336.0 & 354.2 & 374.0 & 395.0 & 425.5 & 441.3 & 447.1 & 448.5 & 450.2 & 451.0 \\
\hline & & SH & 327.9 & 335.4 & 353.6 & 373.4 & 394.4 & 424.9 & 440.8 & 446.5 & 447.9 & 449.6 & 450.4 \\
\hline SSP4-6.0 & & & 2015 & 2025 & 2050 & 2075 & 2100 & 2150 & 2200 & 2250 & 2300 & 2400 & 2500 \\
\hline \multirow[t]{3}{*}{$\mathrm{CO}_{2}$} & \multirow[t]{3}{*}{ ppm } & GL & 399.9 & 428.3 & 515.6 & 606.9 & 668.4 & 741.0 & 783.9 & 786.2 & 768.7 & 739.1 & 714.0 \\
\hline & & $\mathrm{NH}$ & 401.7 & 430.5 & 518.2 & 609.2 & 669.7 & 741.8 & 784.3 & 786.2 & 768.7 & 739.1 & 714.0 \\
\hline & & SH & 398.2 & 426.0 & 513.0 & 604.7 & 667.1 & 740.1 & 783.4 & 786.2 & 768.7 & 739.1 & 714.0 \\
\hline \multirow[t]{3}{*}{$\mathrm{CH}_{4}$} & \multirow{3}{*}{$\mathrm{ppb}$} & GL & 1841.9 & 2049.1 & 2503.7 & 2688.5 & 2645.5 & 2382.6 & 2111.4 & 1864.6 & 1112.0 & 1791.0 & 1785.6 \\
\hline & & $\mathrm{NH}$ & 1889.7 & 2098.2 & 2554.8 & 2739.6 & 2695.8 & 2431.2 & 2158.3 & 1909.8 & 1844.7 & 1836.3 & 1830.9 \\
\hline & & SH & 1794.1 & 1999.9 & 2452.5 & 2637.3 & 2595.3 & 2334.1 & 2064.4 & 1819.3 & 1754.1 & 1745.7 & 1740.4 \\
\hline \multirow[t]{3}{*}{$\mathrm{N}_{2} \mathrm{O}$} & \multirow[t]{3}{*}{$\mathrm{ppb}$} & GL & 328.2 & 335.9 & 359.7 & 383.4 & 404.7 & 435.8 & 451.2 & 456.1 & 456.8 & 457.7 & 458.1 \\
\hline & & $\mathrm{NH}$ & 328.5 & 336.2 & 360.0 & 383.7 & 405.0 & 436.1 & 451.4 & 456.4 & 457.1 & 457.9 & 458.4 \\
\hline & & SH & 327.9 & 335.6 & 359.4 & 383.2 & 404.4 & 435.5 & 450.9 & 455.8 & 456.5 & 457.4 & 457.8 \\
\hline SSP5-3.4-OS & & & 2015 & 2025 & 2050 & 2075 & 2100 & 2150 & 2200 & 2250 & 2300 & 2400 & 2500 \\
\hline \multirow[t]{3}{*}{$\mathrm{CO}_{2}$} & \multirow[t]{3}{*}{ ppm } & GL & 399.9 & 432.2 & 549.3 & 554.5 & 496.6 & 409.4 & 404.7 & 401.8 & 398.5 & 392.4 & 387.5 \\
\hline & & $\mathrm{NH}$ & 401.7 & 434.7 & 551.9 & 553.8 & 495.6 & 408.7 & 404.7 & 401.8 & 398.5 & 392.4 & 387.5 \\
\hline & & $\mathrm{SH}$ & 398.2 & 429.7 & 546.7 & 555.1 & 497.7 & 410.1 & 404.7 & 401.8 & 398.5 & 392.4 & 387.5 \\
\hline \multirow[t]{3}{*}{$\mathrm{CH}_{4}$} & \multirow[t]{3}{*}{$\mathrm{ppb}$} & GL & 1841.9 & 1964.3 & 2125.1 & 1205.4 & 999.7 & 961.8 & 941.9 & 916.8 & 1112.0 & 910.5 & 910.6 \\
\hline & & NH & 1889.7 & 2012.6 & 2168.8 & 1245.2 & 1038.8 & 1000.6 & 980.5 & 955.2 & 950.1 & 948.9 & 948.9 \\
\hline & & SH & 1794.2 & 1916.0 & 2081.4 & 1165.5 & 960.6 & 922.9 & 903.3 & 878.5 & 873.4 & 872.2 & 872.2 \\
\hline \multirow[t]{3}{*}{$\mathrm{N}_{2} \mathrm{O}$} & \multirow[t]{3}{*}{$\mathrm{ppb}$} & GL & 328.2 & 336.3 & 356.3 & 371.1 & 383.8 & 398.4 & 404.7 & 405.1 & 403.6 & 401.9 & 401.1 \\
\hline & & $\mathrm{NH}$ & 328.5 & 336.6 & 356.6 & 371.4 & 384.1 & 398.7 & 405.0 & 405.4 & 403.9 & 402.1 & 401.4 \\
\hline & & SH & 327.9 & 336.0 & 356.1 & 370.8 & 383.6 & 398.1 & 404.4 & 404.8 & 403.3 & 401.6 & 400.8 \\
\hline SSP5-8.5 & & & 2015 & 2025 & 2050 & 2075 & 2100 & 2150 & 2200 & 2250 & 2300 & 2400 & 2500 \\
\hline \multirow[t]{3}{*}{$\mathrm{CO}_{2}$} & \multirow[t]{3}{*}{$\mathrm{ppm}$} & GL & 399.9 & 431.8 & 562.8 & 801.7 & 1135.2 & 1737.3 & 2108.3 & 2206.4 & 2161.7 & 2080.5 & 2010.0 \\
\hline & & $\mathrm{NH}$ & 401.7 & 434.3 & 567.2 & 808.5 & 1142.3 & 1742.0 & 2110.7 & 2206.4 & 2161.7 & 2080.5 & 2010.0 \\
\hline & & SH & 398.2 & 429.4 & 558.3 & 794.9 & 1128.2 & 1732.6 & 2106.0 & 2206.3 & 2161.7 & 2080.5 & 2010.0 \\
\hline \multirow[t]{3}{*}{$\mathrm{CH}_{4}$} & \multirow[t]{3}{*}{$\mathrm{ppb}$} & GL & 1841.9 & 1954.5 & 2446.5 & 2672.3 & 2415.3 & 1906.9 & 1515.6 & 1157.3 & 1112.0 & 1038.5 & 1019.0 \\
\hline & & $\mathrm{NH}$ & 1889.7 & 2002.6 & 2499.2 & 2724.9 & 2465.2 & 1953.8 & 1559.4 & 1198.1 & 1109.0 & 1079.3 & 1059.8 \\
\hline & & SH & 1794.2 & 1906.4 & 2393.7 & 2619.6 & 2365.5 & 1860.1 & 1471.8 & 1116.5 & 1027.4 & 997.7 & 978.2 \\
\hline $\mathrm{N}_{2} \mathrm{O}$ & $\mathrm{ppb}$ & GL & 328.2 & 336.3 & 358.2 & 377.1 & 391.8 & 407.8 & 413.6 & 413.0 & 410.5 & 407.8 & 406.6 \\
\hline & & $\mathrm{NH}$ & 328.5 & 336.6 & 358.5 & 377.4 & 392.1 & 408.1 & 413.9 & 413.3 & 410.8 & 408.1 & 406.9 \\
\hline & & SH & 327.9 & 336.0 & 357.9 & 376.8 & 391.5 & 407.5 & 413.3 & 412.7 & 410.2 & 407.5 & 406.3 \\
\hline
\end{tabular}


yond, with total greenhouse-gas-induced forcing stabilizing around $1.5 \mathrm{~W} \mathrm{~m}^{-2}$ - equivalent to $\mathrm{CO}_{2}$ concentrations of approximately $370 \mathrm{ppm}$ (right axis in panel a of Fig. 7).

\section{Discussion}

In this section, we discuss the SSP greenhouse gas concentration projections in relation to the last 2000 years of observations and cumulative carbon emissions, which are an important metric for mitigation efforts. We also provide a comparison to previous RCP pathways.

\section{1 $\mathrm{CO}_{2}$ and $\mathrm{CH}_{4}$ concentrations}

After $\mathrm{CO}_{2}$, the greenhouse gas with the second largest radiative forcing contribution in the 21st century is $\mathrm{CH}_{4}$ (Fig. 7). To a large extent, greenhouse gas induced future warming is hence influenced by the concentrations of $\mathrm{CO}_{2}$ and $\mathrm{CH}_{4}$. Two examples in which methane and $\mathrm{CO}_{2}$ forcings and their relative strength are important. (i) Firstly, discussions about the benefit of the mitigation of short-lived forcers often accounts for $\mathrm{CH}_{4}$ as a short-lived forcer, which usually contributes most of the climate benefits of any shortlived forcer mitigation strategy (Rogelj et al., 2015, 2014). Hence, when the climate benefits of reducing short-lived forcers are compared to those of reducing $\mathrm{CO}_{2}$ emissions, the actual comparison is mostly between $\mathrm{CH}_{4}$ and $\mathrm{CO}_{2}$. Secondly, deriving the remaining carbon budget from Earth system model runs from single or a few scenario runs is contingent on those scenarios showing a representative level of $\mathrm{CH}_{4}$ versus $\mathrm{CO}_{2}$ concentrations. Here, we consider mid21st-century $\mathrm{CH}_{4}$ and $\mathrm{CO}_{2}$ concentrations across the range of SSP scenarios. We place them in the context of the RCP scenarios as well as 475 scenarios of the IPCC Special Report on $1.5^{\circ} \mathrm{C}$ emissions database (https://data.ene.iiasa.ac. at/iamc-1.5c-explorer/, last access: 20 June 2020) (Fig. 9). We focus on mid-century concentrations as they are close to the expected point of peak warming in the scenarios that are in line with the Paris Agreement temperature targets of $1.5^{\circ} \mathrm{C}$ and well below $2.0^{\circ} \mathrm{C}$. The comparison shows that SSP1-1.9 and SSP1-2.6 result in relatively similar $\mathrm{CH}_{4}$ concentrations by 2050 , albeit their $\mathrm{CO}_{2}$ concentrations differ by approximately $7 \%$ (437 ppm versus $469 \mathrm{ppm}$, respectively, Table 5). The other scenario with low $\mathrm{CH}_{4}$ concentrations in 2050, i.e. SSP3-7.0-lowNTCF, falls outside the scenario space considered here, namely the SR.15 database (https: //data.ene.iiasa.ac.at/iamc-1.5c-explorer/, see Fig. 9 below). This is by design, as this scenario is the result of adapting a high-emission scenario (SSP3-7.0) so that it features very low short-lived climate forcer emissions (Collins et al., 2017). See also Appendix C in Gidden et al. (2019) for a detailed comparison of SSP3-7.0 and SSP3-7.0-lowNTCF emissions. The comparison of mid-century $\mathrm{CO}_{2}$ and $\mathrm{CH}_{4}$ concentrations also reveals that the main reason for higher implied warming of SSP4-3.4 in comparison to SSP1-2.6 are elevated $\mathrm{CH}_{4}$ concentrations. Thus, to a limited extent, the SSP4-3.4 and SSP1.2.6 scenarios represent a similar pair of scenarios to the SSP3-7.0 and SSP3-7.0-lowNTCF scenarios, but for a lower level of cumulative $\mathrm{CO}_{2}$ emissions.

\subsection{Most recent concentration observations}

While updating the historical observations for our future concentrations, several recent trends are noteworthy. We discuss these in this section, covering $\mathrm{CH}_{4}$, ozone-depleting substances CFC-11, CFC-12, CFC-113 as well as HFC-23 and $\mathrm{SF}_{6}$.

Regarding $\mathrm{CH}_{4}$, atmospheric observations show a plateauing of $\mathrm{CH}_{4}$ concentrations from 1999 to 2005 followed by an increased growth rate from 2007 (Nisbet et al., 2016). Available literature suggests that changes in natural and anthropogenic sources and $\mathrm{OH}-$ related sinks are involved (Rigby et al., 2017), for example reduced biomass burning emissions (Worden et al., 2017) or reduced thermogenic fossilfuel-related emissions (Schaefer et al., 2016) to explain the plateau of concentrations until 2006, but large uncertainties remain, particularly related to natural wetland and inland water sources (Saunois et al., 2016). Schaefer et al. (2016) suggest that the renewed onset of increasing $\mathrm{CH}_{4}$ concentrations could be related to increased emissions from the agricultural sector.

Our $\mathrm{CH}_{4}$ concentration time series, both the historical ones and the future projections from 2015 onwards, capture this observed increase in the trend Fig. 6b) - although there is uncertainty as to whether the underlying processes and emission sources are correct. Nevertheless, our employed simple model MAGICC7 also captures this temporary plateau of $\mathrm{CH}_{4}$ concentrations when run in an emission-driven model, possibly not the earlier parts though (left column in Supplement Fig. S1). Note that the transition in 2017 from observationally driven concentrations to our model-driven concentration time series exhibits a slight offset in concentrations (Sect. 5.3), as MAGICC7 inferred a slightly stronger increase in $\mathrm{CH}_{4}$ concentrations over 2016 based on the IAM's emissions, than observed (Fig. 6).

For nitrous oxide, there appears to be a small downward adjustment in the growth rate around 2014, with atmospheric growth in the years 2016 and 2017 being slightly lower than in 2014 (Fig. 6c), although observed 2018 growth rates picked up again and the slight offset seems to be well within the noise of recent growth rate variations. For a close comparison of recent observations and our concentration time series, see the $\mathrm{CH}_{4}$ - and nitrous oxide-related fact sheets at http://greenhousegases.science.unimelb.edu.au.

Recent observations regarding substances whose production is largely phased out under the Montreal Protocol are also notable (Montzka et al., 2018; Rigby et al., 2019). CFC11 measurements show some elevated Northern Hemisphere values from 2013 onward and the global average concentra- 
Table 6. Fraction of greenhouse-gas-induced forcing due to $\mathrm{CO}_{2}$ concentrations in SSP scenarios at the point of maximal greenhouse-gasinduced forcing until 2300 (upper row) or in the year 2100 (lower row).

\begin{tabular}{lrrrrrrrrr}
\hline & SSP1-1.9 & SSP1-2.6 & SSP4-3.4 & SSP2-4.5 & SSP4-6.0 & SSP3-7.0 & SSP5-8.5 & SSP3-7.0-lowntcf & SSP5-3.4-OS \\
\hline $\begin{array}{l}\text { Point of maximal } \\
\text { GHG forcing over }\end{array}$ & $68 \%$ & $74 \%$ & $70 \%$ & $83 \%$ & $81 \%$ & $86 \%$ & $92 \%$ & $90 \%$ & $75 \%$ \\
2000 to 2300 & & & & & & & & & \\
\hline 2100 & $76 \%$ & $80 \%$ & $68 \%$ & $79 \%$ & $76 \%$ & $77 \%$ & $82 \%$ & $85 \%$ & $82 \%$ \\
\hline
\end{tabular}

Table 7. SSP global mean surface air temperature (GMSAT) and global mean sea level rise (GMSLR) projections for the end of the 21st century (2081-2100 average and 2100 estimate) and 2300. GMSAT is shown in kelvin relative to 1750; GMSLR is shown in metres relative to the 1986-2005 average. Mean and 5th to 95th percentiles are provided for both variables.

\begin{tabular}{lrrr|rrr}
\hline & \multicolumn{3}{c}{ GMT in K } & & GMSLR in m \\
\cline { 2 - 7 } & $2081-2100$ & 2100 & 2300 & $2081-2100$ & 2100 \\
\hline SSP1-1.9 & $1.2(0.6$ to 1.8$)$ & $1.1(0.6$ to 1.8$)$ & $0.6(0.1$ to 1.3$)$ & $0.44(0.30$ to 0.62$)$ & $0.47(0.32$ to 0.65$)$ & $0.80(0.54$ to 1.19$)$ \\
SSP1-2.6 & $1.6(1.0$ to 2.4$)$ & $1.6(0.9$ to 2.4$)$ & $1.3(0.6$ to 2.4$)$ & $0.49(0.35$ to 0.69$)$ & $0.53(0.37$ to 0.73$)$ & $1.07(0.69$ to 1.60$)$ \\
SSP2-4.5 & $2.6(1.7$ to 3.8$)$ & $2.8(1.8$ to 4.1$)$ & $3.8(1.7$ to 6.7$)$ & $0.59(0.41$ to 0.82$)$ & $0.66(0.46$ to 0.89$)$ & $2.02(1.13$ to 3.12$)$ \\
SSP4-3.4 & $2.0(1.3$ to 3.1$)$ & $2.1(1.3$ to 3.2$)$ & $1.8(0.9$ to 3.3$)$ & $0.53(0.36$ to 0.75$)$ & $0.58(0.40$ to 0.81$)$ & $1.30(0.82$ to 1.98$)$ \\
SSP3-7.0 & $3.8(2.6$ to 5.7$)$ & $4.4(3.0$ to 6.5$)$ & $9.8\left(5.5\right.$ to $\left.>15^{*}\right)$ & $0.68(0.47$ to 0.95$)$ & $0.79(0.56$ to 1.07$)$ & $4.51(2.36$ to 8.51$)$ \\
SSP3-LowNTCF & $3.4(2.3$ to 5.1$)$ & $3.9(2.6$ to 5.8$)$ & $9.5\left(5.3\right.$ to $\left.>15^{*}\right)$ & $0.64(0.45$ to 0.89$)$ & $0.74(0.53$ to 1.00$)$ & $4.22(2.22$ to 7.63$)$ \\
SSP4-6.0 & $3.3(2.2$ to 4.9$)$ & $3.6(2.4$ to 5.3$)$ & $6.0(2.9$ to 10.8$)$ & $0.65(0.45$ to 0.90$)$ & $0.74(0.53$ to 1.00$)$ & $2.87(1.53$ to 4.72$)$ \\
SSP5-3.4-OS & $2.1(1.2$ to 3.1$)$ & $1.9(1.1$ to 3.0$)$ & $1.1(0.3$ to 2.3$)$ & $0.58(0.40$ to 0.81$)$ & $0.62(0.42$ to 0.87$)$ & $1.08(0.66$ to 1.68$)$ \\
SSP5-8.5 & $5.0(3.3$ to 7.6$)$ & $5.8(3.8$ to 8.6$)$ & $10.8\left(6.4\right.$ to $\left.>15^{*}\right)$ & $0.79(0.54$ to 1.13$)$ & $0.94(0.66$ to 1.29$)$ & $5.31(2.86$ to 10.31$)$ \\
\hline
\end{tabular}

* MAGICC has an internal cutoff temperature in each land-ocean and hemispheric box at $25 \mathrm{~K}$. Any temperatures indications beyond $10 \mathrm{~K}$ should be considered illustrative only given that the calibrated range of MAGICC covers only lower temperature levels.

tions are 5-10 ppt above published projections from 2012 to 2017 which consider compliance with projected Montreal Protocol controls, even though the global concentration continues to decline (Velders and Daniel, 2014) (see panel $\mathrm{h}$ in online CFC-11 fact sheets at http://greenhousegases. unimelb.edu.au). Our projections reflect the elevated atmospheric concentrations until 2016 but then continue on the assumption of compliance with the protocol and those additional emission sources to be halted. By analysing measurement data from sites around the world, it was also concluded that the additional CFC-11 emissions - roughly a $25 \%$ increase since 2012 - originate in part from the eastern Asian region (Rigby et al., 2019; Montzka et al., 2018), and an updated study has identified that about half of the global increase can be attributed to two provinces in eastern China (Rigby et al., 2019). Although less pronounced, CFC-12 and CFC-113 concentrations have also not declined as expected since 2013, although for neither of these gases are emissions thought to have actually increased in recent years, as is the case for CFC-11 (Fig. 10b). More notable is the diversion of projected and recently observed concentrations for CFC-114, when comparing against the recent Velders and Daniel projections (2014). For a discussion of recent concentrations of CFC-13, inferred emissions of CFC-13 (which also seem to increase due to Asian sources), and the two isomers of CFC114 as well as CFC-115, see Vollmer et al. (2018).
Chloroform $\left(\mathrm{CHCl}_{3}\right)$ exhibited a concentration decline since 2000 but is increasing again in the global atmosphere (see chloroform fact sheet available in the online data repository at http://greenhousegases.science.unimelb.edu.au). Fang et al. (2019) point to a recent strong growth of chloroform emissions in China. The similarly short-lived methylene chloride $\left(\mathrm{CH}_{2} \mathrm{Cl}_{2}\right)$ also had almost stagnant atmospheric concentrations around the year 2000, but high growth has been observed in subsequent years, almost doubling atmospheric global-average concentrations from around 20 to 40 ppt by 2017 (Hossaini et al., 2015). See also chap. 1 of the 2018 Ozone Assessment Report (Engel et al., 2018).

Emissions of HFC-23 originate almost completely as a by-product of the production of HCFC-22. Under the Kyoto Protocol, abated emissions of HFC-23 are eligible to be credited in project-based offset mechanisms - leading to a bulk of offset credits under the Clean Development Mechanism and also two former joint implementation projects in Russia (Schneider, 2011). It has been shown that so-called "perverse incentives" likely resulted in additional production - in order to broaden the magnitude of claimable abatement credits (Schneider and Kollmuss, 2015). Given that the monetary value of those offset credits far exceeded the abatement costs, the Kigali Amendment to the Montreal Protocol in October 2016 led to a new regulatory approach for HFC emissions (Velders et al., 2015). Nevertheless, rather high individual station measurements (classified as "pollu- 

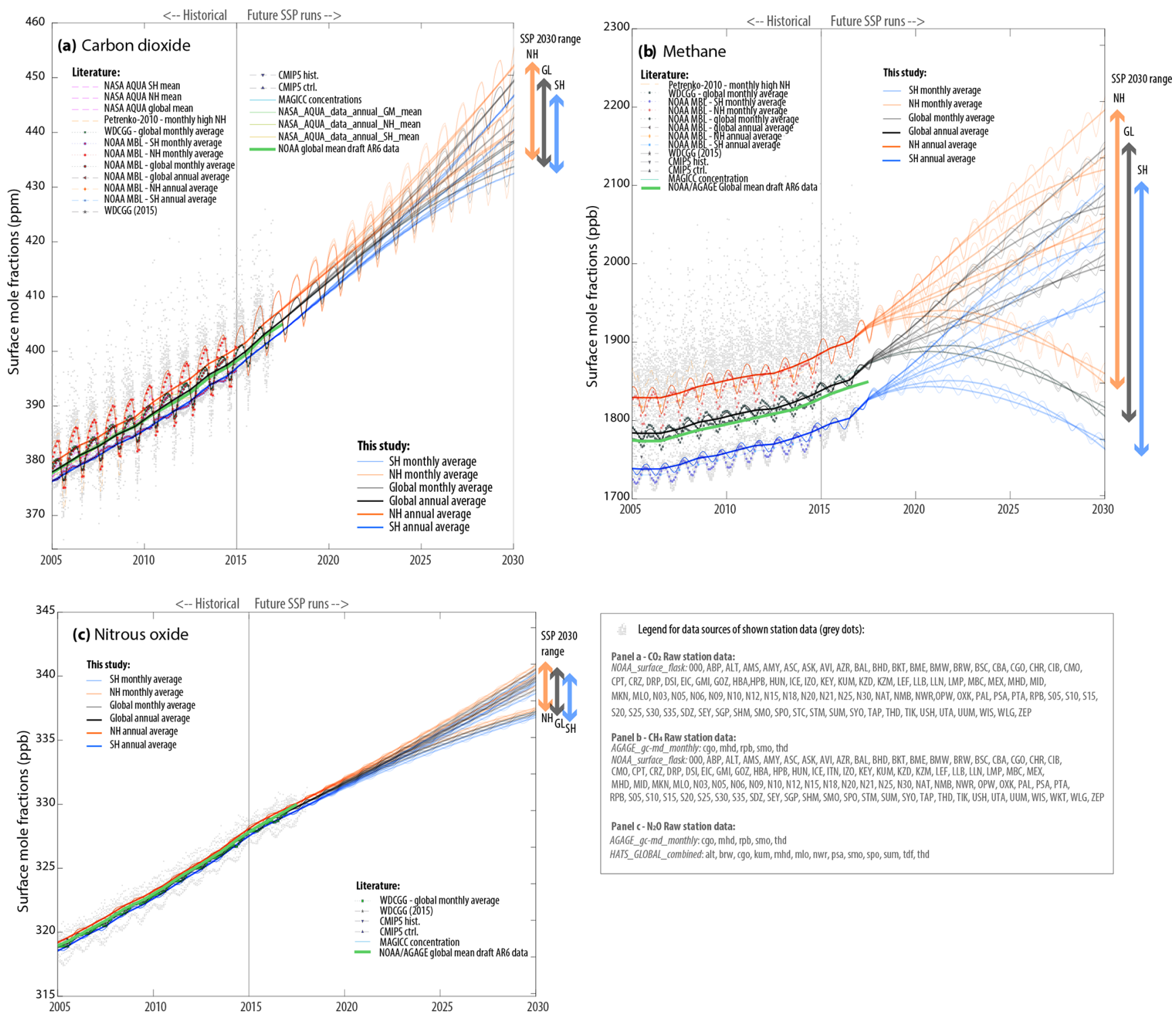

Figure 6. Transition between historical runs and future SSP concentrations for $\mathrm{CO}_{2}(\mathbf{a}), \mathrm{CH}_{4}$ (b), and $\mathrm{N}_{2} \mathrm{O}$ (c) surface mole fractions. The observational in situ and flask station data points reach into the first years of the future SSP datasets (grey dots). Derived northern hemispheric (orange), global (black), and southern hemispheric averages (blue) are shown with annual averages (thick lines) and monthly averages (thin lines with seasonality variability). On the right axis side, the illustrative arrows indicate the min-max range across the scenarios for northern hemispheric, global, and southern hemispheric annual-average concentrations by 2030 across all nine SSP scenarios. The NOAA/AGAGE global mean data series are shown in green. For a description of labels of other comparison data, see Table 12 in Meinshausen et al. (2017).

tion" events) led to high monthly average concentrations at the Gosan South Korean station. Together with accelerating growth trends for HFC-23 since 2015, this could point to a continued large increase in emissions (see panel $\mathrm{h}$ in HFC-23-related fact sheets on http://greenhousegases. science.unimelb.edu.au). Similarly, $\mathrm{SF}_{6}$ concentrations continue to increase at unprecedented rates. They will remain high for a long time (without other anthropogenic interventions) due to $\mathrm{SF}_{6}$ 's very long lifetime. The commonly assumed lifetime so far (also assumed in this study) has been
3200 years (Myhre et al., 2013), although recent findings about a loss mechanism in the polar vortex suggest a lower new best estimate of 850 years (Ray et al., 2017).

\subsection{The long-term projections in the context of the last 2000 years}

As the historical compilation of greenhouse gas concentrations based on firn and ice core records indicated, multiple literature studies indicate relatively flat concentrations of $\mathrm{CO}_{2}, \mathrm{CH}_{4}$, and $\mathrm{N}_{2} \mathrm{O}$ over the past 2000 years. Historical fluc- 


\section{SSP scenarios greenhouse gas radiative forcings}
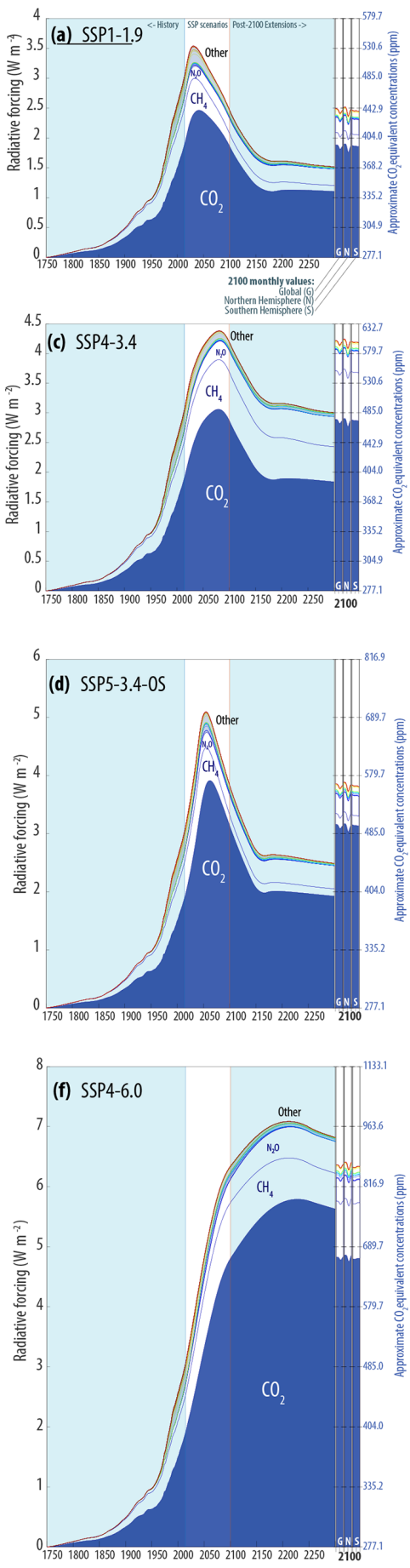
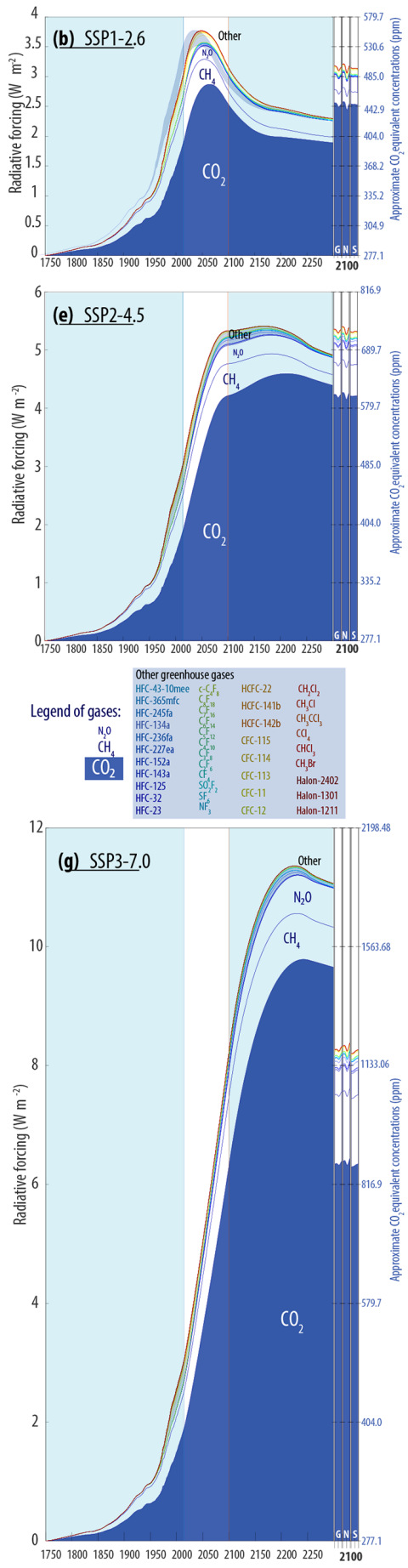

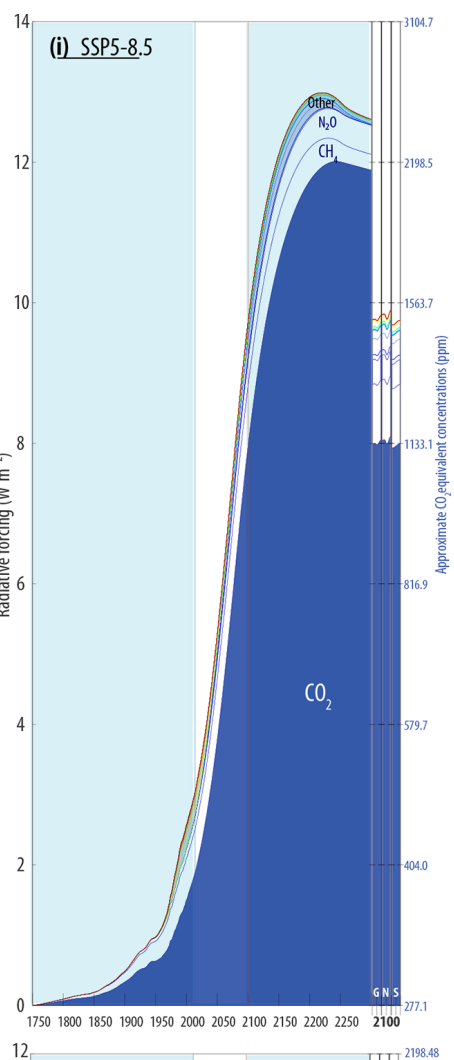

(h) SSP3-7.0 Low NTCF

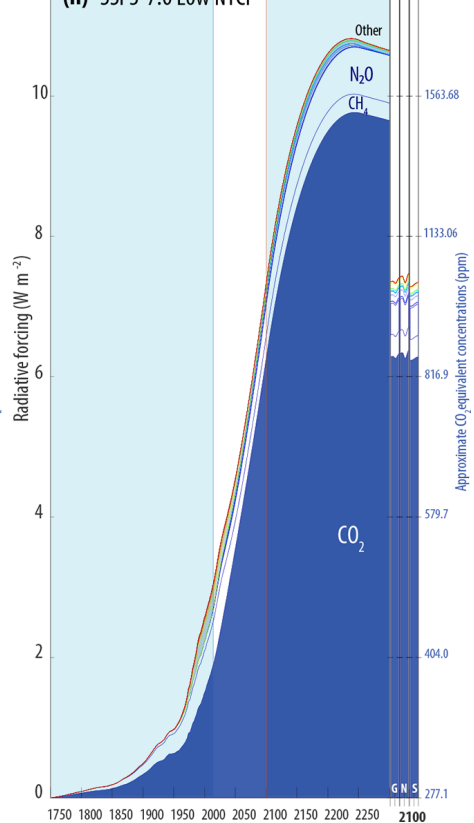

Figure 7. Overview of all greenhouse gases within SSP scenarios and their relative importance in terms of radiative forcing. The radiative forcing contributions are stacked, starting with $\mathrm{CO}_{2}$ (blue shaded area) at the bottom, followed by methane $\left(\mathrm{CH}_{4}\right)$, nitrous oxide $\left(\mathrm{N}_{2} \mathrm{O}\right)$, and the other 40 greenhouse gases. Default radiative forcing efficiencies or parameterizations are used, with $\mathrm{CO}_{2}, \mathrm{CH}_{4}$, and $\mathrm{N}_{2} \mathrm{O}$ being based on a parameterization of the Oslo Line-By-Line model (Sect. 2.7). Seasonal and latitudinal variation is indicated by the three bars on the right of each panel for the global average, northern hemispheric, and southern hemispheric monthly mean concentrations for the year 2100. The light-blue shaded areas on the left side of each panel from 1750 to 2014 are based on historical greenhouse gas observations; the 21 st-century span from 2015 to 2100 (white area) and the extension until 2300 and beyond are based on the MAGICC7.0 model. For the IPCC AR6, the five scenarios SSP1-1.9 (a), SSP1-2.6 (b), SSP2-4.5 (d), SSP3-7.0 (g), and SSP5-8.5 (i) are chosen as key scenarios for knowledge integration across chapters and working groups. 


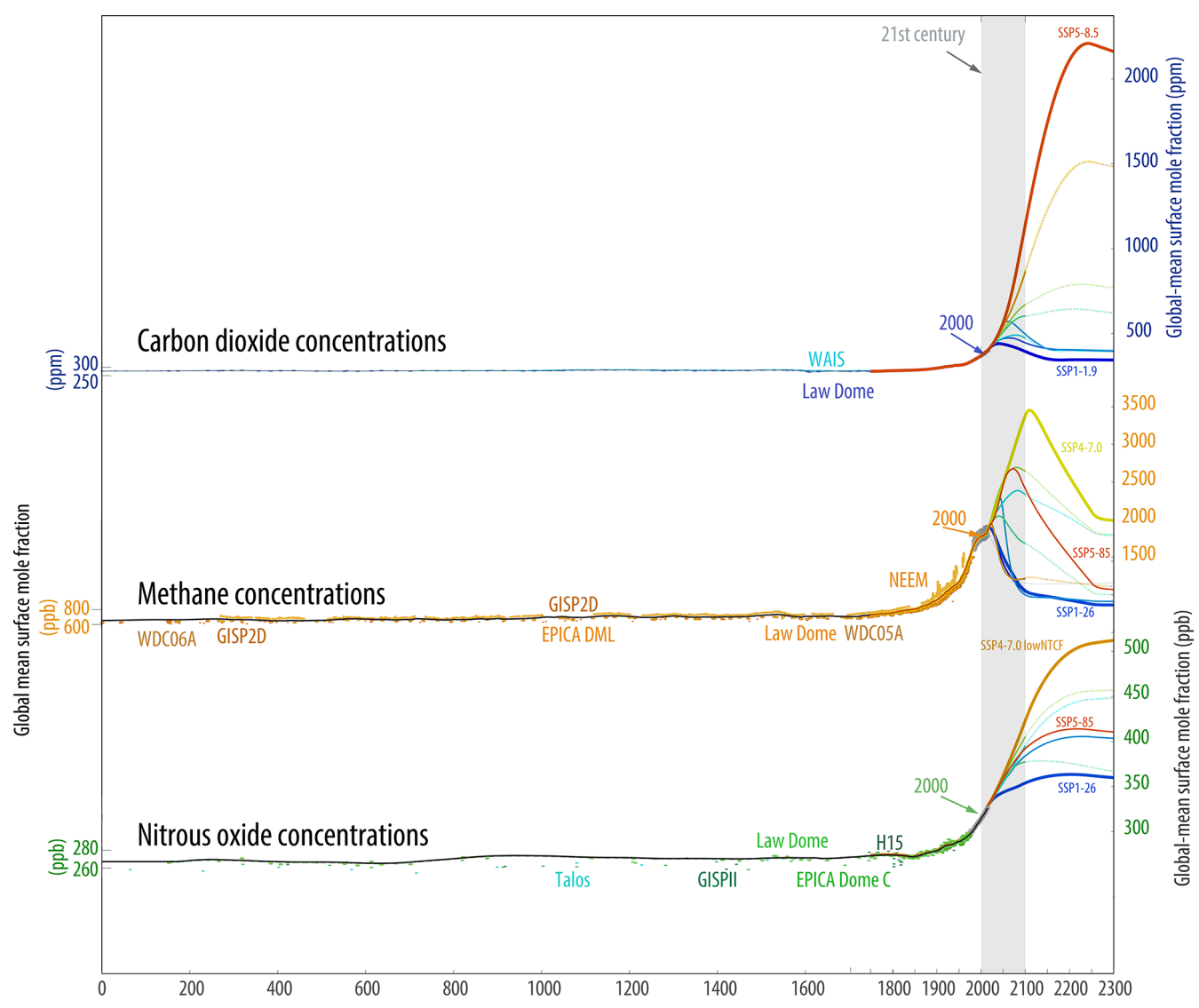

Figure 8. Overview of SSP concentrations of $\mathrm{CO}_{2}, \mathrm{CH}_{4}$, and $\mathrm{N}_{2} \mathrm{O}$ in the context of the historical observational dataset. For the respective main ice core and firn datasets (WAIS, Law Dome, EPICA DML, etc.), please see Fig. 6b in Meinshausen et al. (2017). The 21st century is shown as a grey vertical band.

tuations over the last 2000 years of a few parts per million or parts per billion, e.g. around 1650 for $\mathrm{CO}_{2}$, are minuscule in comparison to recently observed concentration changes since the onset of industrialization and projected future changes (Fig. 8). For example, $\mathrm{CO}_{2}$ concentrations could reach levels beyond $1500 \mathrm{ppm}$ in the SSP3-7.0 and SSP5-8.5 scenarios and even reach beyond 2000 ppm by 2200 under SSP5-8.5. $\mathrm{CO}_{2}$ concentrations in excess of $1500 \mathrm{ppm}$ have likely not been present on Earth for more than 40 million years (Fig. 4 in Royer, 2006) - i.e. before the current Antarctic and Northern Hemisphere ice sheets formed. Reflecting the shorter lifetime, concentrations of methane decrease pronouncedly over the 21 st century. The stronger mitigation scenarios foresee the option of net negative emissions for $\mathrm{CO}_{2}$, so that $\mathrm{CO}_{2}$ concentrations recede over the long term to around $350 \mathrm{ppm}$ in the case of the SSP1-1.9 scenario. Reflecting the longer lifetime and base level of agricultural emissions, $\mathrm{N}_{2} \mathrm{O}$ concentrations are not foreseen to drop below current levels in any of the investigated SSP scenarios over the coming 500 years (Fig. 8 ).

\subsection{Comparing SSP and RCP concentrations}

For every generation of climate scenarios, whether these are the IS92, SRES, RCP, or now the SSP scenarios, it is pertinent to clarify the differences and similarities of the new scenario set to the previous one(s). In particular due to the unavoidable delay in the analysis and use of the climate projections in the impact communities, clarifying the comparability to previous scenarios is paramount. Here, we compare the greenhouse gas concentrations.

Four RCP scenarios are now replaced in the SSP generation of scenarios with five high-priority scenarios (four ScenarioMIP "Tier1" cases plus SSP1-1.9) in addition to four additional scenarios that investigate additional forcing levels (see panels a, c in Fig. 11). Aside from this difference in the sheer number of scenarios, compared to the RCPs, the actual concentration levels differ substantially for most corresponding SSP scenarios. For example, the SSP5-8.5 scenario features substantially higher $\mathrm{CO}_{2}$ concentrations by 2100 and beyond than the RCP8.5 scenario (panels a, b in Fig. 11). Somewhat compensating though, the $\mathrm{CH}_{4}$ concentrations by 2100 are substantially lower under the SSP5-8.5 scenario 


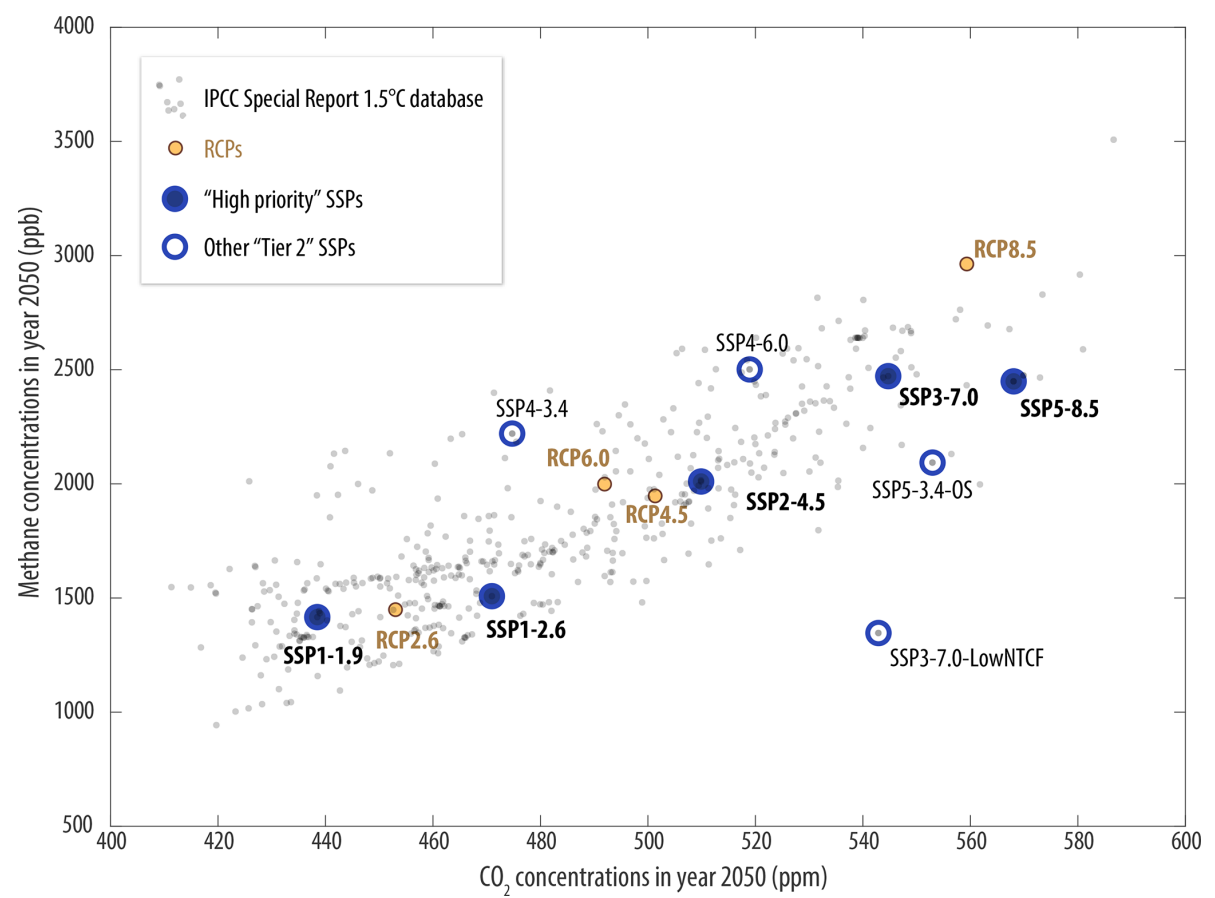

Figure 9. The $2050 \mathrm{CO}_{2}$ and $\mathrm{CH}_{4}$ concentrations of SSPs (dark-blue circles), RCP (orange circles), and scenarios of the IPCC Special Report on $1.5^{\circ} \mathrm{C}$ warming database (grey dots). All scenarios' concentrations were derived by using the SSP or RCP or SR1.5 harmonized emission scenarios together with the same MAGICC7.0 default settings as used for the CMIP6 SSP concentration projections.

compared to the RCP8.5 scenarios (Fig. 11c), and that difference is even more pronounced by 2300 due to the different extension principles followed for RCP extensions (Meinshausen et al., 2011b) and those for SSPs (Sect. 2.3). Specifically, the SSP5-8.5 fossil and industrial $\mathrm{CH}_{4}$ emissions are assumed to be phased out by 2250 with land-use-related $\mathrm{CH}_{4}$ emissions kept constant at 2100 under the SSP5-8.5 extension. That contrasts with the RCP8.5 extension, in which a long-term $\mathrm{CH}_{4}$ concentration stabilization at very high levels of $3500 \mathrm{ppb}$ was implemented. Similarly, for $\mathrm{N}_{2} \mathrm{O}$, the new SSP5-8.5 scenario implies lower concentrations by 2100 and beyond compared to the RCP8.5 (Fig. 11e, f). Under the SSP family, the SSP3-7.0 becomes the scenario with the highest emissions and concentrations for both $\mathrm{CH}_{4}$ and $\mathrm{N}_{2} \mathrm{O}$.

On the lower side of the scenarios, the most marked differences are that the new SSP1-2.6 has higher $\mathrm{CO}_{2}$ concentrations, compared to the previous RCP2.6 and SSP1-1.9 has the lowest $\mathrm{CO}_{2}$ concentrations (Figs. 9 and 11a). $\mathrm{CH}_{4}$ concentrations are very similar across these three scenarios by the middle of the century, whereas by the end of the $21 \mathrm{st}$ century, the new SSP1-1.9 and SSP1-2.6 scenarios show reduced levels of only $1000 \mathrm{ppb}$, substantially below today's $\mathrm{CH}_{4}$ concentration levels. For $\mathrm{N}_{2} \mathrm{O}$, the story is the other way around: SSP1-1.9 and SSP1-2.6 follow almost identical concentration trajectories, while the previous RCP2.6 scenario is lower.

\subsection{Estimating the effect of latitudinally and seasonally resolved GHG concentrations on surface air temperatures in ESMs}

A much-improved assimilation process results from considering seasonally and latitudinally resolved GHG concentration - as individual station monthly mean measurements can easily be "bias"-corrected to account for their latitudinal and seasonal variations to inform the global mean. In addition, however, the latitudinally and seasonally resolved GHG concentration data we provide also offer an opportunity to drive Earth system models with more accurate forcings, so that a comparison of the ESM historical runs with observational data can be performed - excluding ESM biases that might result from GHG concentrations that are applied with a globally uniform GHG concentration level or spatial fields that are sometimes rather dissimilar from observations (Figs. S46 and S47 in the Supplement of Meinshausen et al., 2017). In order to test the approximate magnitude of applying either globally uniform ("yearmean-global") or latitudinally and seasonally resolved GHG concentrations ("latmon"), we performed six historical ensemble members of the CESM1.2.2 model (Hurrell et al., 2013) under each setup. To increase the signal-to-noise ratio, we then took the averages over the 155 years of model simulations from 1850 to 2005 across the six ensembles, resulting in 930 years of model data under each experiment. Given the seasonality of the data, we average the DJF (December-January-February) and 

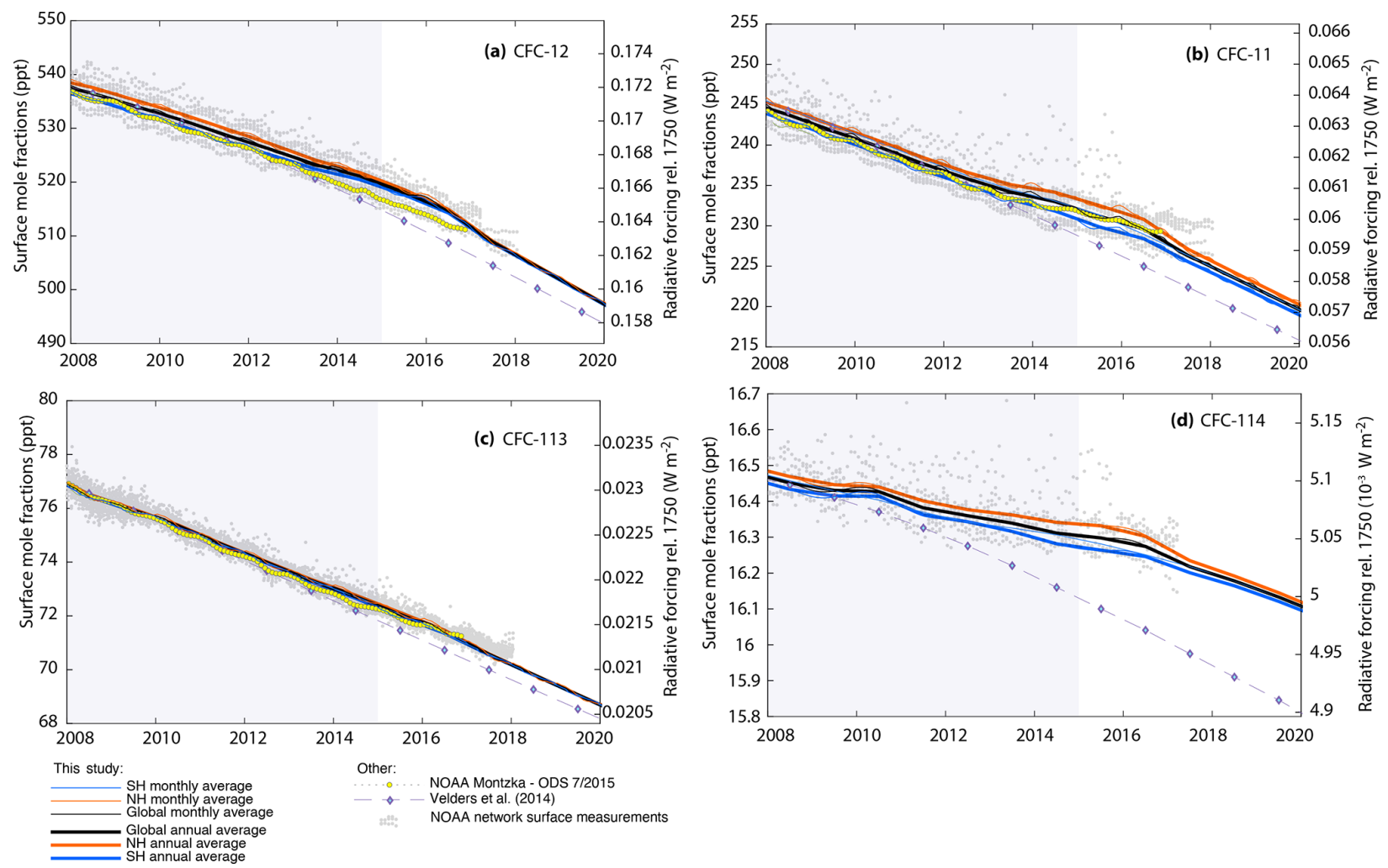

Figure 10. Atmospheric surface air mole fractions of four CFCs, namely CFC-12 (a), CFC-11 (b), CFC-113 (c), and CFC-114 (d). This study's northern hemispheric averages (orange lines), southern hemispheric averages (blue lines), and global averages (black lines) are shown in comparison with recent measurements of the NOAA and/or AGAGE networks (grey dots), the global averages derived by Montzka et al. (2018), and the projections by Velders and Daniel (2014) (dashed lines with diamond markers). The latter can be seen as near-lifetime limited projections, whereas observations hint at recent (since 2012) emissions increases, leading to a slower-than-projected fall in global atmospheric concentrations. For an exploration of CFC-11's decline rates, see the recent studies by Montzka et al. (2018) and Rigby et al. (2019). Note that the high "outlier" monthly mean values for CFC-11 and CFC-114 are primarily from the AGAGE Gosan station and include all data, i.e. so-called "pollution" events, in which case temporary high-concentration air masses pass the measurement station. The apparent disappearance of those high-pollution events at the end of 2015 is due to that particular AGAGE data time series only having been available until then at the point of this analysis, although a recent publication (Rigby et al., 2019) shows that these enhancements continued at least through 2017.

MAM (March-April-May) monthly means in the "lat-mon" experiment and subtract the reference scenario's "yearmeanglobal" respective average. In the DJF and MAM northern hemispheric winter and spring season, one would expect a slight positive warming signal in the higher northern latitudes - given the latitudinal gradient of methane concentrations and the seasonally higher $\mathrm{CO}_{2}$ concentrations. Indeed, we observe a regional warming signal of up to $0.4 \mathrm{~K}$ over northern American and Eurasian land masses, which is - in the DJF season - however latitudinally overcompensated by a strong cooling signal in the North Atlantic (Fig. 12a). In the MAM season, the slight cooling signal in the North Atlantic does not fully offset the warming over the land masses (Fig. 12b), resulting in a latitudinally averaged warming signal of approximately $0.1 \mathrm{~K}$ poleward of $65^{\circ}$ north (Fig. 12d). Given the high natural variability in the higher latitudes, we consider the significance of this warming signal by compar- ing our warming signal to corresponding differences of arbitrarily chosen control run segments. From an approximately 4500-year-long control run for CESM1.2.2 at pre-industrial conditions, we randomly chose 100 pairs of 930 -year-long segments to compute the variability of the differences. It turns out that our warming signals are within the min-max range of those 100 sample pairs regarding the latitudinally averaged warming differences, indicating that the expected warming signal due to applying latitudinally and seasonally resolved GHG concentration data is not beyond the variability range. For the MAM period, there are only a few (approximately three to five) of the paired differences that result in a higher warming signal though, suggesting that the GHG warming signal might be comparable in magnitude to the variability to be expected at a $5 \%$ confidence level. In the DJF period, a strong North Atlantic cooling is reducing the latitudinally aggregated warming signal. Whether that North 

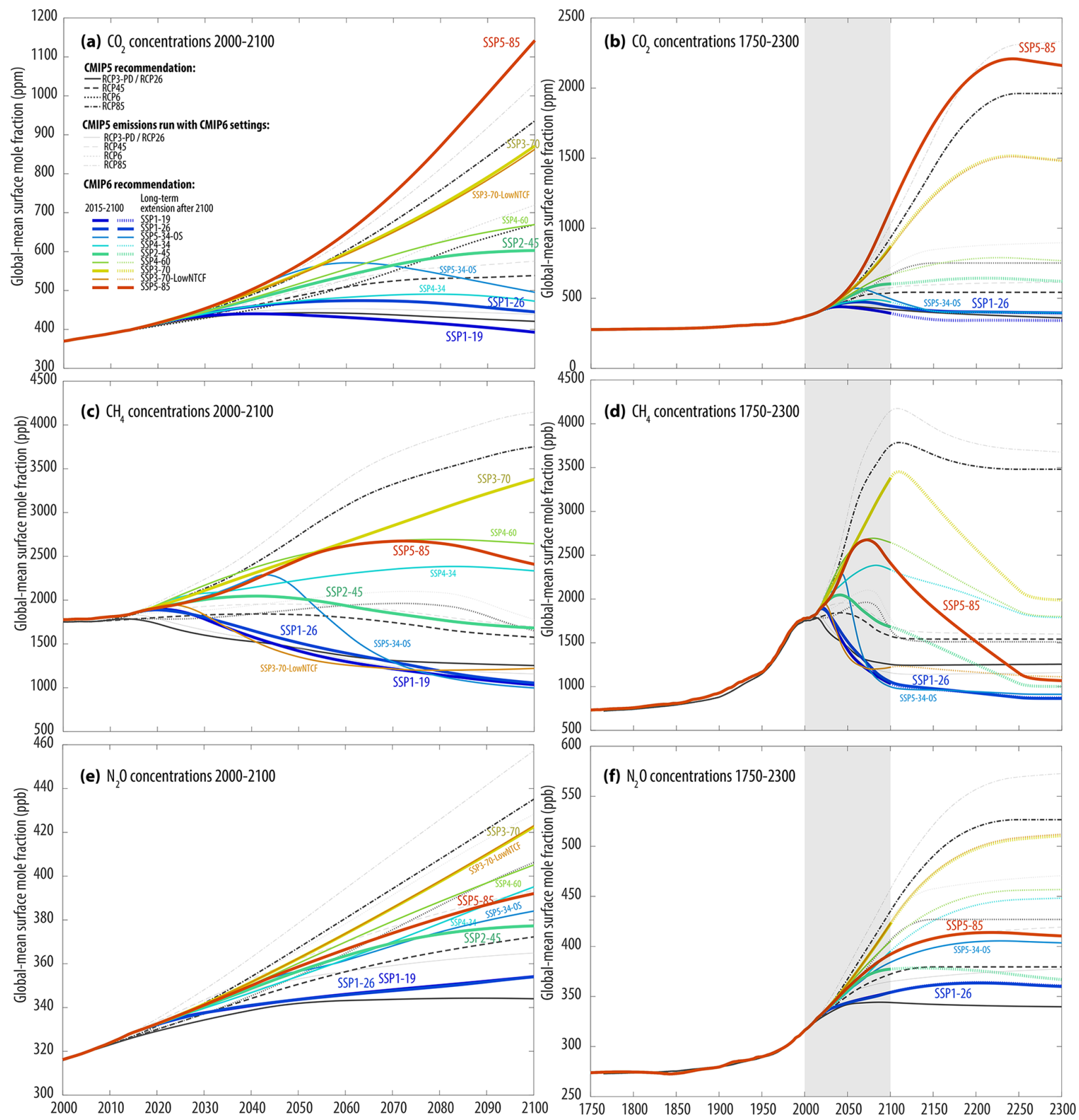

Figure 11. Overview of SSP concentrations in comparison with RCP concentrations for $\mathrm{CO}_{2}, \mathrm{CH}_{4}$, and $\mathrm{N}_{2} \mathrm{O}$. The original RCP scenarios are shown in thicker black lines and various line styles. Applying the new MAGICC7 default setting used for the SSP scenarios to the RCP emissions results in generally higher concentrations (grey lines).

Atlantic cooling is a result of natural variability in our modestly sized six-member ensembles or whether it is a dynamical response to generally higher-latitude forcing (and possible reduced overturning in the North Atlantic thermohaline circulation branch) cannot be detected from our initial ESM runs.

As one would expect, our analysis does not suggest significant latitudinal temperature perturbations at the $5 \%$ level for the JJA (June-July-August) and SON (September-OctoberNovember) periods (not shown), when seasonally lower $\mathrm{CO}_{2}$ concentrations are partially offset by the latitudinal gradient of concentrations in the Northern Hemisphere 


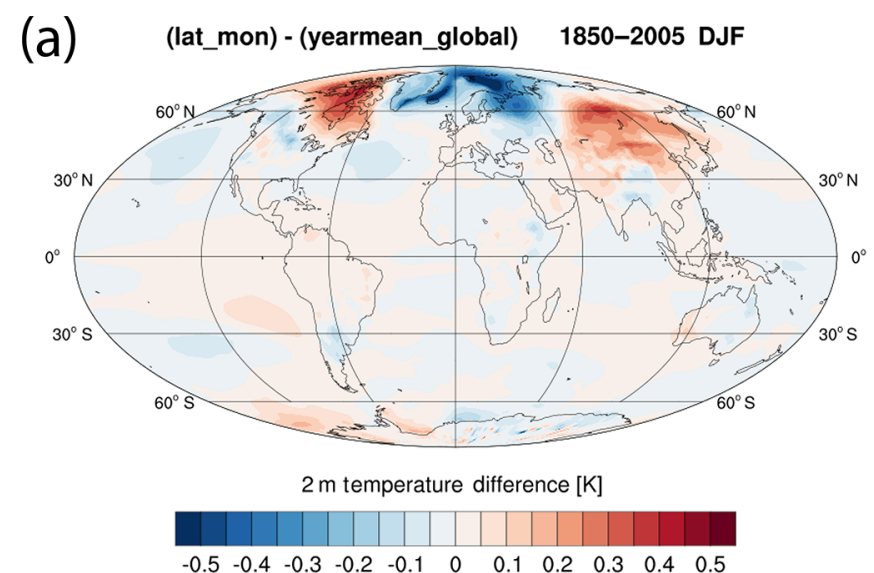

(c)

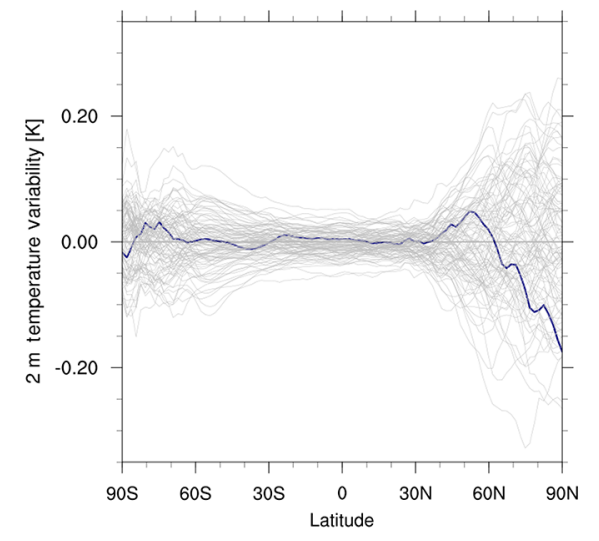

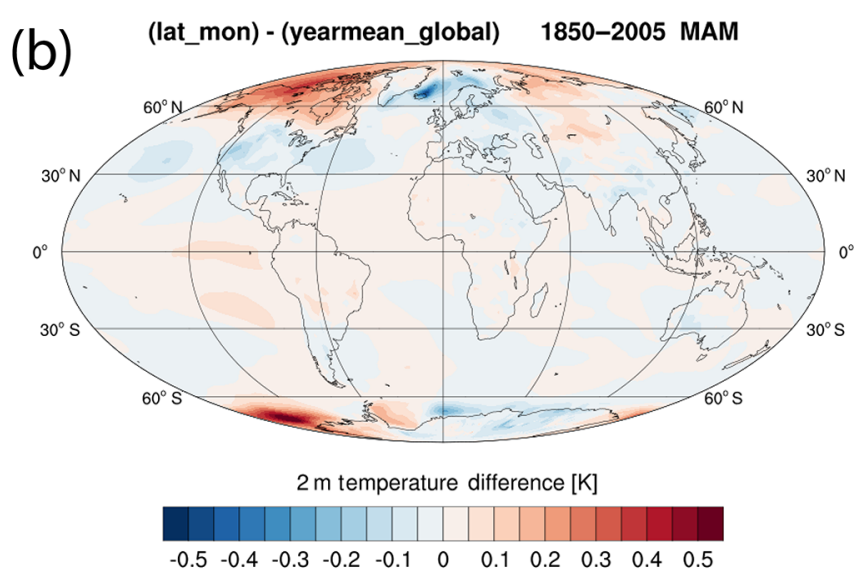

(d)

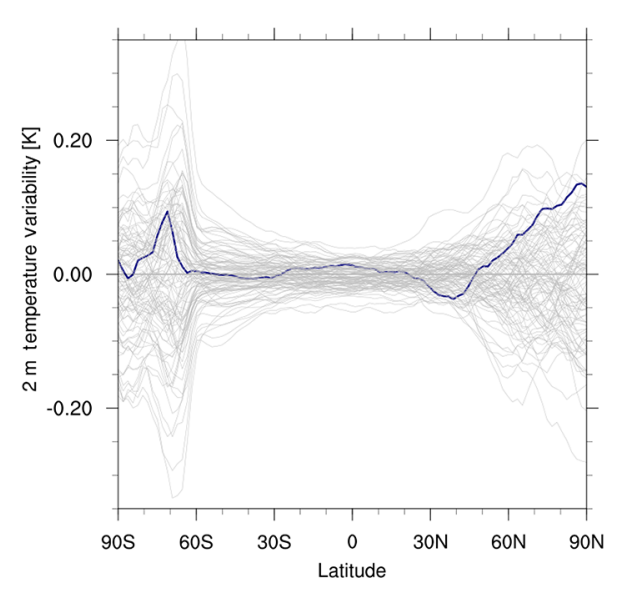

Figure 12. Warming signal induced by latitudinally and seasonally resolved GHG concentrations ("lat_mon”) compared to an annually and global-mean uniform GHG concentrations ("yearmean_global") in an Earth system model, namely CESM1.2.2 (Hurrell et al., 2013). We averaged the full historical scenario from 1850 to 2005 across all six ensemble members in each setup ("lat_mon" and "yearmean_global") and produced the averages for the December-January-February DJF average (a) and the March-April-May averages (b). The latitudinally averaged warming signals that result from using spatially and temporarily resolved GHG concentrations are shown in (c) and (d) (thick blue lines), here compared against comparable 100 differenced pairs of 930-year-long control run segments (thin grey lines). In the high upper north during the MAM season, the comparison with control run segment differences suggests that these ESM model results show a significant warming at the $5 \%$ level, given that only 3 to 5 of the 100 control run differences are higher.

\section{Limitations}

In this section, we provide a number of key limitations that come with the SSP concentration datasets. Some of these limitations arise from the underlying emission scenario data (Sect. 5.1 and 5.2), some due to imperfect matches between recent observational and model results (Sect. 5.3), some are intrinsic model limitations (Sect. 5.4 and 5.5). Likely the largest limitation is that - by design - this study provides default concentration time series for the future but does not represent the uncertainty range of future greenhouse gas concentrations for each scenario (Sect. 5.6).

\subsection{Limited emission variations across scenarios for gases other than $\mathrm{CO}_{2}, \mathrm{CH}_{4}$, and $\mathrm{N}_{2} \mathrm{O}$}

The main focus of integrated assessment models rests on projecting sectorally resolved energy, transport, industry, waste, agricultural, and land use emissions for $\mathrm{CO}_{2}, \mathrm{CH}_{4}$, and $\mathrm{N}_{2} \mathrm{O}$ as well as air pollutant emissions. The other industrial greenhouse gases in the basket of gases of the Kyoto Protocol, namely HFCs, PFCs, $\mathrm{SF}_{6}$, and $\mathrm{NF}_{3}$, are often modelled as a group or in subgroups. Subsequent downscaling mechanisms can then yield individual gas time series, although they often lack specific process dynamics, i.e. following the same growth and decline trajectory independent of their actual 
end-use applications. This is certainly a limitation of many of the forward-looking PFC projections.

In terms of the ozone-depleting substances (ODSs), a feature, or limitation, is that the presented SSP scenarios do not capture baseline or reference scenarios or in fact any emission-driven scenario variation at all. This is because the future ODS emissions are strongly constrained by the Montreal Protocol phase-out schedules. The real-world uncertainty in ODS emissions comes from non-compliance to the Protocol and from uncertainties in emission factors from banks and bank magnitudes. In our study, in which we assume identical emissions in all of our different scenarios, future variations in concentrations are hence purely climate-driven, i.e. illustrate the effect that circulation or atmospheric chemistry changes across the scenarios can have on the ODS lifetimes. It might be worth considering whether, for future assessments, the climate community's scenarios and the ozone community's scenarios could not be commonly designed. For example, some of the scenarios could include ODS emission futures that reflect lower or even noncompliance with the Montreal Protocol to allow studies on the "world avoided" (Morgenstern et al., 2008; Velders et al., 2007). An integration of scenarios used for the ozone assessments and the climate assessments may be desirable.

Finally, another limitations is that a few minor long-lived greenhouse gases are not included in this compilation of 43 gases, such as CFC-13 or the isomer CFC-114a (Vollmer et al., 2018).

\subsection{Individual scenario features and overall scenario spectrum}

Despite all the multi-year design efforts by large research international communities, there are some inevitable limitations of the overall group of scenarios. In particular, the final set of scenarios might be more appropriate for the Earth system research community than for those interested in exploring policy-relevant outcomes. For example, one of the scenarios that features new characteristic is the SSP5-3.4OS scenario. That scenario assumes the greatest net negative emissions after an initial high-emission growth rate. Its highpeak-then-strong-decline feature tests the biophysical models and will be pivotal to examining the asymmetry of the ramp-up and ramp-down characteristics of the carbon cycle, ocean heat uptake, and multiple other Earth system properties. Yet, for policy purposes, that is substantially outside the target space of the Paris Agreement, aiming to keep temperatures to below $2{ }^{\circ} \mathrm{C}$ warming.

A possible shortcoming for the climate science and impact community is that the new SSP generation of scenarios does not provide a very closely matching overlap with the RCP scenarios, as multiple scenario features are substantially different (see, e.g., $\mathrm{CO}_{2}$ and $\mathrm{CH}_{4}$ concentrations in Fig. 9). Thus, from a climate science perspective, maintaining a single multi-gas scenario unaltered from the previous generation of scenarios could have provided a useful reference point with which to quantify the change in our climate system knowledge for future projections. Given the amount of human and material resources used for the CMIP6 runs, it is, however, a question of balance between historical comparability and the capability to link to earlier studies and putting resources into the most relevant, up-to-date, scenarios. However, there is also a desire to use the best available forcing data to simulate the historical period. Because the actual historical evolution of concentrations and SLCF emissions has been different in detail from previous scenarios and historical emission and concentration estimates are updated over time (e.g. Hoesly et al., 2018), the community has thus far decided to use the most up to date data for each subsequent CMIP exercise.

\subsection{Transition issues from observational to modelled concentrations}

MAGICC has been calibrated to allow a smooth continuation from historical time series to future projections. For some gases, this transition is possibly suboptimal. For example, atmospheric measurements since 2013 produced some rather high chloroform $\left(\mathrm{CHCl}_{3}\right)$ concentrations in the Northern Hemisphere, which lead to a stronger latitudinal gradient assumption in the assimilation framework for those recent years. The future projections do not reflect a continuation of this high implied emission spike and hence revert to a lower latitudinal gradient and slightly smaller globalmean chloroform concentrations (see panel $\mathrm{f}$ in the Chloroform fact sheet available on http://greenhousegases.science. unimelb.edu.au). A similar transition issue is also present for HFC-23, HFC-245fa, HFC-43-10mee, $\mathrm{CH}_{2} \mathrm{Cl}_{2}$, and Halon1301 and even more pronounced for HFC-32, whose actual global emissions seem to increase much more strongly than assumed in the 2020s in our Kigali-aligned emission scenario by Velders et al. (2015).

\subsection{Main limitations due to sequential scenario generation process}

The sequential and concentration-driven nature of the main ESM CMIP6 experiments poses the challenge that future projections of greenhouse gas concentrations are required before the ESM results can be evaluated. In other words, the best estimate of future $\mathrm{CO}_{2}$ concentrations, given a certain emission pathway, will certainly differ at the end of the CMIP6 analysis cycle from the setting with which the MAGICC7 climate model was driven for this study. This sequential problem could only be avoided with an altered experimental design, performing most future ESM experiments in an emission-driven, but computationally more demanding, design. An advantage of the concentration-driven runs is that climate feedbacks and carbon cycle feedbacks can more easily be separated. 
In addition to the inconsistencies introduced by the sequential and concentration-driven nature of future climate scenario experiments, there are clearly limitations of MAGICC and its chosen default parameter settings for this study. A full evaluation of the extent to which the chosen parameters yield a concentration response that is representative of the higher-complexity atmospheric chemistry model projections that are part of CMIP6 will be of key interest for future studies.

\subsection{Variable natural emissions}

Except for the interactive carbon cycle, this study assumes constant natural emissions levels for substances like $\mathrm{CH}_{4}$, $\mathrm{N}_{2} \mathrm{O}, \mathrm{CH}_{3} \mathrm{Br}, \mathrm{CH}_{3} \mathrm{Cl}$, and others. This is clearly a limitation, as under climate change and human management of the land and ocean, the magnitude of these natural emissions (indirectly influenced by human activities) will change over time. Future research could build knowledge of the time-varying natural emission sources into the projection model used.

\subsection{No uncertainty estimates}

A major limitation of our study is the lack of uncertainty estimates. Given the primary purpose of this study of providing a single reference concentration projection as input dataset for the CMIP6 experiments, uncertainty ranges around the projections are not necessary. However, in multiple other potential applications of this dataset, properly derived uncertainty information could have opened up new use cases. For example, simple inversion studies could attempt to derive seasonally varying sink and source patterns from our observationally based historical monthly and latitudinally resolved concentration patterns. Without the appropriate uncertainty information, any inversion approach will have to make ad hoc assumptions.

\section{Conclusions}

The projected human-induced increase in atmospheric greenhouse gas abundances over the 21 st century swamps all observed variations for the last 2000 years (Fig. 8). The new SSP scenarios span an even broader range of $\mathrm{CO}_{2}$ concentration futures, with the higher end (SSP5-8.5) yielding higher concentrations than the previous RCP8.5 scenario and the lower end SSP1-1.9 scenario resulting in $\mathrm{CO}_{2}$ emissions down to $350 \mathrm{ppm}$ in the longer term (2150). Also, in a more technical aspect, the SSP concentrations are breaking new ground. For the first time, the greenhouse gas projections are available for 43 greenhouse gases, with latitudinal and seasonal variations captured. For example, by 2050, northern hemispheric concentrations in the SSP3-7.0 scenario are $1.2 \%$ and $4.3 \%$ higher than southern hemispheric averages for $\mathrm{CO}_{2}$ and $\mathrm{CH}_{4}$, respectively - with corresponding nonnegligible implications for radiative forcing (Table 5).
Given the substantial efforts that go into the data collection by observational network communities, a worthwhile effort in continuation from the present study would be to build a real-time framework to provide a system that updates GHG historical and future projections, including uncertainties, for a wide range of - perhaps also updated - scenarios from the integrated assessment community. While updates of observations, gas cycle models, or emission scenarios in between the major IPCC or WMO assessments are useful for a range of scientific studies, the new GHG projections data could be frozen every several years to provide a new range of benchmark scenarios for Earth system models. Efforts to provide more frequent updates for emissions data are also underway (e.g. Hoesly et al., 2018).

More than 20 years ago, the IPCC started to put forward future concentration scenarios, the so-called IS-92 scenarios. Back then in 1992, $\mathrm{CO}_{2}$ concentrations were at $356 \mathrm{ppm}$ (Keeling et al., 1976; Keeling and Whorf, 2004). In 2019, atmospheric $\mathrm{CO}_{2}$ concentrations are $411 \mathrm{ppm}$. In equilibrium and assuming a central climate sensitivity of $3{ }^{\circ} \mathrm{C}$, these $\mathrm{CO}_{2}$ concentrations of $411 \mathrm{ppm}$ alone would imply a temperature change of $1.7^{\circ} \mathrm{C}$ above pre-industrial levels (using the simple and standard $\mathrm{CO}_{2}$ forcing formula of $\mathrm{RF}=5.35 \times \ln \left(C / C_{0}\right)$ with $C$ being the current and $C_{0}$ being the pre-industrial concentrations). While zero $\mathrm{CO}_{2}$ emissions would yield decreasing concentrations, it becomes clear that only a future emission trajectory that effectively reduces atmospheric $\mathrm{CO}_{2}$ concentration levels below today's levels would provide a reasonable chance to keep warming at or below $1.5^{\circ} \mathrm{C}$ in the longer term. And even such $1.5^{\circ} \mathrm{C}$ of warming could come with multi-metre sea level rise by 2300 (Mengel et al., 2018) and the likely demise of coral reefs (Frieler et al., 2013). Thus, while the scenarios shown span a scientifically valid wide range of plausible futures, from a climate impact point of view - and trying to achieve the Paris Agreement targets all except for the lowest scenarios investigated in this study will hopefully remain hypothetical futures.

Data availability. A supplementary data table is available with global and annual mean mole fractions. The complete dataset with latitudinally and monthly resolved data in netcdf format is available via the Earth System Grid Federation (ESGF) servers at https://esgf-node.llnl.gov/search/input4mips/ (Department of Energy, Lawrence Livermore National Laboratory and Earth System Grid Federation, 2020) with a total of 1656 files for source version 1.2.1. The license for all data is Creative Commons Attribution-ShareAlike 4.0 International License (CC BY-SA 4.0). The digital identifiers of the produced datasets, as provided by the ESGF servers, are specific to the nine SSP scenarios: SSP53.4-over - https://doi.org/10.22033/ESGF/input4MIPs.9867 (Meinshausen and Nicholls, 2018a); SSP5-8.5 - $\quad$ https://doi.org/10.22033/ESGF/input4MIPs.9868

(Meinshausen and Nicholls, 2018b); SSP2-4.5 - $\quad$ https://doi.org/10.22033/ESGF/input4MIPs.9866 (Meinshausen and Nicholls, 2018c); SSP4- 


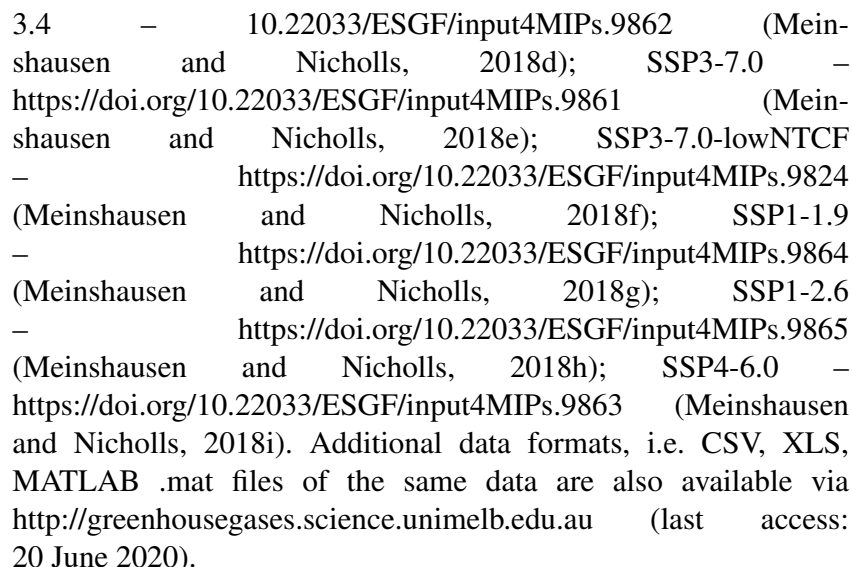
20 June 2020).

Supplement. The supplement related to this article is available online at: https://doi.org/10.5194/gmd-13-3571-2020-supplement.

Author contributions. Together with EV, MM designed the study. $\mathrm{ZN}$ and $\mathrm{MG}$ performed the emission data collation, downscaling, and harmonization steps. MM, EV, and MF built the MATLAB libraries for this project. $\mathrm{MF}, \mathrm{ZN}$, and $\mathrm{MM}$ did the verification of the final data product in comparison to the historical datasets. The new MAGICC parameterizations were developed by MM, ZN, and AJ. MAGICC runs for the concentration projections and postprocessing of the data were performed by $\mathrm{MM}, \mathrm{ZN}, \mathrm{EV}$, and MF. $\mathrm{ZN}$ coordinated the transfer of data to the Input4MIP project. JL, $\mathrm{ZN}$, and AN performed the MAGICC temperature and SLR projections. UB set up and performed the CESM1.2.2 runs with CG leading the analysis. GJMV contributed the future ODS and halogenated emission projections. MM produced the figures, with Fig. 8 being produced by JL and MM. All authors contributed to writing and commenting on the paper.

Competing interests. The authors declare that they have no conflict of interest.

Acknowledgements. We would like to thank the broad community of scientists, lab technicians, research assistants, and respective funding agencies that make the observational records of greenhouse gas concentrations possibly, specifically those of the AGAGE and NOAA networks. The primary networks AGAGE and the Cooperative Air Sampling Network managed by NOAA deserve the utmost credit, including all its individual researchers and the networks' policy to make the raw data available to the broader scientific community. The Law Dome firn and ice core programme is supported by the Australian Antarctic Division. We thank in particular the following researchers for invaluable efforts to collect, screen, and make available NOAA network data: Ed Dlugokencky, Pieter Tans, David Nance, Bradley Hall, Geoff Dutton, James Elkins, Debra Mondeel, Carolina Siso, and Ben Miller. Ray Langenfelds and Paul Steele (CSIRO) are thanked for their long-term support of the Cape Grim, Cape Grim Air Archive, and AGAGE activities. Without those observational records, our ability to project greenhouse gas into the future would not be possible. We also would like to thank the IAM modelling teams, especially the IMAGE, MESSAGEGlobiom, AIM, REMIND-MagPie, and GCAM4 teams, who created chosen SSP benchmark emission scenarios underlying this study. The author team is thankful for the discussions with the IAM modellers on the design of the SSP extensions, especially Keywan Riahi, Detlef van Vuuren, David Klein, and Shinichiro Fujimori. Lastly, the authors acknowledge the web teams that make the use of the datasets possible. Specifically, we would like to thank Paul Durack for handling the data integration for the ESGF server. Also, we would warmly like to thank Melissa Makin, Usha Nattala, and Uli Felzmann from the Faculty of Science IT team at the University of Melbourne, who made it possible for the full datasets, fact sheets, and interactive plots of this study to be available in a useraccessible fashion on http://greenhousegases.unimelb.edu.au. Deep thanks goes to Christopher Holmes, who helped tremendously in providing data and code to calibrate MAGICC to abundance projections presented in Prather et al. (2012) and Holmes et al. (2013). We thank Keith Shine for very helpful discussions on Sect. 2.7. Malte Meinshausen thankfully acknowledges the support by the Australian Research Council Future Fellowship grant FT130100809. This work was undertaken in collaboration with partners in the European Union's Horizon 2020 research and innovation programme CRESCENDO (grant no. 641816), of which the University of Melbourne is an unfunded partner.

Financial support. This research has been supported by the Australian Research Council (grant no. FT130100809).

Review statement. This paper was edited by Olaf Morgenstern and reviewed by two anonymous referees.

\section{References}

Beckley, B. D., Zelensky, N. P., Holmes, S. A., Lemoine, F. G., Ray, R. D., Mitchum, G. T., Desai, S. D., and Brown, S. T.: Assessment of the Jason-2 Extension to the TOPEX/Poseidon, Jason-1 Sea-Surface Height Time Series for Global Mean Sea Level Monitoring, Mar. Geod., 33, 447-471, https://doi.org/10.1080/01490419.2010.491029, 2010.

Brohan, P., Kennedy, J. J., Harris, I., Tett, S. F. B., and Jones, P. D.: Uncertainty estimates in regional and global observed temperature changes: A new data set from 1850, J. Geophys. Res.Atmos., 111, D12106, https://doi.org/10.1029/2005JD006548, 2006.

Buizert, C., Martinerie, P., Petrenko, V. V., Severinghaus, J. P., Trudinger, C. M., Witrant, E., Rosen, J. L., Orsi, A. J., Rubino, M., Etheridge, D. M., Steele, L. P., Hogan, C., Laube, J. C., Sturges, W. T., Levchenko, V. A., Smith, A. M., Levin, I., Conway, T. J., Dlugokencky, E. J., Lang, P. M., Kawamura, K., Jenk, T. M., White, J. W. C., Sowers, T., Schwander, J., and Blunier, T.: Gas transport in firn: multiple-tracer characterisation and model intercomparison for NEEM, Northern Greenland, Atmos. Chem. Phys., 12, 4259-4277, https://doi.org/10.5194/acp12-4259-2012, 2012. 
Butchart, N. and Scaife, A. A.: Removal of chlorofluorocarbons by increased mass exchange between the stratosphere and troposphere in a changing climate, Nature, 410, 799-802, 2001.

Collins, W. J., Lamarque, J.-F., Schulz, M., Boucher, O., Eyring, V., Hegglin, M. I., Maycock, A., Myhre, G., Prather, M., Shindell, D., and Smith, S. J.: AerChemMIP: quantifying the effects of chemistry and aerosols in CMIP6, Geosci. Model Dev., 10, 585607, https://doi.org/10.5194/gmd-10-585-2017, 2017.

Cunnold, D., Steele, L., Fraser, P., Simmonds, P., Prinn, R., Weiss, R., Porter, L., O'Doherty, S., Langenfelds, R., and Krummel, P.: In situ measurements of atmospheric methane at GAGE/AGAGE sites during 1985-2000 and resulting source inferences, J. Geophys. Res.-Atmos., 107, D14, https://doi.org/10.1029/2001JD001226, 2002.

Department of Energy, Lawrence Livermore National Laboratory and Earth System Grid Federation: input4MIPs, available at: https://esgf-node.llnl.gov/search/input4mips/, last access: 20 June 2020.

Dlugokencky, E. J., Lang, P. M., Crotwell, A. M., Masarie, K. A., and Crotwell, M. J.: Atmospheric Methane Dry Air Mole Fractions from the NOAA ESRL Carbon Cycle Cooperative Global Air Sampling Network, 1983-2014, NOAA, 2015a.

Dlugokencky, E. J., Lang, P. M., Masarie, K. A., Crotwell, A. M., and Crotwell, M. J.: Atmospheric Carbon Dioxide Dry Air Mole Fractions from the NOAA ESRL Carbon Cycle Cooperative Global Air Sampling Network, 1968-2014, NOAA, 2015b.

Durack, P. J. and Taylor, K.: CMIP6 Forcing datasets summary, available at: http://goo.gl/r8up31 (last access: 20 June 2020), 46, 2019.

Ehhalt, D., Prather, M. J., Dentener, F., Derwent, R. G., Dlugokencky, E., Holland, E., Isaksen, I. S. A., Katima, J., Kirchhoff, V., Matson, P., Midgley, P., and Wang, M.: Atmospheric Chemistry and Greenhouse Gases, in: Climate Change 2001: The Scientific Basis, edited by: Houghton, J. T., Ding, Y., Griggs, D. J., Noguer, M., van der Linden, P. J., Dai, X., Maskell, K., and Johnson, C. A., Cambridge University Press, Cambridge, UK, 241-287, 2001.

Engel, A., Rigby, M., Burkholder, J. B., Fernandez, R. P., Froidevaux, L., Hall, B. D., Hossaini, R., Saito, T., Vollmer, M. K., and Yao, B.: Update on Ozone-Depleting Substances (ODCss) and Other Gases of Interest to the Montreal Protocol, chap. 1, in: Scientific Assessment of Ozone Depletion: 2018, World Meterological Organization, Geneva, Switzerland, 2018.

Etminan, M., Myhre, G., Highwood, E., and Shine, K.: Radiative forcing of carbon dioxide, methane, and nitrous oxide: A significant revision of the methane radiative forcing, Geophys. Res. Lett., 43, 12614-12623, https://doi.org/10.1002/2016GL071930, 2016.

Eyring, V., Bony, S., Meehl, G. A., Senior, C. A., Stevens, B., Stouffer, R. J., and Taylor, K. E.: Overview of the Coupled Model Intercomparison Project Phase 6 (CMIP6) experimental design and organization, Geosci. Model Dev., 9, 1937-1958, https://doi.org/10.5194/gmd-9-1937-2016, 2016.

Fang, X., Park, S., Saito, T., Tunnicliffe, R., Ganesan, A. L., Rigby, M., Li, S., Yokouchi, Y., Fraser, P. J., Harth, C. M., Krummel, P. B., Mühle, J., O’Doherty, S., Salameh, P. K., Simmonds, P. G., Weiss, R. F., Young, D., Lunt, M. F., Manning, A. J., Gressent, A., and Prinn, R. G.: Rapid increase in ozone- depleting chloroform emissions from China, Nat. Geosci., 12, 89-93, https://doi.org/10.1038/s41561-018-0278-2, 2019.

Forkel, M., Carvalhais, N., Rödenbeck, C., Keeling, R., Heimann, M., Thonicke, K., Zaehle, S., and Reichstein, M.: Enhanced seasonal $\mathrm{CO}_{2}$ exchange caused by amplified plant productivity in northern ecosystems, Science, 696-699, https://doi.org/10.1126/science.aac4971, 2016.

Friedlingstein, P., Cox, P., Betts, R., Bopp, L., von Bloh, W., Brovkin, V., Cadule, P., Doney, S., Eby, M., Fung, I., Bala, G., John, J., Jones, C., Joos, F., Kato, T., Kawamiya, M., Knorr, W., Lindsay, K., Matthews, H. D., Raddatz, T., Rayner, P., Reick, C., Roeckner, E., Schnitzler, K.-G., Schnur, R., Strassmann, K., Weaver, K., Yoshikawa, C., and Zeng, N.: Climate-Carbon Cycle Feedback Analysis: Results from the C4MIP Model Intercomparison, J. Climate, 19, 3337-3353, https://doi.org/10.1175/JCLI3800.1, 2006.

Friedlingstein, P., Meinshausen, M., Arora, V. K., Jones, C. D., Anav, A., Liddicoat, S. K., and Knutti, R.: Uncertainties in CMIP5 Climate Projections due to Carbon Cycle Feedbacks, J. Climate, 27, 511-526, https://doi.org/10.1175/jcli-d-12-00579.1, 2014.

Frieler, K., Meinshausen, M., Golly, A., Mengel, M., Lebek, K., Donner, S. D., and Hoegh-Guldberg, O.: Limiting global warming to 2 degrees $\mathrm{C}$ is unlikely to save most coral reefs, Nature Climate Change, 3, 165-170, https://doi.org/10.1038/nclimate1674, 2013.

Fuss, S., Lamb, W. F., Callaghan, M. W., Hilaire, J., Creutzig, F., Amann, T., Beringer, T., de Oliveira Garcia, W., Hartmann, J., and Khanna, T.: Negative emissions - Part 2: Costs, potentials and side effects, Environ. Res. Lett., 13, 063002 , https://doi.org/10.1088/1748-9326/aabf9f, 2018.

Gidden, M. J., Fujimori, S., van den Berg, M., Klein, D., Smith, S. J., van Vuuren, D. P., and Riahi, K.: A methodology and implementation of automated emissions harmonization for use in Integrated Assessment Models, Environ. Modell. Softw., 105, 187200, https://doi.org/10.1016/j.envsoft.2018.04.002, 2018.

Gidden, M. J., Riahi, K., Smith, S. J., Fujimori, S., Luderer, G., Kriegler, E., van Vuuren, D. P., van den Berg, M., Feng, L., Klein, D., Calvin, K., Doelman, J. C., Frank, S., Fricko, O., Harmsen, M., Hasegawa, T., Havlik, P., Hilaire, J., Hoesly, R., Horing, J., Popp, A., Stehfest, E., and Takahashi, K.: Global emissions pathways under different socioeconomic scenarios for use in CMIP6: a dataset of harmonized emissions trajectories through the end of the century, Geosci. Model Dev., 12, 14431475, https://doi.org/10.5194/gmd-12-1443-2019, 2019.

Graven, H. D., Keeling, R. F., Piper, S. C., Patra, P. K., Stephens, B. B., Wofsy, S. C., Welp, L. R., Sweeney, C., Tans, P. P., Kelley, J. J., Daube, B. C., Kort, E. A., Santoni, G. W., and Bent, J. D.: Enhanced Seasonal Exchange of $\mathrm{CO}_{2}$ by Northern Ecosystems Since 1960, Science, 341, 1085-1089, https://doi.org/10.1126/science.1239207, 2013.

Gray, J. M., Frolking, S., Kort, E. A., Ray, D. K., Kucharik, C. J., Ramankutty, N., and Friedl, M. A.: Direct human influence on atmospheric $\mathrm{CO}_{2}$ seasonality from increased cropland productivity, Nature, 515, 398-401, https://doi.org/10.1038/nature13957, 2014.

Gütschow, J., Jeffery, M. L., Gieseke, R., Gebel, R., Stevens, D., Krapp, M., and Rocha, M.: The PRIMAP-hist national histor- 
ical emissions time series, Earth Syst. Sci. Data, 8, 571-603, https://doi.org/10.5194/essd-8-571-2016, 2016.

Hoesly, R. M., Smith, S. J., Feng, L., Klimont, Z., JanssensMaenhout, G., Pitkanen, T., Seibert, J. J., Vu, L., Andres, R. J., Bolt, R. M., Bond, T. C., Dawidowski, L., Kholod, N., Kurokawa, J.-I., Li, M., Liu, L., Lu, Z., Moura, M. C. P., O'Rourke, P. R., and Zhang, Q.: Historical (1750-2014) anthropogenic emissions of reactive gases and aerosols from the Community Emissions Data System (CEDS), Geosci. Model Dev., 11, 369-408, https://doi.org/10.5194/gmd-11-369-2018, 2018.

Holmes, C. D., Prather, M. J., Søvde, O. A., and Myhre, G.: Future methane, hydroxyl, and their uncertainties: key climate and emission parameters for future predictions, Atmos. Chem. Phys., 13, 285-302, https://doi.org/10.5194/acp-13-285-2013, 2013.

Hossaini, R., Chipperfield, M., Montzka, S., Rap, A., Dhomse, S., and Feng, W.: Efficiency of short-lived halogens at influencing climate through depletion of stratospheric ozone, Nat. Geosci., 8, 186-190, 2015.

Hurrell, J. W., Holland, M. M., Gent, P. R., Ghan, S., Kay, J. E., Kushner, P. J., Lamarque, J.-F., Large, W. G., Lawrence, D., Lindsay, K., Lipscomb, W. H., Long, M. C., Mahowald, N., Marsh, D. R., Neale, R. B., Rasch, P., Vavrus, S., Vertenstein, M., Bader, D., Collins, W. D., Hack, J. J., Kiehl, J., and Marshall, S.: The Community Earth System Model: A Framework for Collaborative Research, B. Am. Meteorol. Soc., 94, 13391360, https://doi.org/10.1175/bams-d-12-00121.1, 2013.

Jones, C. D., Arora, V., Friedlingstein, P., Bopp, L., Brovkin, V., Dunne, J., Graven, H., Hoffman, F., Ilyina, T., John, J. G., Jung, M., Kawamiya, M., Koven, C., Pongratz, J., Raddatz, T., Randerson, J. T., and Zaehle, S.: C4MIP - The Coupled Climate-Carbon Cycle Model Intercomparison Project: experimental protocol for CMIP6, Geosci. Model Dev., 9, 2853-2880, https://doi.org/10.5194/gmd-9-2853-2016, 2016.

Keeling, C. D. and Whorf, T. P.: Atmospheric $\mathrm{CO}_{2}$ records from sites in the SIO air sampling network, available at: http://cdiac. esd.ornl.gov/trends/co2/sio-keel.htm (last access: May 2017), 2004.

Keeling, C. D., Bacastow, R. B., Bainbridge, A. E., Ekdahl, C. A., Guenther, P. R., Waterman, L. S., and Chin, J. F.: Atmospheric carbon dioxide variations at Mauna Loa observatory, Hawaii, Tellus, 28, 538-551, 1976.

Lawrence, D. M., Hurtt, G. C., Arneth, A., Brovkin, V., Calvin, K. V., Jones, A. D., Jones, C. D., Lawrence, P. J., de NobletDucoudré, N., Pongratz, J., Seneviratne, S. I., and Shevliakova, E.: The Land Use Model Intercomparison Project (LUMIP) contribution to CMIP6: rationale and experimental design, Geosci. Model Dev., 9, 2973-2998, https://doi.org/10.5194/gmd-9-29732016, 2016.

Matthes, K., Funke, B., Andersson, M. E., Barnard, L., Beer, J., Charbonneau, P., Clilverd, M. A., Dudok de Wit, T., Haberreiter, M., Hendry, A., Jackman, C. H., Kretzschmar, M., Kruschke, T., Kunze, M., Langematz, U., Marsh, D. R., Maycock, A. C., Misios, S., Rodger, C. J., Scaife, A. A., Seppälä, A., Shangguan, M., Sinnhuber, M., Tourpali, K., Usoskin, I., van de Kamp, M., Verronen, P. T., and Versick, S.: Solar forcing for CMIP6 (v3.2), Geosci. Model Dev., 10, 2247-2302, https://doi.org/10.5194/gmd-10-2247-2017, 2017.

Meehl, G. A., Covey, C., Delworth, T., Latif, M., McAvaney, B., Mitchell, J. F., Stouffer, R. J., and Taylor, K. E.: The WCRP
CMIP3 multimodel dataset: A new era in climate change research, B. Am. Meteorol. Soc., 88, 1383-1394, 2007.

Meinshausen, M. and Nicholls, Z. R. J.: UoM-REMINDMAGPIE-ssp534-over-1-2-1 GHG concentrations, Version 20181127, Earth System Grid Federation, https://doi.org/10.22033/ESGF/input4MIPs.9867, 2018a.

Meinshausen, M. and Nicholls, Z. R. J.: UoM-REMINDMAGPIE-ssp585-1-2-1 GHG concentrations, Version 20181127, Earth System Grid Federation, https://doi.org/10.22033/ESGF/input4MIPs.9868, 2018b.

Meinshausen, M. and Nicholls, Z. R. J.: UoM-MESSAGEGLOBIOM-ssp245-1-2-1 GHG concentrations, Version 20181127, Earth System Grid Federation, https://doi.org/10.22033/ESGF/input4MIPs.9866, 2018c.

Meinshausen, M. and Nicholls, Z. R. J.: UoM-GCAM4-ssp434-12-1 GHG concentrations, Version 20181127, Earth System Grid Federation, https://doi.org/10.22033/ESGF/input4MIPs.9862, 2018d.

Meinshausen, M. and Nicholls, Z. R. J.: UoM-AIM-ssp370-1-2-1 GHG concentrations, Version 20181127, Earth System Grid Federation, https://doi.org/10.22033/ESGF/input4MIPs.9861, 2018e.

Meinshausen, M. and Nicholls, Z. R. J.: UoM-AIMssp370-lowNTCF-1-2-1 GHG concentrations, Version 20181127, Earth System Grid Federation, https://doi.org/10.22033/ESGF/input4MIPs.9824, $2018 \mathrm{f}$.

Meinshausen, M. and Nicholls, Z. R. J.: UoM-IMAGE-ssp119-12-1 GHG concentrations, Version 20181127, Earth System Grid Federation, https://doi.org/10.22033/ESGF/input4MIPs.9864, 2018g.

Meinshausen, M. and Nicholls, Z. R. J.: UoM-IMAGE-ssp126-12-1 GHG concentrations, Version 20181127, Earth System Grid Federation, https://doi.org/10.22033/ESGF/input4MIPs.9865, 2018h.

Meinshausen, M. and Nicholls, Z. R. J.: UoM-GCAM4-ssp460-12-1 GHG concentrations, Version 20181127, Earth System Grid Federation, https://doi.org/10.22033/ESGF/input4MIPs.9863, $2018 \mathrm{i}$

Meinshausen, M., Raper, S. C. B., and Wigley, T. M. L.: Emulating coupled atmosphere-ocean and carbon cycle models with a simpler model, MAGICC6 - Part 1: Model description and calibration, Atmos. Chem. Phys., 11, 1417-1456, https://doi.org/10.5194/acp-11-1417-2011, 2011a.

Meinshausen, M., Smith, S., Calvin, K., Daniel, J., Kainuma, M., Lamarque, J. F., Matsumoto, K., Montzka, S., Raper, S., Riahi, K., Thomson, A., Velders, G., and van Vuuren, D. P.: The RCP greenhouse gas concentrations and their extensions from 1765 to 2300, Climatic Change, 109, 213-241, https://doi.org/10.1007/s10584-011-0156-z, 2011 b.

Meinshausen, M., Wigley, T. M. L., and Raper, S. C. B.: Emulating atmosphere-ocean and carbon cycle models with a simpler model, MAGICC6 - Part 2: Applications, Atmos. Chem. Phys., 11, 1457-1471, https://doi.org/10.5194/acp-111457-2011, 2011c.

Meinshausen, M., Vogel, E., Nauels, A., Lorbacher, K., Meinshausen, N., Etheridge, D. M., Fraser, P. J., Montzka, S. A., Rayner, P. J., Trudinger, C. M., Krummel, P. B., Beyerle, U., Canadell, J. G., Daniel, J. S., Enting, I. G., Law, R. M., Lunder, C. R., O’Doherty, S., Prinn, R. G., Reimann, S., Rubino, 
M., Velders, G. J. M., Vollmer, M. K., Wang, R. H. J., and Weiss, R.: Historical greenhouse gas concentrations for climate modelling (CMIP6), Geosci. Model Dev., 10, 2057-2116, https://doi.org/10.5194/gmd-10-2057-2017, 2017.

Mengel, M., Nauels, A., Rogelj, J., and Schleussner, C.-F.: Committed sea-level rise under the Paris Agreement and the legacy of delayed mitigation action, Nat. Commun., 9, 601, https://doi.org/10.1038/s41467-018-02985-8, 2018.

Montzka, S., McFarland, M., Andersen, S., Miller, B., Fahey, D., Hall, B., Hu, L., Siso, C., and Elkins, J.: Recent trends in global emissions of hydrochlorofluorocarbons and hydrofluorocarbons: Reflecting on the 2007 adjustments to the Montreal Protocol, J. Phys. Chem. A, 119, 4439-4449, 2015.

Montzka, S. A., Dutton, G. S., Yu, P., Ray, E., Portmann, R. W., Daniel, J. S., Kuijpers, L., Hall, B. D., Mondeel, D., Siso, C., Nance, J. D., Rigby, M., Manning, A. J., Hu, L., Moore, F., Miller, B. R., and Elkins, J. W.: An unexpected and persistent increase in global emissions of ozone-depleting CFC-11, Nature, 557, 413-417, https://doi.org/10.1038/s41586-018-0106-2, 2018.

Morgenstern, O., Braesicke, P., Hurwitz, M. M., O'Connor, F. M., Bushell, A. C., Johnson, C. E., and Pyle, J. A.: The World Avoided by the Montreal Protocol, Geophys. Res. Lett., 35, L16811, https://doi.org/10.1029/2008g1034590, 2008.

Myhre, G., Shindell, D., Breon, F. M., Collins, W., Fuglestvedt, J., Huang, J., Koch, D., Lamarque, J. F., Lee, D., Mendoza, B., Nakajima, T., Robock, A., Stephens, G., Takemura, T., and Zhang, H.: Anthropogenic and Natural Radiative Forcing, in: Climate Change 2013: The Physical Science Basis. Contribution of Working Group I to the Fifth Assessment, Report of the Intergovernmental Panel on Climate Change, edited by: Stocker, T. F., Qin, D., Plattner, G.-K., Tignor, M., Allen, S. K., Boschung, J., Nauels, A., Xia, Y., Bex, V., and Midgley, P. M., Cambridge University Press, Cambridge, New York, 2013.

Nisbet, E. G., Dlugokencky, E. J., Manning, M. R., Lowry, D., Fisher, R. E., France, J. L., Michel, S. E., Miller, J. B., White, J. W. C., Vaughn, B., Bousquet, P., Pyle, J. A., Warwick, N. J., Cain, M., Brownlow, R., Zazzeri, G., Lanoisellé, M., Manning, A. C., Gloor, E., Worthy, D. E. J., Brunke, E.-G., Labuschagne, C., Wolff, E. W., and Ganesan, A. L.: Rising atmospheric methane: 2007-2014 growth and isotopic shift, Global Biogeochem. Cy., 30, 1356-1370, https://doi.org/10.1002/2016gb005406, 2016.

NOAA ESRL GMD: Atmospheric Carbon Dioxide Dry Air Mole Fractions from quasi-continuous measurements at American Samoa, edited by: Thoning, K. W., Kitzis, D. R., and Crotwell, A., National Oceanic and Atmospheric Administration (NOAA), Earth System Research Laboratory (ESRL), Global Monitoring Division (GMD): Boulder, Colorado, USA, 2014a.

NOAA ESRL GMD: Atmospheric Carbon Dioxide Dry Air Mole Fractions from quasi-continuous measurements at South Pole, edited by: Thoning, K. W., Kitzis, D. R., and Crotwell, A., National Oceanic and Atmospheric Administration (NOAA), Earth System Research Laboratory (ESRL), Global Monitoring Division (GMD), Boulder, Colorado, USA, 2014b.

NOAA ESRL GMD: Atmospheric Carbon Dioxide Dry Air Mole Fractions from quasi-continuous measurements at Mauna Loa, Hawaii, edited by: Thoning, K. W., Kitzis, D. R., and Crotwell, A., National Oceanic and Atmospheric Administration (NOAA),
Earth System Research Laboratory (ESRL), Global Monitoring Division (GMD), Boulder, Colorado, USA, 2014c.

NOAA ESRL GMD: Atmospheric Carbon Dioxide Dry Air Mole Fractions from quasi-continuous measurements at Barrow, Alaska, edited by: Thoning, K. W., Kitzis, D. R., and Crotwell, A., National Oceanic and Atmospheric Administration (NOAA), Earth System Research Laboratory (ESRL), Global Monitoring Division (GMD), Boulder, Colorado, USA, 2014d.

O’Neill, B. C., Tebaldi, C., Vuuren, D. P. v., Eyring, V., Friedlingstein, P., Hurtt, G., Knutti, R., Kriegler, E., Lamarque, J.-F., and Lowe, J.: The scenario model intercomparison project (ScenarioMIP) for CMIP6, Geoscientific Model Development, 9, 34613482, 2016.

Prather, M. J., Holmes, C. D., and Hsu, J.: Reactive greenhouse gas scenarios: Systematic exploration of uncertainties and the role of atmospheric chemistry, Geophys. Res. Lett., 39, L09803, https://doi.org/10.1029/2012GL051440, 2012.

Prinn, R., Cunnold, D., Rasmussen, R., Simmonds, P., Alyea, F., Crawford, A., Fraser, P., and Rosen, R.: Atmospheric emissions and trends of nitrous oxide deduced from 10 years of ALEGAGE data, J. Geophys. Res.-Atmos., 95, 18369-18385, 1990.

Prinn, R. G., Weiss, R. F., Arduini, J., Arnold, T., DeWitt, H. L., Fraser, P. J., Ganesan, A. L., Gasore, J., Harth, C. M., Hermansen, O., Kim, J., Krummel, P. B., Li, S., Loh, Z. M., Lunder, C. R., Maione, M., Manning, A. J., Miller, B. R., Mitrevski, B., Mühle, J., O’Doherty, S., Park, S., Reimann, S., Rigby, M., Saito, T., Salameh, P. K., Schmidt, R., Simmonds, P. G., Steele, L. P., Vollmer, M. K., Wang, R. H., Yao, B., Yokouchi, Y., Young, D., and Zhou, L.: History of chemically and radiatively important atmospheric gases from the Advanced Global Atmospheric Gases Experiment (AGAGE), Earth Syst. Sci. Data, 10, 9851018, https://doi.org/10.5194/essd-10-985-2018, 2018.

Ray, E. A., Moore, F. L., Elkins, J. W., Rosenlof, K. H., Laube, J. C., Röckmann, T., Marsh, D. R., and Andrews, A. E.: Quantification of the SF6 lifetime based on mesospheric loss measured in the stratospheric polar vortex, J. Geophys. Res.-Atmos., 122, 46264638, https://doi.org/10.1002/2016JD026198, 2017.

Rigby, M., Montzka, S. A., Prinn, R. G., White, J. W. C., Young, D., O'Doherty, S., Lunt, M. F., Ganesan, A. L., Manning, A. J., Simmonds, P. G., Salameh, P. K., Harth, C. M., Mühle, J., Weiss, R. F., Fraser, P. J., Steele, L. P., Krummel, P. B., McCulloch, A., and Park, S.: Role of atmospheric oxidation in recent methane growth, P. Natl. Acad. Sci. USA, 114, 5373-5377, https://doi.org/10.1073/pnas.1616426114, 2017.

Rigby, M., Park, S., Saito, T., Western, L. M., Redington, A. L., Fang, X., Henne, S., Manning, A. J., Prinn, R. G., Dutton, G. S., Fraser, P. J., Ganesan, A. L., Hall, B. D., Harth, C. M., Kim, J., Kim, K. R., Krummel, P. B., Lee, T., Li, S., Liang, Q., Lunt, M. F., Montzka, S. A., Mühle, J., O’Doherty, S., Park, M. K., Reimann, S., Salameh, P. K., Simmonds, P., Tunnicliffe, R. L., Weiss, R. F., Yokouchi, Y., and Young, D.: Increase in CFC11 emissions from eastern China based on atmospheric observations, Nature, 569, 546-550, https://doi.org/10.1038/s41586019-1193-4, 2019.

Rogelj, J., Schaeffer, M., Meinshausen, M., Shindell, D. T., Hare, W., Klimont, Z., Velders, G. J., Amann, M., and Schellnhuber, H. J.: Disentangling the effects of $\mathrm{CO}_{2}$ and short-lived climate forcer mitigation, P. Natl. Acad. Sci. USA, 111, 16325-16330, 2014. 
Rogelj, J., Meinshausen, M., Schaeffer, M., Knutti, R., and Riahi, $\mathrm{K}$.: Impact of short-lived non- $\mathrm{CO}_{2}$ mitigation on carbon budgets for stabilizing global warming, Environ. Res. Lett., 10, 075001, https://doi.org/10.1088/1748-9326/10/7/075001, 2015.

Royer, D. L.: $\mathrm{CO}_{2}$-forced climate thresholds during the Phanerozoic, Geochim. Cosmochim. Ac., 70, 5665-5675, 2006.

Saunois, M., Bousquet, P., Poulter, B., Peregon, A., Ciais, P., Canadell, J. G., Dlugokencky, E. J., Etiope, G., Bastviken, D., Houweling, S., Janssens-Maenhout, G., Tubiello, F. N., Castaldi, S., Jackson, R. B., Alexe, M., Arora, V. K., Beerling, D. J., Bergamaschi, P., Blake, D. R., Brailsford, G., Brovkin, V., Bruhwiler, L., Crevoisier, C., Crill, P., Covey, K., Curry, C., Frankenberg, C., Gedney, N., Höglund-Isaksson, L., Ishizawa, M., Ito, A., Joos, F., Kim, H.-S., Kleinen, T., Krummel, P., Lamarque, J.-F., Langenfelds, R., Locatelli, R., Machida, T., Maksyutov, S., McDonald, K. C., Marshall, J., Melton, J. R., Morino, I., Naik, V., O'Doherty, S., Parmentier, F.-J. W., Patra, P. K., Peng, C., Peng, S., Peters, G. P., Pison, I., Prigent, C., Prinn, R., Ramonet, M., Riley, W. J., Saito, M., Santini, M., Schroeder, R., Simpson, I. J., Spahni, R., Steele, P., Takizawa, A., Thornton, B. F., Tian, H., Tohjima, Y., Viovy, N., Voulgarakis, A., van Weele, M., van der Werf, G. R., Weiss, R., Wiedinmyer, C., Wilton, D. J., Wiltshire, A., Worthy, D., Wunch, D., Xu, X., Yoshida, Y., Zhang, B., Zhang, Z., and Zhu, Q.: The global methane budget 2000-2012, Earth Syst. Sci. Data, 8, 697-751, https://doi.org/10.5194/essd-8-697-2016, 2016.

Schaefer, H., Fletcher, S. E. M., Veidt, C., Lassey, K. R., Brailsford, G. W., Bromley, T. M., Dlugokencky, E. J., Michel, S. E., Miller, J. B., Levin, I., Lowe, D. C., Martin, R. J., Vaughn, B. H., and White, J. W. C.: A 21st-century shift from fossil-fuel to biogenic methane emissions indicated by ${ }^{13} \mathrm{CH}_{4}$, Science, 352, 80-84, https://doi.org/10.1126/science.aad2705, 2016.

Schneider, L. and Kollmuss, A.: Perverse effects of carbon markets on HFC-23 and SF6 abatement projects in Russia, Nat. Clim. Change, 5, 1061, https://doi.org/10.1038/nclimate2772, 2015.

Schneider, L. R.: Perverse incentives under the CDM: an evaluation of HFC-23 destruction projects, Climate Policy, 11, 851864, https://doi.org/10.3763/cpol.2010.0096, 2011.

Schneider von Deimling, T., Meinshausen, M., Levermann, A., Huber, V., Frieler, K., Lawrence, D. M., and Brovkin, V.: Estimating the near-surface permafrost-carbon feedback on global warming, Biogeosciences, 9, 649-665, https://doi.org/10.5194/bg-9649-2012, 2012.

Schneider von Deimling, T., Grosse, G., Strauss, J., Schirrmeister, L., Morgenstern, A., Schaphoff, S., Meinshausen, M., and Boike, J.: Observation-based modelling of permafrost carbon fluxes with accounting for deep carbon deposits and thermokarst activity, Biogeosciences, 12, 3469-3488, https://doi.org/10.5194/bg12-3469-2015, 2015.

Smith, C. J., Kramer, R. J., Myhre, G., Forster, P. M., Soden, B. J., Andrews, T., Boucher, O., Faluvegi, G., Fläschner, D., Hodnebrog, Ø., Kasoar, M., Kharin, V., Kirkevåg, A., Lamarque, J.-F., Mülmenstädt, J., Olivié, D., Richardson, T., Samset, B. H., Shindell, D., Stier, P., Takemura, T., Voulgarakis, A., and Watson-Parris, D.: Understanding Rapid Adjustments to Diverse Forcing Agents, Geophys. Res. Lett., 45, 12023-12031, https://doi.org/10.1029/2018gl079826, 2018

Smith, P., Davis, S. J., Creutzig, F., Fuss, S., Minx, J., Gabrielle, B., Kato, E., Jackson, R. B., Cowie, A., and Kriegler, E.: Biophys- ical and economic limits to negative $\mathrm{CO}_{2}$ emissions, Nat. Clim. Change, 6, 42-50, 2016.

Stevens, B., Fiedler, S., Kinne, S., Peters, K., Rast, S., Müsse, J., Smith, S. J., and Mauritsen, T.: MACv2-SP: a parameterization of anthropogenic aerosol optical properties and an associated Twomey effect for use in CMIP6, Geosci. Model Dev., 10, 433452, https://doi.org/10.5194/gmd-10-433-2017, 2017.

Taylor, K. E., Stouffer, R. J., and Meehl, G. A.: An overview of CMIP5 and the experiment design, B. Am. Meteorol. Soc., 93, 485-498, 2012.

Toohey, M., Stevens, B., Schmidt, H., and Timmreck, C.: Easy Volcanic Aerosol (EVA v1.0): an idealized forcing generator for climate simulations, Geosci. Model Dev., 9, 4049-4070, https://doi.org/10.5194/gmd-9-4049-2016, 2016.

Tsutsumi, Y., Mori, K., Hirahara, T., Ikegami, M., and Conway, T. J.: Technical report of global analysis method for major greenhouse gases by the World Data Center for greenhouse gases, WMO/TD, 2009.

Velders, G. J. M. and Daniel, J. S.: Uncertainty analysis of projections of ozone-depleting substances: mixing ratios, EESC, ODPs, and GWPs, Atmos. Chem. Phys., 14, 2757-2776, https://doi.org/10.5194/acp-14-2757-2014, 2014.

Velders, G. J. M., Andersen, S. O., Daniel, J. S., Fahey, D. W., and McFarland, M.: The importance of the Montreal Protocol in protecting climate, P. Natl. Acad. Sci. USA, 104, 4814-4819, 2007.

Velders, G. J. M., Fahey, D. W., Daniel, J. S., Andersen, S. O., and McFarland, M.: Future atmospheric abundances and climate forcings from scenarios of global and regional hydrofluorocarbon (HFC) emissions, Atmos. Environ., 123, 200-209, https://doi.org/10.1016/j.atmosenv.2015.10.071, 2015.

Vollmer, M. K., Young, D., Trudinger, C. M., Mühle, J., Henne, S., Rigby, M., Park, S., Li, S., Guillevic, M., Mitrevski, B., Harth, C. M., Miller, B. R., Reimann, S., Yao, B., Steele, L. P., Wyss, S. A., Lunder, C. R., Arduini, J., McCulloch, A., Wu, S., Rhee, T. S., Wang, R. H. J., Salameh, P. K., Hermansen, O., Hill, M., Langenfelds, R. L., Ivy, D., O’Doherty, S., Krummel, P. B., Maione, M., Etheridge, D. M., Zhou, L., Fraser, P. J., Prinn, R. G., Weiss, R. F., and Simmonds, P. G.: Atmospheric histories and emissions of chlorofluorocarbons CFC-13 $\left(\mathrm{CClF}_{3}\right), \Sigma \mathrm{CFC}-114\left(\mathrm{C}_{2} \mathrm{Cl}_{2} \mathrm{~F}_{4}\right)$, and $\mathrm{CFC}-115\left(\mathrm{C}_{2} \mathrm{ClF}_{5}\right)$, Atmos. Chem. Phys., 18, 979-1002, https://doi.org/10.5194/acp-18-979-2018, 2018.

Welp, L. R., Patra, P. K., Rödenbeck, C., Nemani, R., Bi, J., Piper, S. C., and Keeling, R. F.: Increasing summer net $\mathrm{CO}_{2}$ uptake in high northern ecosystems inferred from atmospheric inversions and comparisons to remote-sensing NDVI, Atmos. Chem. Phys., 16, 9047-9066, https://doi.org/10.5194/acp-16-9047-2016, 2016.

WMO: Scientific Assessment of Ozone Depletion: 2006, World Meteorological Organization, Geneva, Switzerland, 572 pp. 2006.

WMO: Scientific Assessment of Ozone Depletion: 2014, World Meteorological Organization, Geneva, Switzerland, 416 pp., 2014.

Worden, J. R., Bloom, A. A., Pandey, S., Jiang, Z., Worden, H. M., Walker, T. W., Houweling, S., and Röckmann, T.: Reduced biomass burning emissions reconcile conflicting estimates of the post-2006 atmospheric methane budget, Nat. Commun., 8, 2227, https://doi.org/10.1038/s41467-017-02246-0, 2017. 